Les sources de l'Histoire des Mines : Nouveaux outils, Nouvelles approches

\title{
Pour une histoire de la méthode de Renau d'Élissagaray
}

Jean-Jacques Brioist et Hélène Vérin

\section{CpenEdition}

\section{Journals}

Édition électronique

URL : http://journals.openedition.org/dht/681

DOI : $10.4000 /$ dht.681

ISSN : 1775-4194

Éditeur :

Centre d'histoire des techniques et de l'environnement du Cnam (CDHTE-Cnam), Société des élèves du CDHTE-Cnam

Édition imprimée

Date de publication : 1 décembre 2008

Pagination : $112-142$

ISBN : 978-2-95-30779-2-6

ISSN : $0417-8726$

Référence électronique

Jean-Jacques Brioist et Hélène Vérin, « Pour une histoire de la méthode de Renau d'Élissagaray », Documents pour l'histoire des techniques [En ligne], 16 | $2^{\mathrm{e}}$ semestre 2008, mis en ligne le 04 octobre 2010, consulté le 08 septembre 2020. URL : http://journals.openedition.org/dht/681 ; DOI : https:// doi.org/10.4000/dht.681

(c) Tous droits réservés 


\title{
Pour une histoire de la méthode de Renau d'Élissagaray
}

\author{
Jean-Jacques Brioist \\ Service de la Navigation du Nord \\ Hélène Vérin \\ CNRS Centre A. Koyré
}

Lim e mémoire inédit dont nous proposons ici l'édition critique est le premier écrit de Bernard Renau d'Élissagaray qui nous soit parvenu. Nous disposons de deux manuscrits : I'un, d'une écriture du XVIIe siècle, se trouve aux Archives nationales', il porte en marge: " par le Petit Renau d'Élissagaray "; l'autre est à la Bibliothèque nationale de France ${ }^{2}$. Ce dernier est une copie plus récente, faite pour ou par Augustin Jal, probablement en vue de son ouvrage sur l'archéologie navale. À la suite de cette copie, Jal note : « ce mémoire pourrait bien être du Ch. Renau » et au-dessous, « il est assurément de lui. Sa machine à tracer les ellipses. Voir 5 janvier 1681 ». On trouve plus loin, dans le même manuscrit, p. 268, la copie d'une dépêche envoyée à cette date par Colbert à Langeron, alors inspecteur des constructions navales qui indique que Langeron s'applique aux constructions navales qui se font à Brest et précise « comme S.M. envoyera dans peu le Sr Renau en ce port pour mettre en pratique l'instrument dont il se sert pour marquer la coupe des façons d'un vaisseau, il sera bon que vous soyez sur les lieux pour reconnoistre l'utilité que le service de S.M. en pourra recevoir $"$.

En effet, comme nous allons le voir, de nombreuses références dans les archives de la marine rendent compte de la mise en œuvre de la méthode de Renau pour la conduite des façons - celle des formes à donner à la carène - dans la construction de plusieurs vaisseaux. Cette méthode qui est exposée dans le mémoire implique le recours à un instrument de tracé

1 Archives nationales [ensuite AN]: Mar DI 10, fo 5-17. 2 Bibliothèque nationale de France [ensuite $\mathrm{BnF}$ ] : n.a.f. ms 9481, pp. 229-238. d'ellipses. Si l'identification du manuscrit ne fait pas problème, en revanche il n'est pas daté et il faut donc procéder par recoupements pour déterminer la période pendant laquelle il a pu être écrit.

La première information dont nous disposons se trouve dans le texte lui-même. En effet, au début de son mémoire Renau annonce qu'il va y reproduire une " démonstration » qu'il fit sur la demande de Desclouzeaux, intendant de l'arsenal de Brest. A une question que le roi aurait faite à Anthony Deane : « pourquoy un vaisseau va pour ainsy dire contre le vent ", Renau se fit fort de répondre en démontrant, non seulement qu'on peut en rendre raison, « mais encore déterminer l'endroit où le vaisseau doit aller par toutes ses voilles, certaines choses estant suposées ॥. Cette dernière incise signale le caractère spéculatif de la démonstration. Toujours d'après Renau, Desclouzeaux aurait demandé à Renau de faire cette démonstration au cours d'une discussion avec Deane, qui était venu à Versailles pour y présenter les yacks que Louis XIV Iui avait commandés. Cet épisode se situe pendant la dernière semaine d'août ou au début de septembre1675. Bien entendu, dans cette présentation que fait Renau de sa démonstration, il faut faire la part de la rhétorique : présenter la théorie de «la manœuvre à la mer ॥ à laquelle il prétend, comme une réponse à une question du roi, transmise par Deane, en accroît d'emblée l'intérêt et la valeur.

Dans le mémoire que nous présentons, cette démonstration correspond à une première partie comprenant les folios 5 à 10 ; la deuxième partie, comprenant les folios 10 (verso) à 17 est consacrée à la méthode de tracé des gabarits avec la « machine» proposée par Renau. Cette deuxième partie est déri- 
vée de la précédente par la « démonstration » que la carène doit être formée de courbes et que la meilleure des courbes régulières pour la décrire est l'ellipse. D'où la mise en œuvre d'un ellipsographe. Pour savoir quand cette dernière partie du mémoire fut écrite, notre seule certitude est que la méthode de Renau était assez connue en mai 1680, pour que Seignelay demande à Tourville d'en faire l'essai à Rochefort ${ }^{3}$. On peut néanmoins penser que Renau la conçut à la suite du grand projet de 1678, où Colbert et Seignelay avaient relancé l'idée d'un règlement pour la construction des vaisseaux, idée déjà présente dans certaines mesures prises par Colbert dès 1670 et surtout en 1673.

Pour comprendre le déroulement de ce qui s'ensuivit, il faut distinguer les deux parties du mémoire. Lorsque Seignelay décida de faire faire l'essai de cette machine dans les arsenaux, son projet se limitait à obtenir la même méthode de tracé pour tous les vaisseaux construits, en conservant les proportions et les formes propres aux maîtres-charpentiers. II ne s'agissait nullement de prendre le risque d'appliquer les élaborations théoriques de la première partie du mémoire, pour en décider. C'est bien ce qui ressort de la question qu'il pose aux académiciens dont la première réponse est la suivante : "Le samedy $3^{e}$ de May 1681 la Compagnie étant assemblée [...] Mr. Blondel a rendu compte à la Compagnie de la commission qui luy avoit été donnée, et à M. Mariotte par Mgr le Marquis de Seignelay d'examiner l'invention de Mr. Renault pour une nouvelle construction de vaisseaux, qui se fait avec plus de facilité et toujours d'une même manière, laquelle invention a esté approuvée de la Compagnie $\|{ }^{4}$.

Mais encore, si l'on suit l'histoire de la mise en œuvre de la méthode de Renau, on s'aperçoit qu'après avoir, dans les années 1680, travaillé dans les ports à apprendre aux charpentiers l'usage de sa machine pour conduire les façons selon les formes qui leur étaient habituelles, il obtint, dans les années 16901692, de faire construire des vaisseaux selon ses propres mesures et non plus en se bornant à suivre celles des charpentiers. On assiste donc à une inversion chronologique de l'ordre logique du mémoire. Quelles sont les raisons de cette inversion ? Plusieurs hypothèses sont possibles, qu'il nous semble utile d'examiner pour comprendre ce qui est à l'œuvre dans cette ex-

3 « Je n'ay pas manqué de faire examiner aux Mes charpentiers la machine du Sr Renauld et luy ay donné des proportions qu'il m'a demandé pour construire le petit navire que nous faisons presentement. ॥ Rochefort, le 26 mai 1680, AN : Mar B3 33 f० 412 .

4 Procès-verbal du 3 mai 1681, fo 99. périence. En effet, si l'on se borne à dire à la suite de Pierre Bouguer qu'elle fut un échec, on élimine tout moyen d'en saisir les attendus et les enjeux. D'où une question préalable qui nous semble s'imposer : pour quelles raisons ce mémoire n'a fait l'objet ni d'une étude particulière, ni d'une publication des historiens?

Pour le comprendre, donnons à grands traits quelques repères. Pour les historiens des sciences, les outils théoriques d'une véritable sciencia navalis ne sont pas encore disponibles, et encore moins ceux qui auraient pu s'appliquer dans une architecture navale. En quelque sorte, la science dont dispose Renau témoigne d'une grande naïveté de sorte qu'elle ne mérite pas une attention particulière. En outre, son intervention se borna, dit Pierre Bouguer, à la régularisation géométrique des tracés de charpentiers. Notons que des travaux récents se dégagent de ces points de vue pour aborder des travaux contemporains de ceux de Renau, qui connurent le même échec d'application d'une théorie du navire, comme ceux du père Paul Hoste ${ }^{5}$.

Pour comprendre le désintérêt des historiens de la marine, il convient de noter que l'essor de l'histoire de la construction navale est relativement récent. Depuis quelques décennies de nombreux travaux ont très largement renouvelé nos connaissances. E† ceci d'autant mieux que l'on bénéficie des rencontres internationales mais aussi de la confrontation de différentes approches. Sans entrer trop avant dans la question on peut simplement remarquer un renouvellement des sources utilisées. Elles sont de trois ordres: l'écrit, la figuration graphique et le vestige archéologique.

Les sources écrites ont longtemps été privilégiées. Les travaux sur la marine royale se partageant entre ceux qui concernaient I'histoire militaire et politique des guerres navales, et l'histoire administrative. Si la construction navale a peu de part dans la première, vouée à des aspects plus nobles voire marquée d'un certain goût patriotique pour les actions militaires et les officiers d'épée, la seconde entre dans la question controversée de la centralisation et du souci de contrôle étatique de Colbert puis de Seignelay. Dans les deux cas on a longtemps signalé tout à la fois le manque d'intérêt des souverains français pour la puissance maritime avec leur obsession continentale et la lourdeur bureaucratique du secrétariat d'État à la mer. Les aspects plus proprement gestionnaires de ce service ont été étudiés dans des travaux sensibles aux aspects économiques et sociaux de cette énor-

5 Cf. par exemple Larrie Ferreiro, Ship and science : the birth of naval architecture in the scientific revolution, Cambridge (Mass.), MIT Press, 2006. 


\section{Pour une histoire de la méthode de Renau d'Élissagaray}

me organisation industrielle. II faut sans doute faire une place à part aux travaux précoces d'Augustin Jal auquel nous devons, outre un dictionnaire de la marine qui a irrigué les dictionnaires suivants sur les termes de marine, une étude historique qui est aussi un de nos grands classiques. Or comme le prouve le manuscrit de la Bibliothèque nationale de France, Jal s'était intéressé de près au mémoire de Renau.

L'étude systématique des sources graphiques est plus récente. Les travaux bien connus de Jean Boudrioł d'édition et d'examen des plans et devis de différents vaisseaux ${ }^{6}$ ont suscité l'intérêt des modélistes mais ont également sollicité un renouvellement de l'étude des sources écrites dont Jean Meyer signalait, dans les années 1980, les récentes avancées mais aussi les insuffisances ${ }^{7}$. Ce travail magistral constitue aujourd'hui pour les chercheurs un ensemble de données factuelles inestimable. Certaines assertions concernant les vaisseaux du roi sous le règne de Louis XIV - comme durant le XVIII siècle - peuvent à présent donner lieu à de véritables vérifications.

On peut dire la même chose des travaux de l'archéologie navale moderne qui se sont développés en France depuis les années 1980. Les relevés d'épaves modernes mais aussi la confrontation des données de l'archéologie avec les résultats d'autres méthodes d'investigation ont eu des effets comparables. Ainsi, les conclusions de Jean Boudriot et celles de Michel I'Hour et Elisabeth Veyrat sur les vaisseaux du $X V I^{e}$ siècle $^{8}$, appuyées sur leurs sources respectives, se recoupent et se confortent pour apporter la preuve que la normalisation voulue par Colbert et Seignelay n'aboutit pas. Mais la multiplication et la diversification des sources ont aussi favorisé un retour aux archives écrites porté par d'autres grilles de lecture. À cet égard, le travail d'Éric Rieth est exemplaire? et de nombreux écrits manuscrits sur la construction navale sont aujourd'hui étudiés de près, et édités ${ }^{10}$. Autrement dit, on est capable à présent de compren-

6 Voir les volumes de la collection Archéologie navale française, sous la direction de Jean Boudriot et Hubert Berti, aux éditions Ancre.

7 En particulier dans Martine Acerra, José Merino, Jean Meyer éd., Les marines de guerre européennes XVIIe-XVIII siècles, Paris, Presses de l'Unoiversité Paris-Sorbonne, 1985.

8 II s'agit des fouilles archéologiques des épaves de La Hougue (1692).

9 A commencer par Le maître-gabarit la tablette et le trébuchet. essai sur la conception non-graphique des carènes du Moyen Age au XXe siècle, Paris, Comité des travaux historiques et scientifiques, 1996.

10 On les trouve dans la Collection archéologie navale française précitée. dre ce qu'étaient les méthodes des charpentiers de vaisseaux et les subtilités de leur outillage de calcul et de tracé. Du coup, on est mieux armé pour examiner la tentative de Renau et en particulier la priorité qui fut accordée, parmi ses propositions, à la simple uniformisation des tracés à l'aide de sa machine.

Si l'on essaye de situer cette tentative dans l'histoire des techniques constructives, il faut faire une première remarque. En tant que méthode qui promeut un art du tracé géométrisé des carènes - la conduite des façons - elle s'inscrit dans un mouvement de rationalisation des pratiques beaucoup plus large, c'est-àdire qui touche toutes sortes de métiers et d'activités techniques qui ont en commun de s'enseigner et de prétendre tenir leur efficacité technique du recours à la géométrie, aux mécaniques, au calcul et même à la physique. A cet égard, son double aspect : se fonder sur une approche à caractère théorique et la rendre applicable par l'usage d'un instrument mathématique, situe ce mémoire parmi les travaux des mécaniciens et ingénieurs qui se développent surtout depuis le second $\left.\mathrm{XV}\right|^{\mathrm{e}}$ siècle et ont toute leur place dans l'essor technique de l'époque moderne. A la guerre (fortification, attaque et défense des places, artillerie, mines... ), dans l'architecture civile ou dans la conception-construction d'instruments mathématiques et de machines, ces méthodes sont acquises et institutionnalisées. On peut ainsi remarquer que lorsque des oppositions, voir des conflits se font jour entre ingénieurs, officiers d'artillerie, architectes ou mécaniciens, c'est au nom des mêmes attendus technologiques ". Ce qui n'est pas le cas dans la construction navale et c'est bien le constat qui ouvre le mémoire de Renau et justifie sa proposition : introduire dans une même rationalité mécanique, la navigation et la construction des vaisseaux. Il est possible de concevoir abstraitement une fortification comme un système obéissant aux principes de la mécanique, de développer à partir de là les maximes et règles qui justifient les choix techniques retenus, et enfin de soumettre au préalable à la Cour, les plans et profils et le devis de construction. Dans la construction navale, on ne dispose pas d'une hydrostatique et a fortiori de l'hydrodynamique indispensable à une telle conceptualisation, pas davantage à la justification théorique des choix constructifs. Déterminer le rapport entre les qualités et défauts de navigation d'un bâtiment et sa méthode de construction demeure affaire toute empirique de comparaisons mal étayées, tant sont nombreuses et hétéroclites les variables qui marquent

11 On peut aussi remarquer que les fondements théoriques y sont souvent assez élémentaires. 
les différentes construction réalisées, et difficile à cerner des constantes mesurables. Enfin, les méthodes utilisées ne sauraient faire de l'établissement des plans et profils un préalable déterminant la suite des opérations. L'ambition de cette méthode de tracé, est de supplanter celles, diverses, qui sont utilisées dans les ports par les maîtres-charpentiers. Pour ces derniers, il s'agit bien d'une innovation au sens que ce mot avait à l'époque, c'est-à-dire d'une invention qui met en cause leur statut dans l'organisation des chantiers, et en particulier la mainmise que leur confère alors des compétences techniques qu'ils sont seuls à exercer et qui se transmettent exclusivement à l'intérieur de la lignée familiale. Enseignée à tous dans les écoles de construction, la méthode de Renau devait permettre l'établissement de plans et profils soumis à l'autorité du roi. Si l'on retient ces trois points : conceptualisation, justification des choix techniques, uniformisation mécanique des tracés, pour comprendre l'histoire de la tentative et de l'échec de la méthode de Renau, on s'aperçoit de l'inversion que nous avons indiquée plus haut dans le déroulement de cette expérience, soit : obtenir une uniformisation des tracés, afin d'atteindre une meilleure justification empirique des choix constructifs et déterminer ainsi les modèles retenus qui pourront donner lieu à une anticipation mieux contrôlée du rapport entre construction et qualités nautiques et des coûts de production. Soit évaluation technique et estimation monétaire.

Dès lors, l'injonction qui fut faite à Renau de ne procéder, au moins dans un premier temps, qu'à une régularisation instrumentée des façons des charpentiers manifeste un sens pratique éclairé de la part de Colbert puis de Seignelay. En quelque sorte, c'était rendre opératoire une évaluation empirique - la seule à laquelle on pouvait prétendre.

Pourtant, Colbert puis Seignelay déclarent leur voIonté de mettre en place une « théorie de la construction des vaisseaux "1, qui a été assimilée à la tentative de Renau dans la première partie de son mémoire. Mais il nous faut aller plus avant et se poser la question de savoir ce que le roi, les Colbert, peuvent entendre par là. Quel est, dans leurs dépêches, leurs enquêtes, leurs ordonnances, le statut de cette catégorie : " théorie » ? Comment s'accorde-t-elle avec ce que signifie théorie à cette époque?

Si l'on consulte les dictionnaires de l'Académie et le Richelet, on trouve deux définitions différentes: la première, consiste à définir une " théorie », comme étant strictement de l'ordre de la " contemplation ", et la définition se précise par l'exclusion de toute visée pratique. L'autre définition est tout aussi intéressante, mais différente, puisque ce qui définit la théorie est qu'elle n'est fondée que sur le raisonnement, et exclut le recours à l'expérience sensible. C'est donc soit par rapport à l'usage des données de la théorie (la contemplation et non la pratique), soit par rapport aux sources de la connaissance qu'elle offre (la raison et non les expériences empiriques), que la théorie est définie.

Comment Colbert et Seignelay peuvent-ils prétendre à une "théorie » de la construction des vaisseaux, pour un type de connaissance qui présente à la fois les deux caractéristiques qui excluent a priori que l'on parle de " théorie " : la visée pratique - obtenir de meilleurs vaisseaux, et l'origine empirique - il n'est question que de prendre appui sur la confrontation des comportements de navires, fruit de la compétences des meilleurs maîtres.

Néanmoins on peut remarquer que les Colbert attendent de cette « théorie " qu'elle donne l'assurance que l'on obtiendra des vaisseaux qui auront les qualités nautiques prévues au moment de leur commande, autrement dit, qu'elle assure un résultat certain et ceci parce qu'elle constitue un savoir valable et utilisable toujours et partout - « une fois pour toutes » est le leitmotiv des correspondances sur le sujet. Ce sont donc bien deux caractéristiques de ce qu'est une théorie : la certitude et l'universalité qui sont visées.

On peut donc considérer qu'il y a bien une ambition à prétention " théorique " : atteindre l'universel et le certain, mais avec des moyens qui sont tous techniques : arts du charpentier, colloque dans des conseils, donc discussion et confrontation d'opinions, devant des modèles sensibles. Ce qui correspond davantage à une standardisation des modèles selon un règlement, donc des dispositions administratives. La prise de décision relève de l'opinion avertie et du partage, de l'échange de compétences fondées empiriquement. Dès lors la méthode de tracé Renau mérite qu'on en fasse l'essai.

La méthode de Renau fut diversement appréciée à son époque et jusqu'au XIXe siècle. Plus récemment des historiens ont mis en doute l'intérêt de sa démarche en s'appuyant sur les échecs pratiques de sa mise en œuvre. Ainsi Jean Boudriot, dans la première partie de son livre consacré au Vaisseau trois-ponts du chevalier de Tourville, Mélanges sur l'Architecture navale française au XVIle siècle, consacre un chapitre à «la vaine recherche d'une théorie de la conception des vaisseaux " dans laquelle il juge fort sévèrement la tentative de Renau (toutes ses appréciations sont négatives), jusqu'à en nier les mises en œuvre, l'accueil qu'elle reçut ou certaines réussites pratiques. Sans doute la contribution de Jean Boudriot à la connaissance des vaisseaux construits pendant et après l'es- 


\section{Pour une histoire de la méthode de Renau d’Élissagaray}

sai de Renau lui permet de prouver qu'elle n'aboutit pas à ses fins. Nous espérons néanmoins montrer que cet épisode complexe de l'histoire de la construction navale conserve tout son intérêt.

La présente édition critique du mémoire de Renau sur la conduite des façons, outre les notes qui devraient en éclairer la lecture par une mise en perspective dans son contexte historique, comprend un premier article, « L'ingénierie cartésienne de Renau d'Élissagaray », qui s'attache à étudier le manuscrit en dégageant ses emprunts théoriques, et en examinant du point de vue de la cohérence interne de son propos, les postulats qu'il soutient, les formes de démonstration qu'il met en œuvre, voire, ce qui en fait un essai scientifique de contrôle et de production d'une technique constructive jusqu' alors et pour longtemps encore, essentiellement empirique. Un second article est consacré à l'exploration chronologique de la mise en œuvre de la méthode promue par Renau, dans les arsenaux de la marine royale.

\section{Nota bene}

Pour cette publication du mémoire de Renau, nous avons utilisé le manuscrit des archives nationales, la copie manuscrite de la Bibliothèque nationale de France étant souvent fautive. Notre transcription, aussi fidèle que possible, a exigé quelques modifications dans la présentation, qui tiennent à des questions de mise en page et de lisibilité. Elles concernent l'introduction de quelques alinéas et la disposition des opérations. Notre objectif a été de permettre au lecteur de refaire lui-même les opérations selon leur ordre de succession initial. Tous les signes ont été respectés, comme l'orthographe des mots et la ponctuation. Nous nous sommes permis d'ajouter un accent pour " à ", " où ", "là » et « dès », toujours absents dans les manuscrits de l'époque, et ceci en vertu du même souci de lisibilité

\section{Remerciements}

Nous tenons tout particulièrement à associer à cette publication les noms du Dr Larrie D. Ferreiro et de Gérard Louyot, qui ont participé aux commencements de nos travaux, dont nous avons dû, ultérieurement, réduire les ambitions. Qu'ils soient remerciés ici pour tout ce que nos discussions, souvent passionnées, ont apporté à l'achèvement de ce projet. 


\section{Mémoire sur la construction des vaisseaux dans lequel il y a une méthode pour en constuire les façons (1679)}

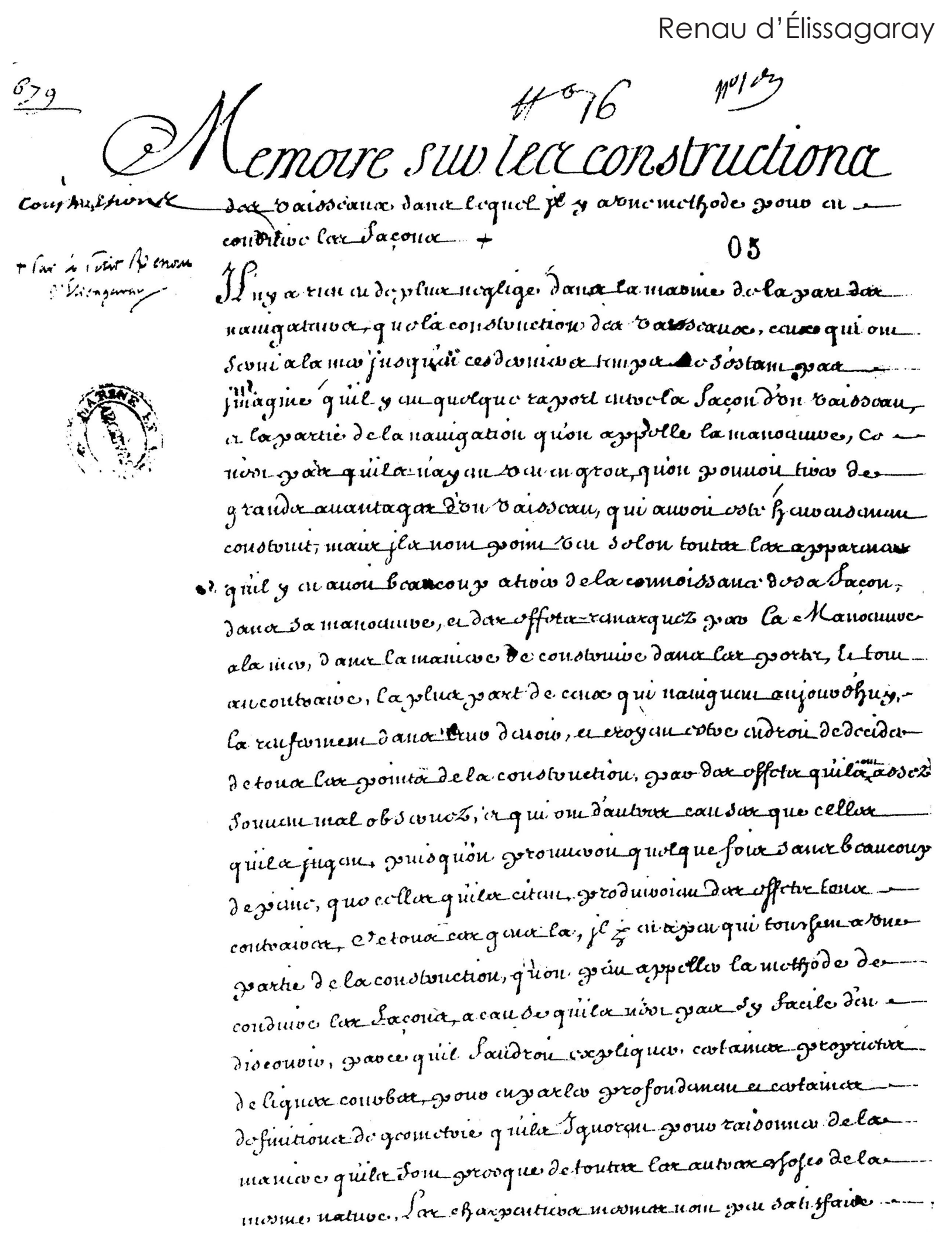




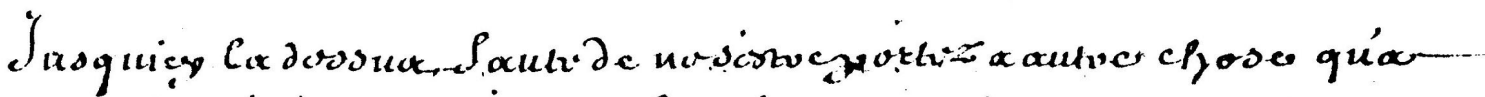

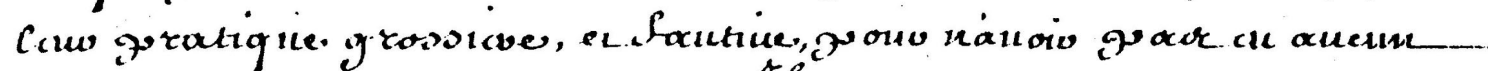

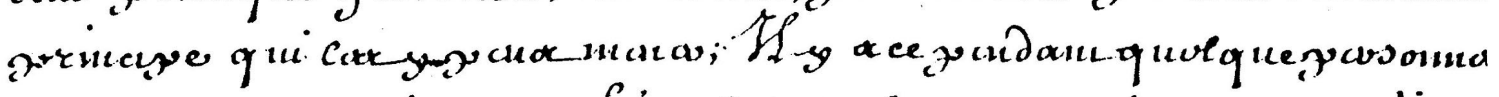

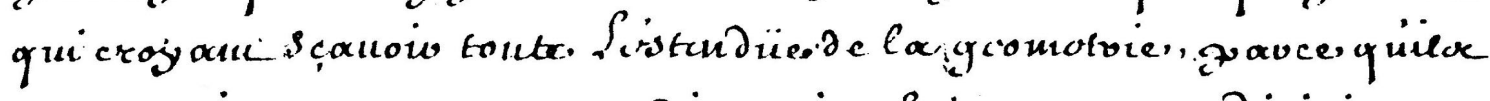

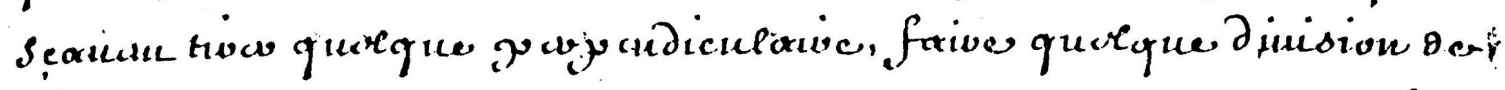

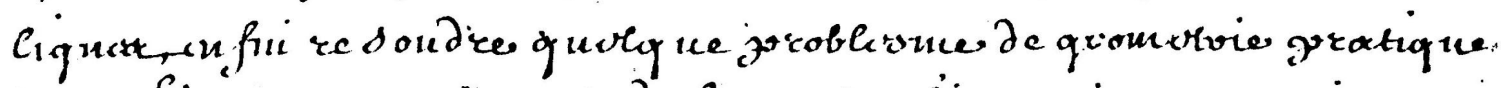

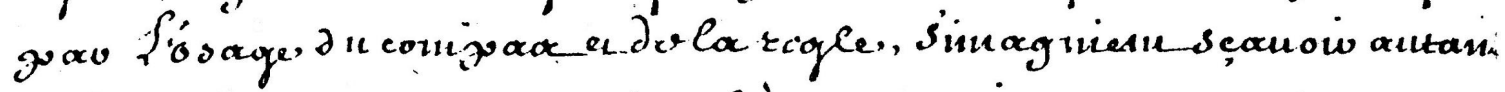

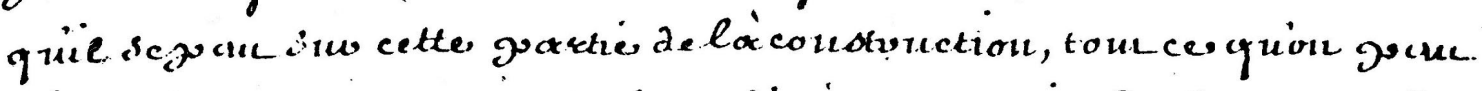

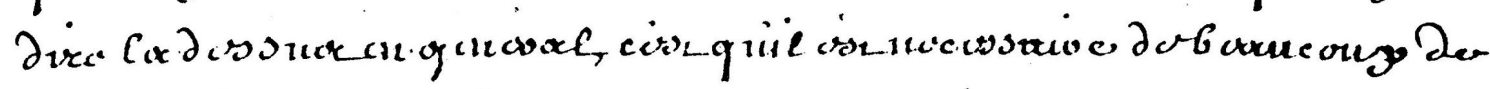

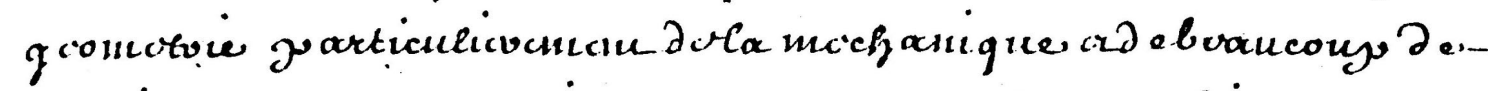

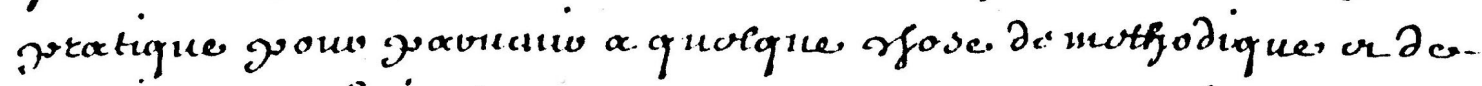

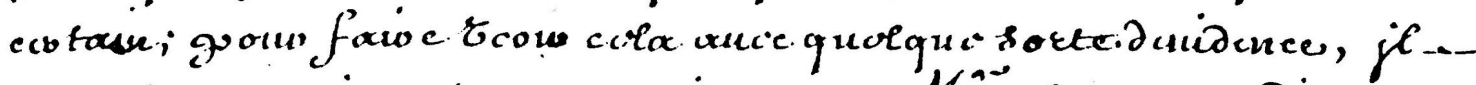

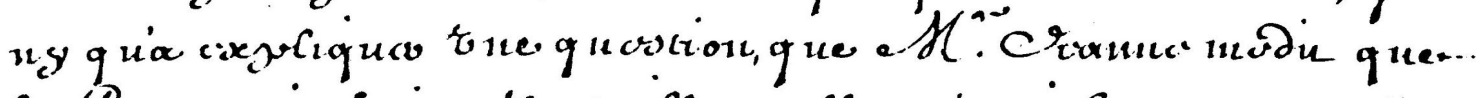

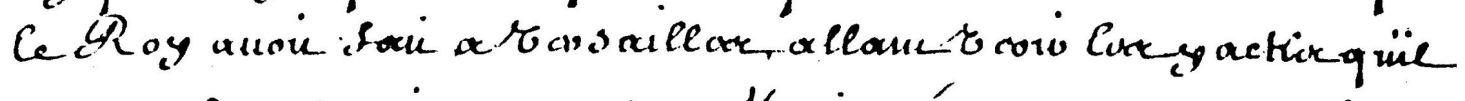

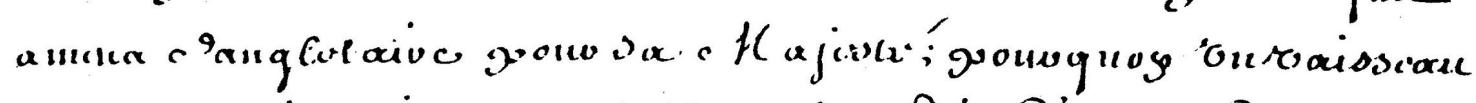

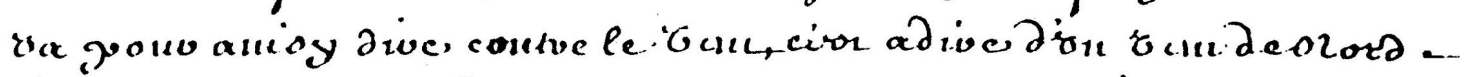

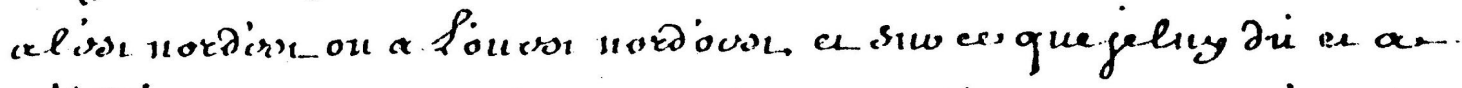

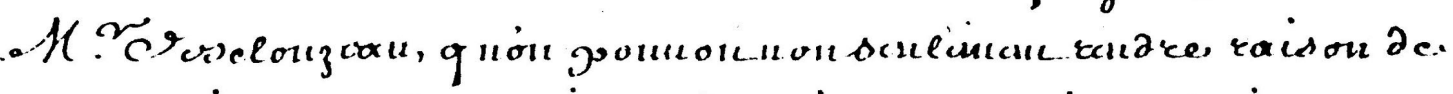

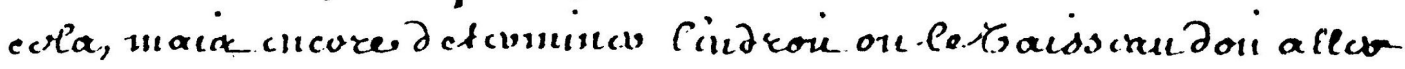

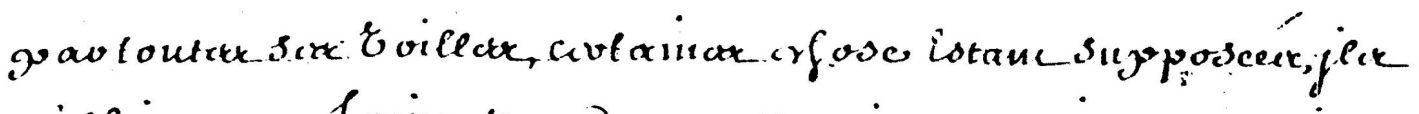

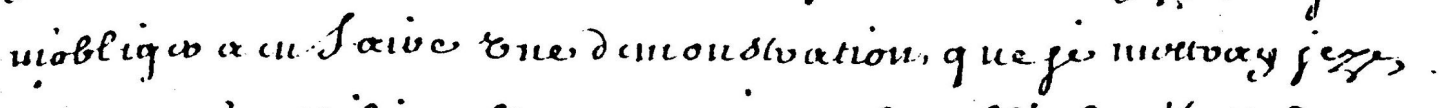

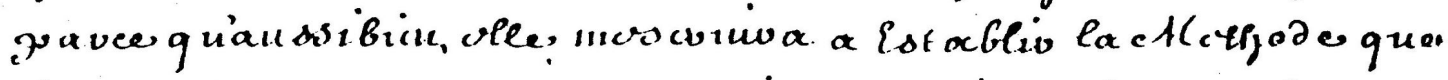

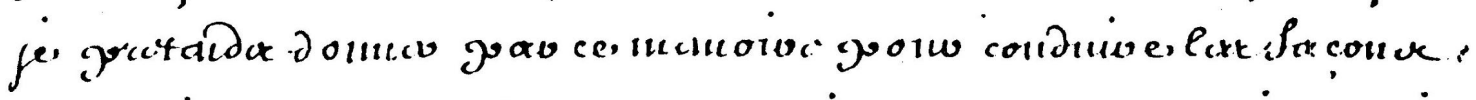

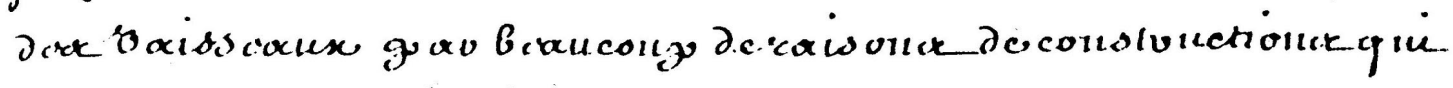

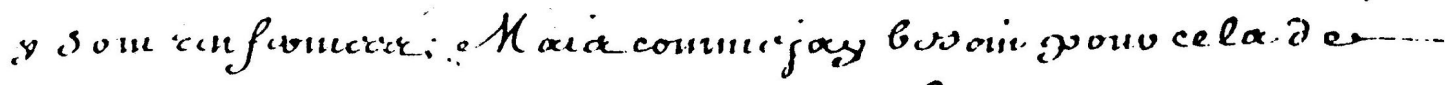

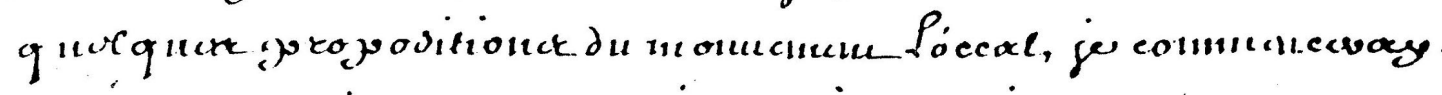

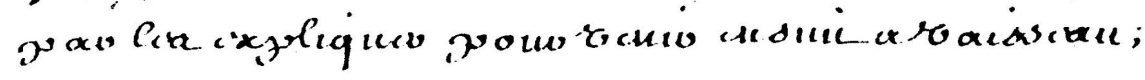

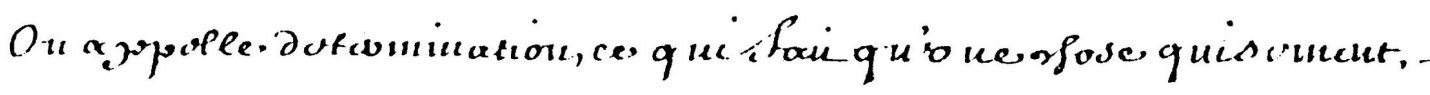




\section{6}
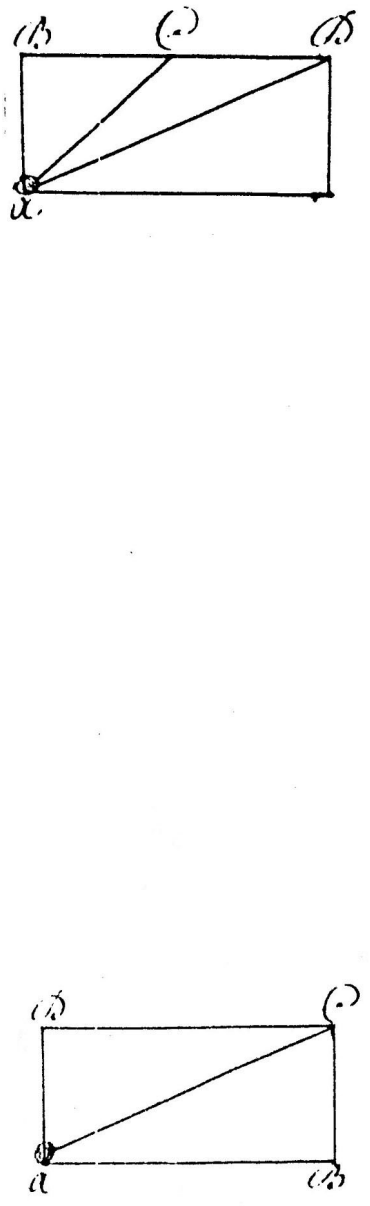

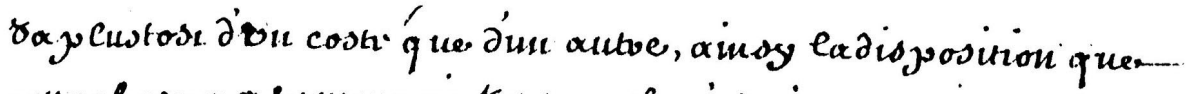

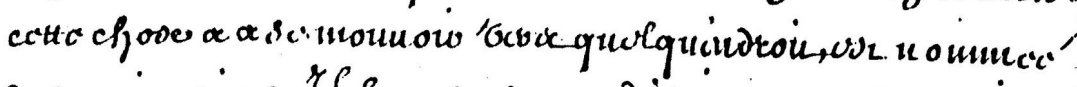

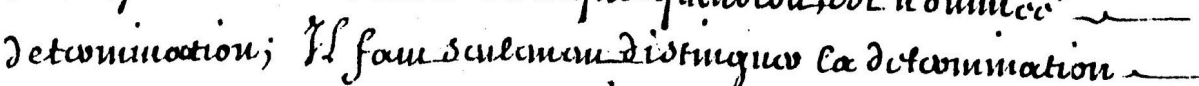

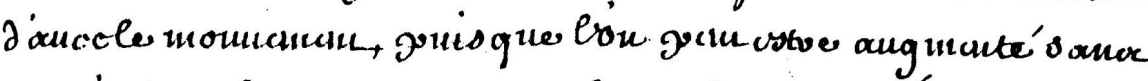

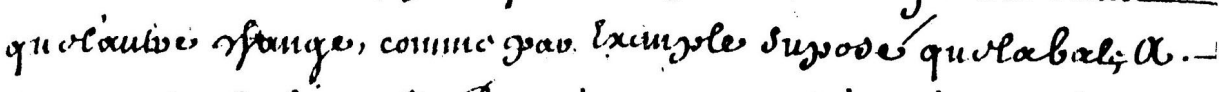

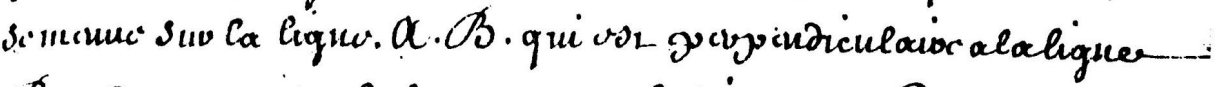

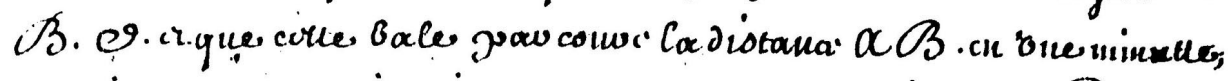

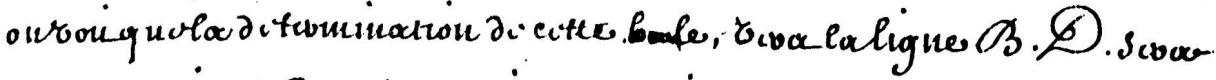

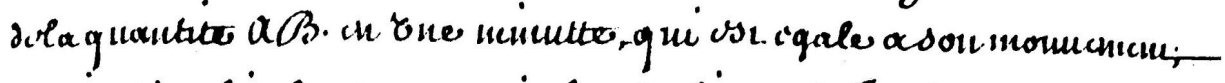

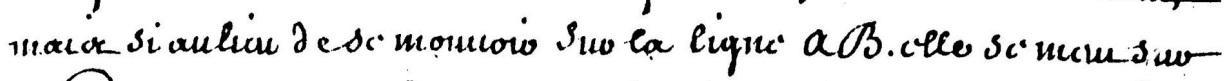

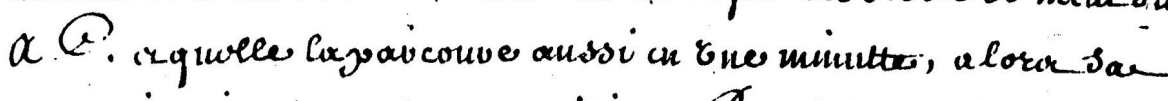

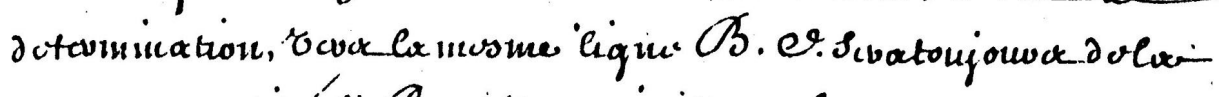

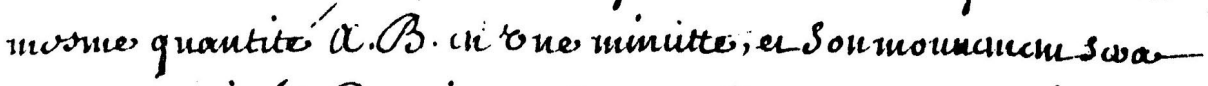

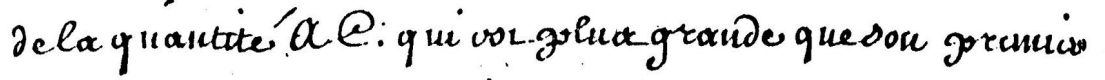

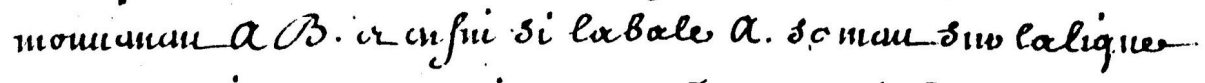

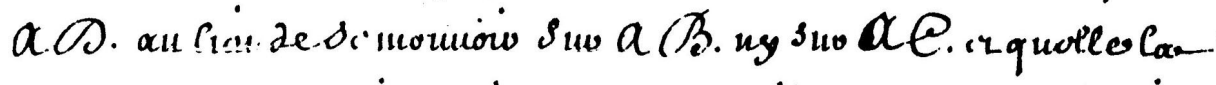

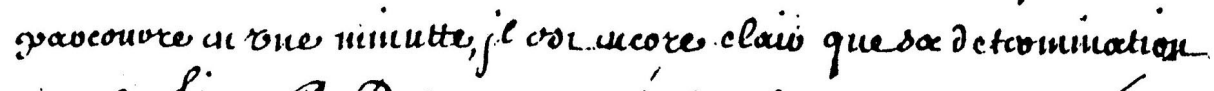

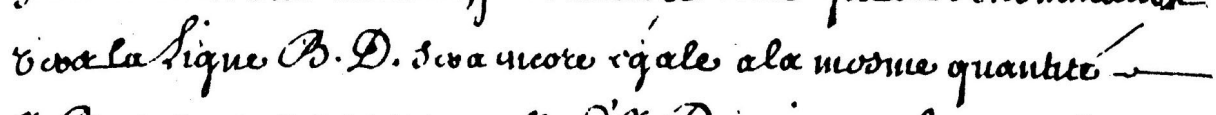

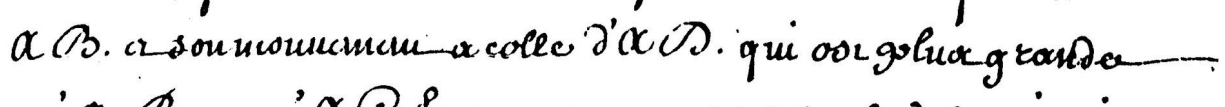

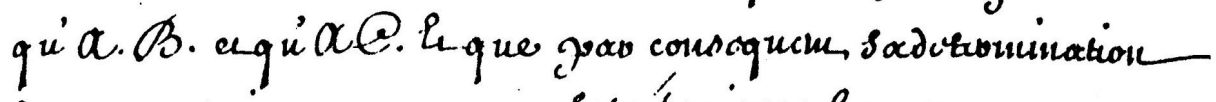

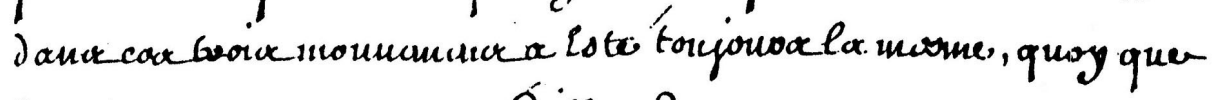
Catmornancuct ay an ostoriffucuda.

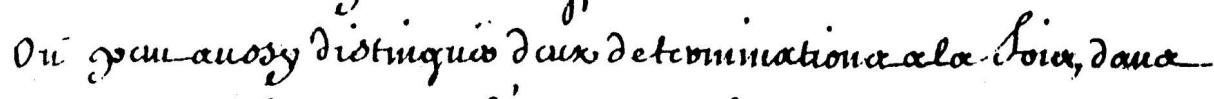

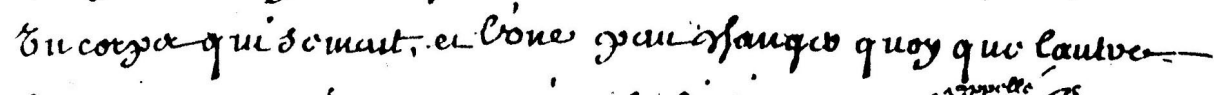

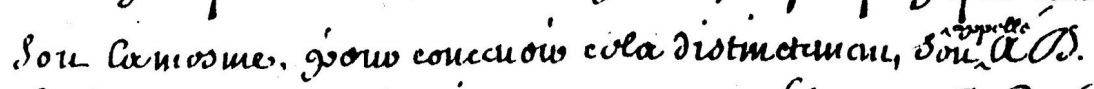

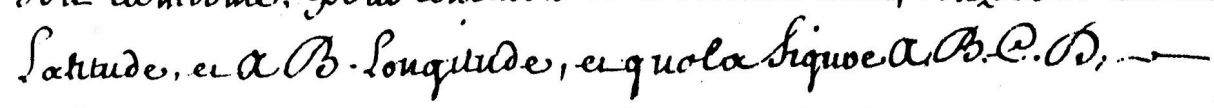

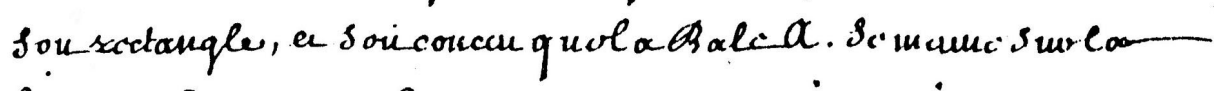

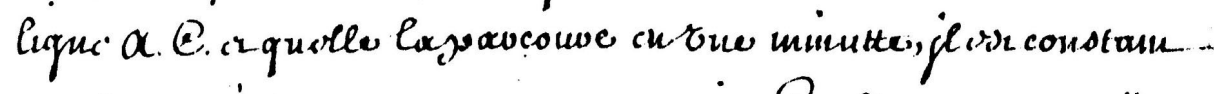

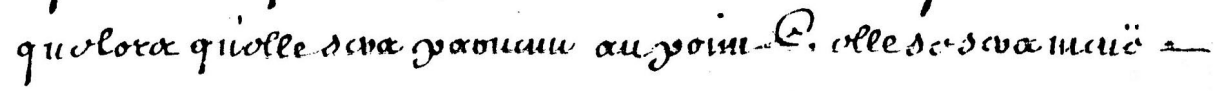




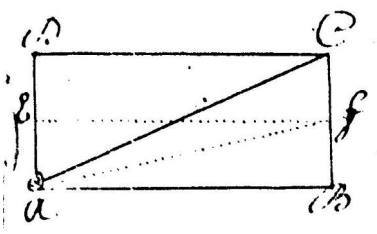

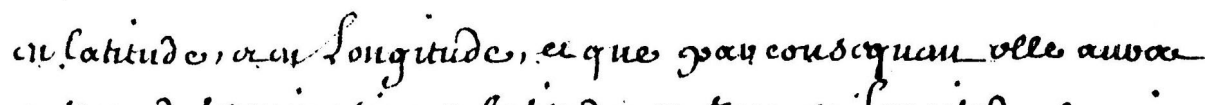

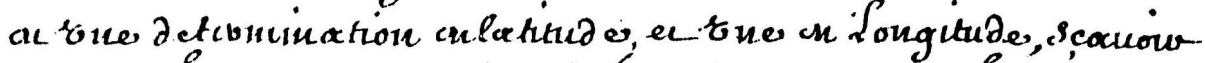

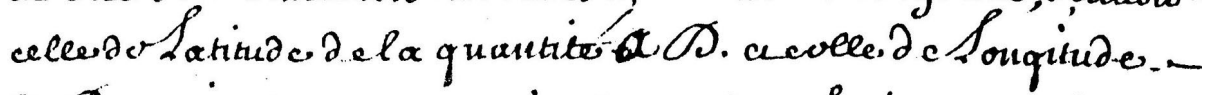

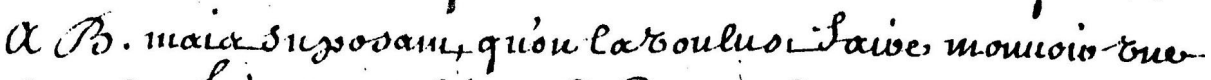

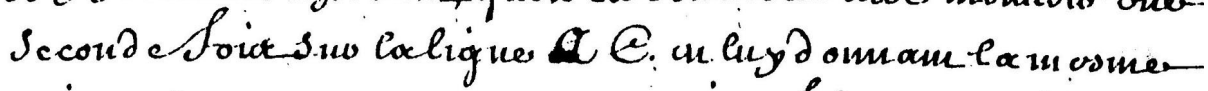

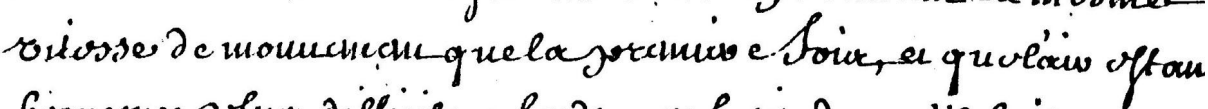

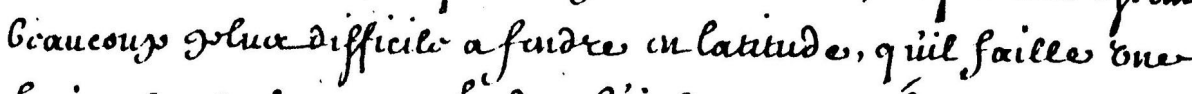

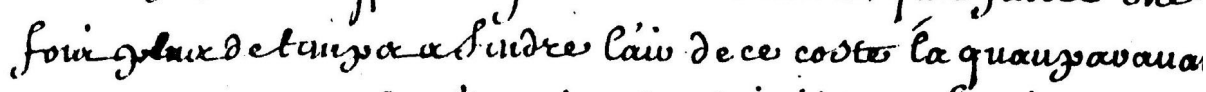

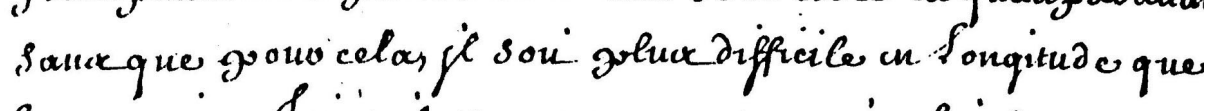

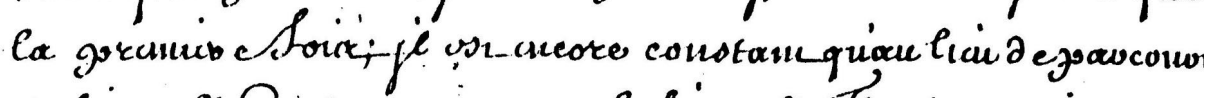

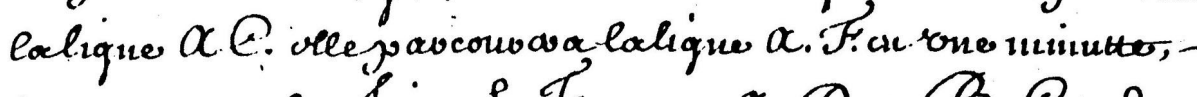

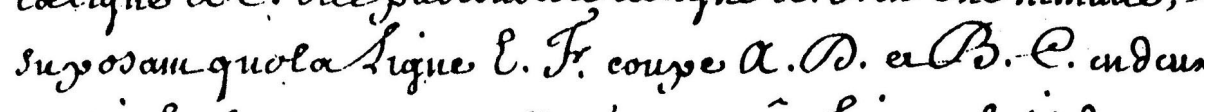

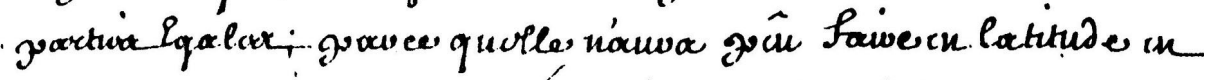

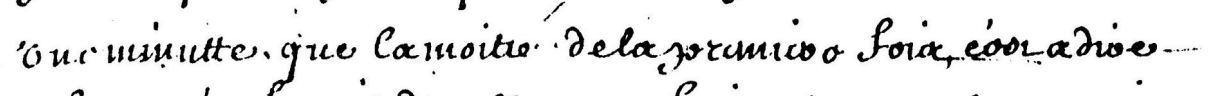

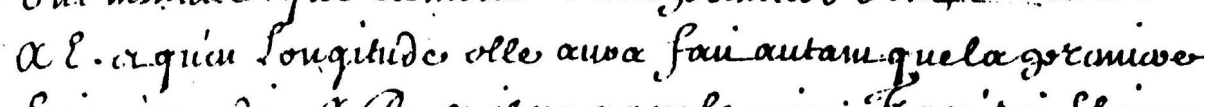

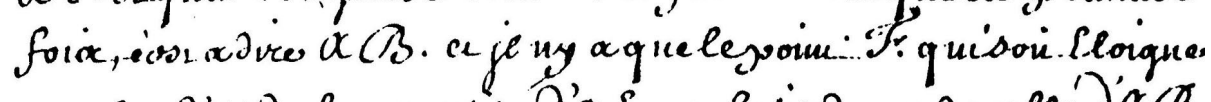

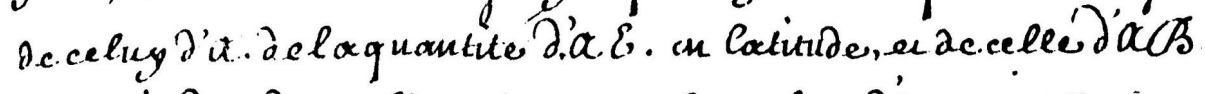

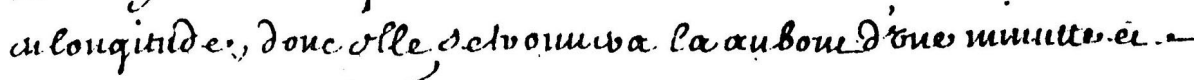
unox gaxucourit: $A$. \&.

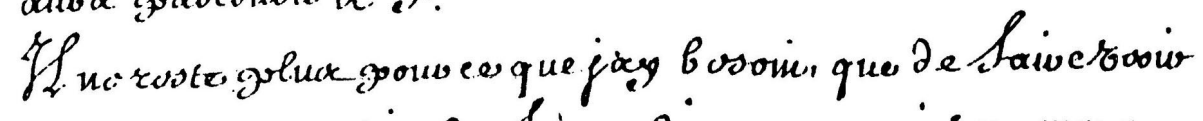

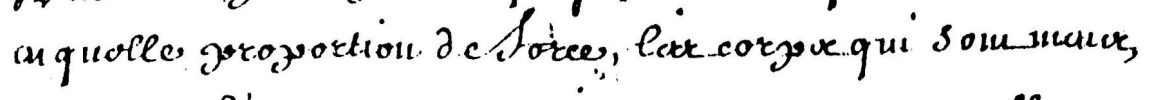

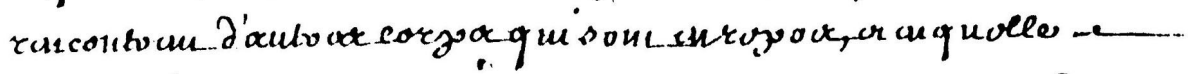

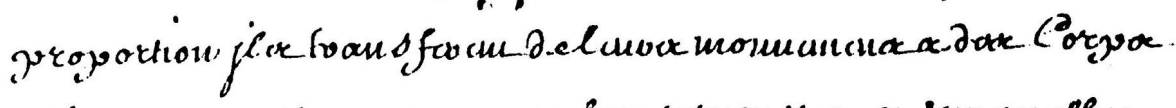

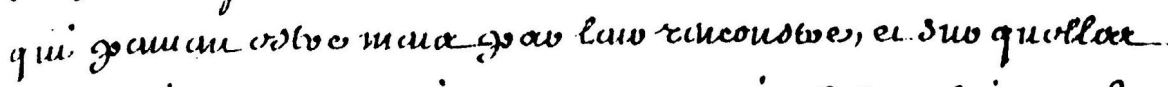

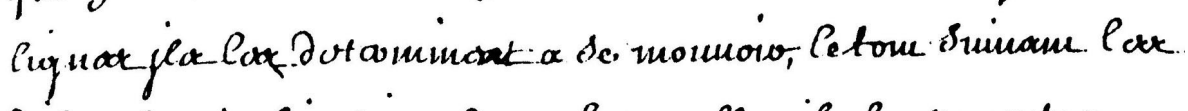

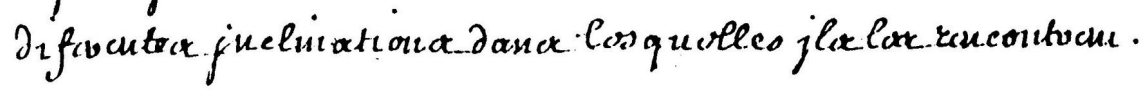

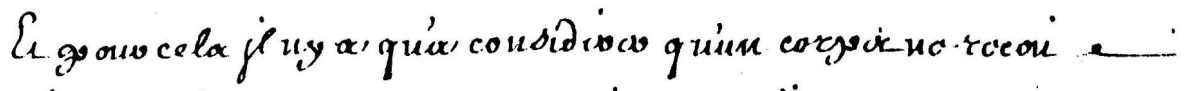

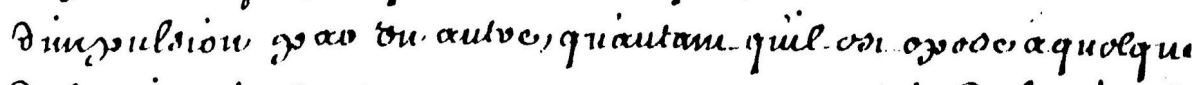
defivinimotion aeson nu 


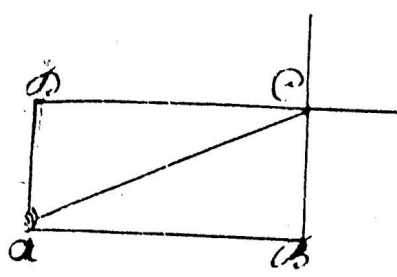

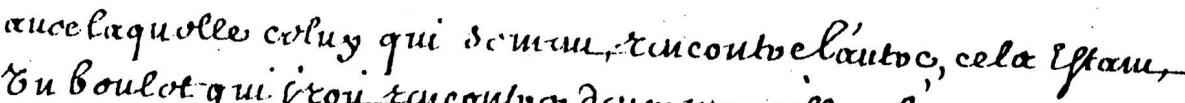

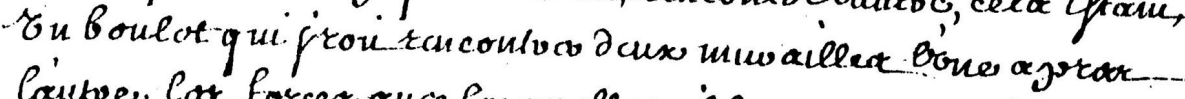

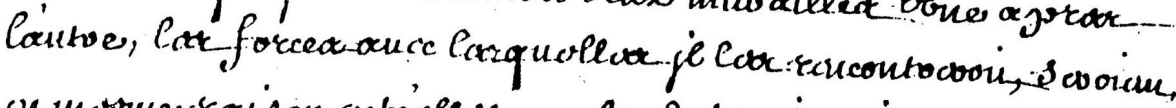

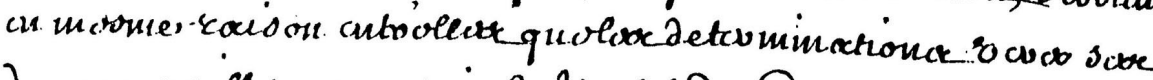

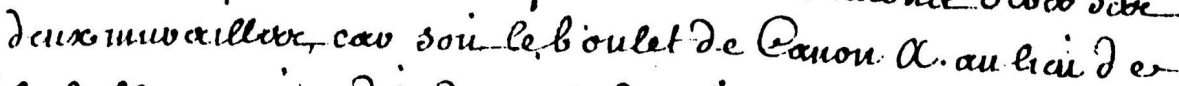

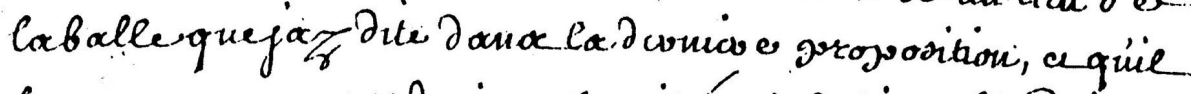

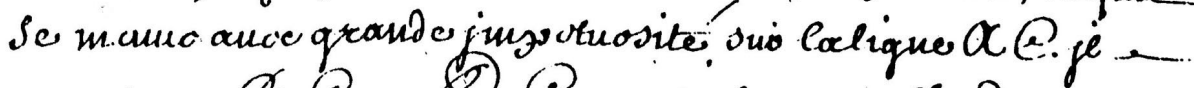

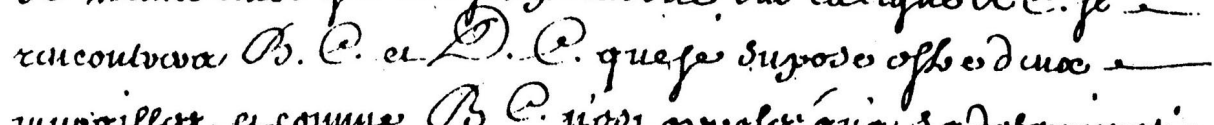

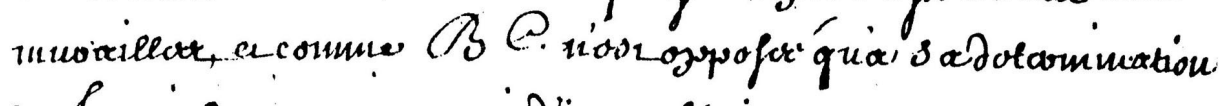

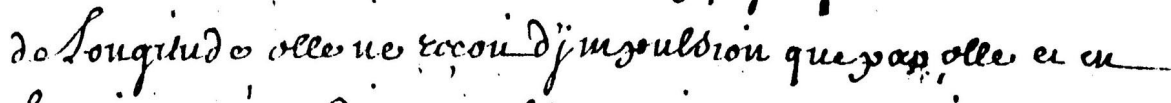

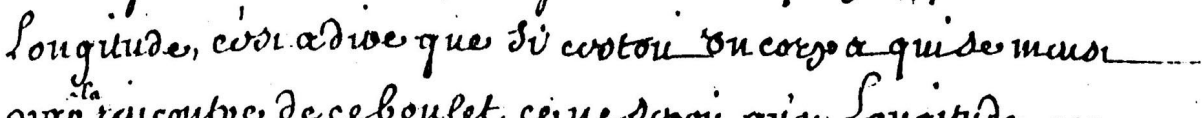

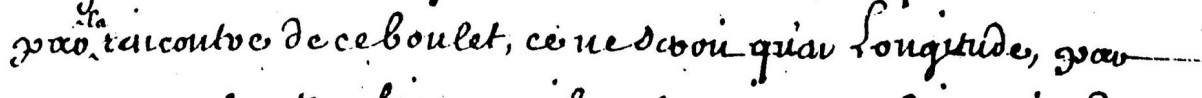

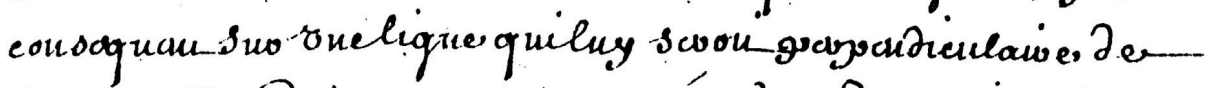

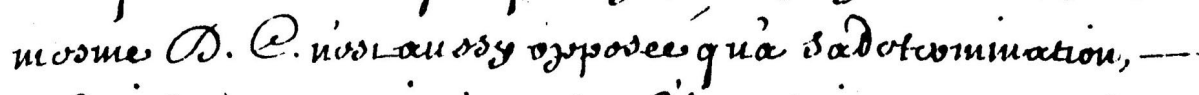

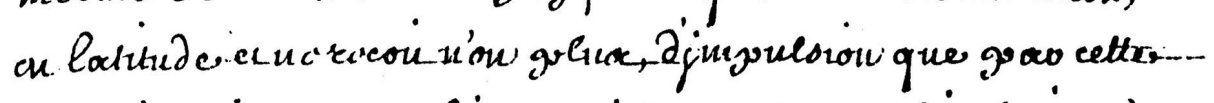

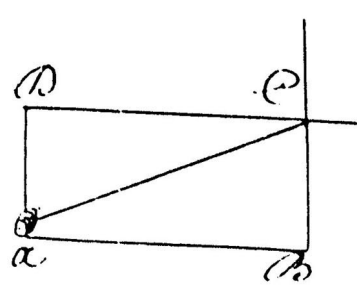

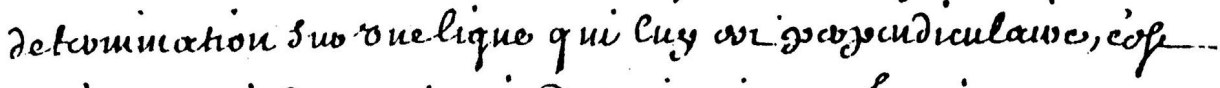

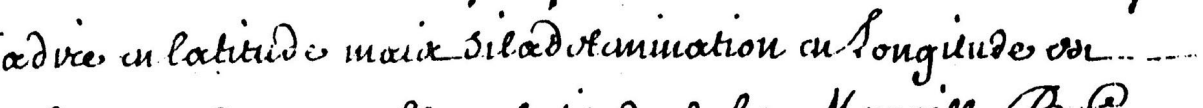

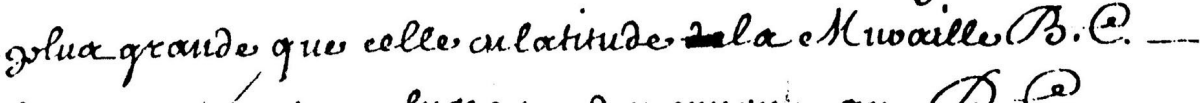

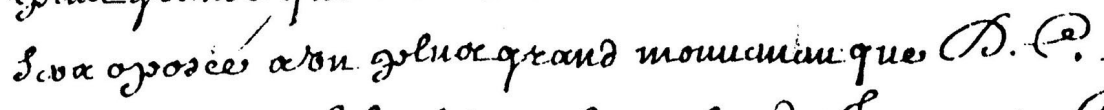

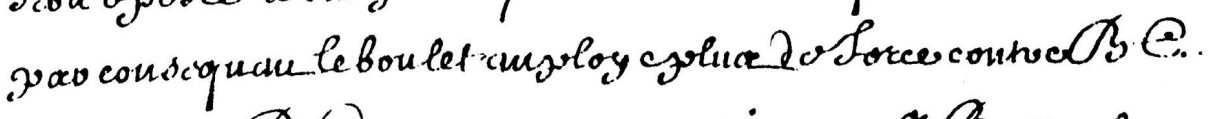

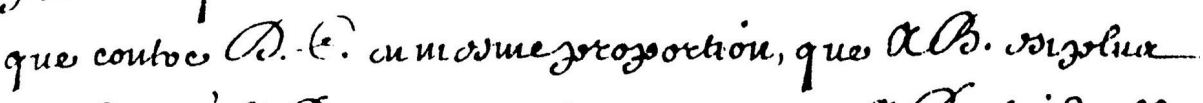

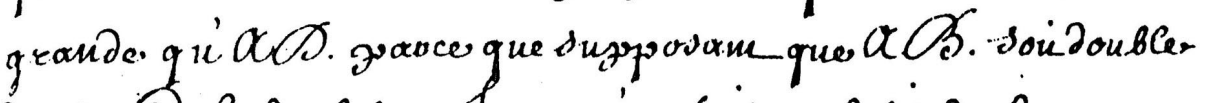

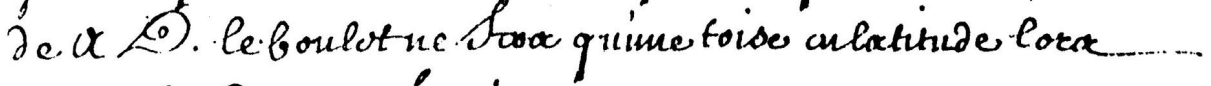

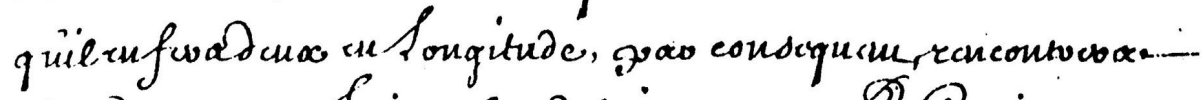

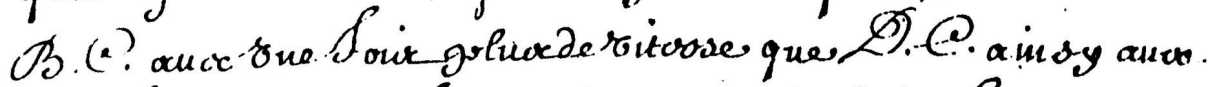

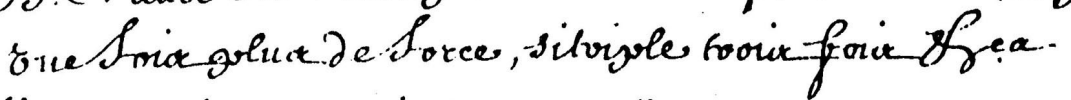

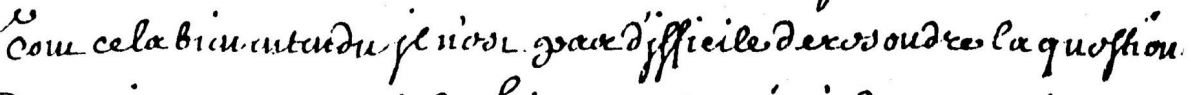

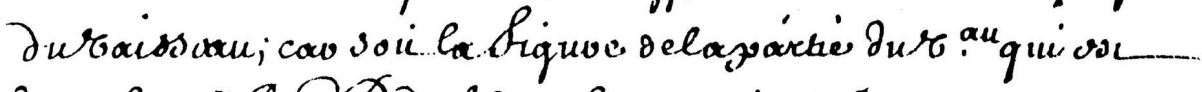

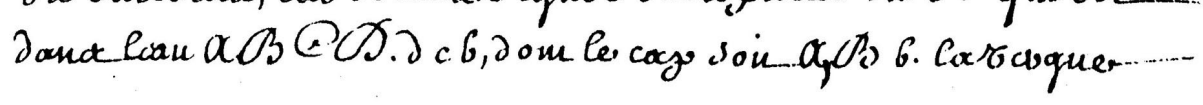




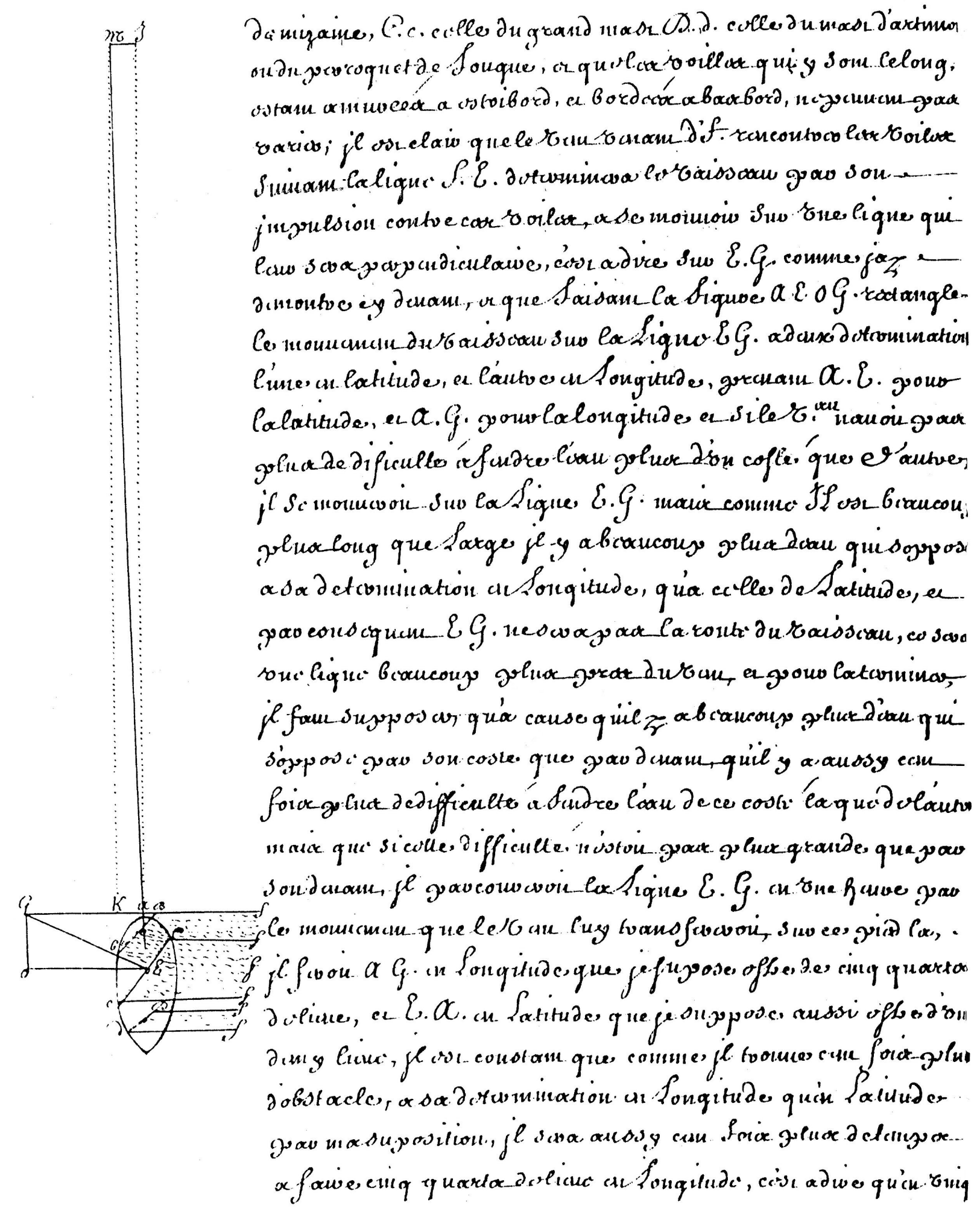




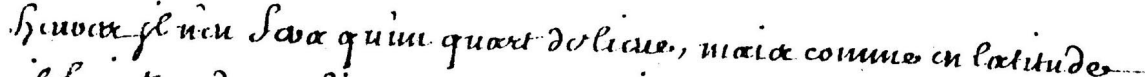

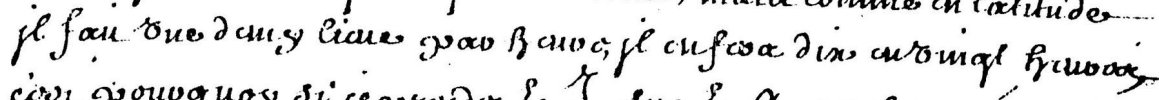

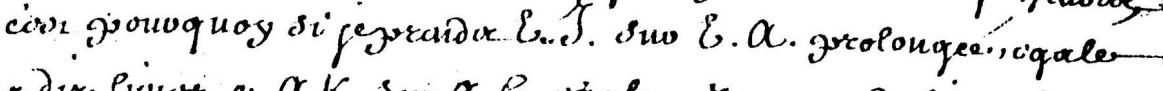

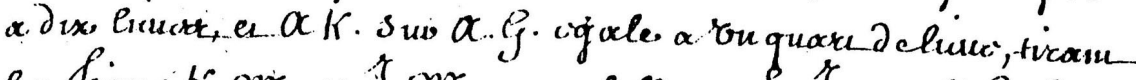

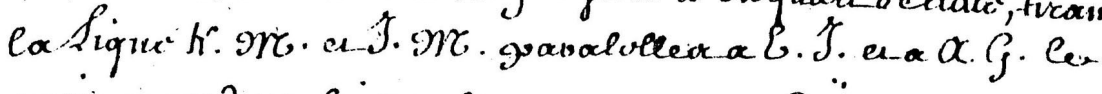

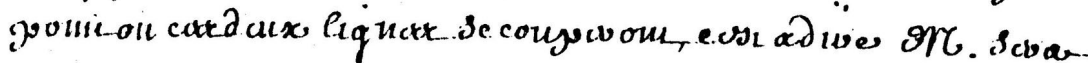

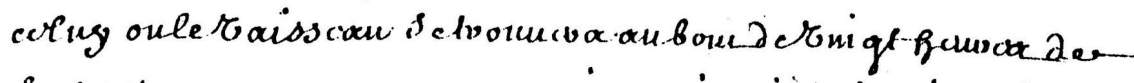

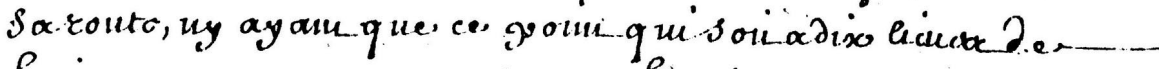

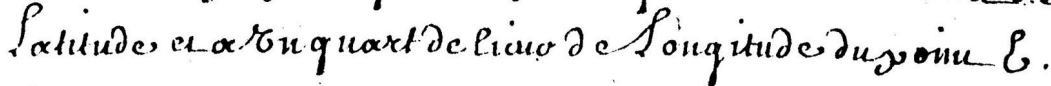

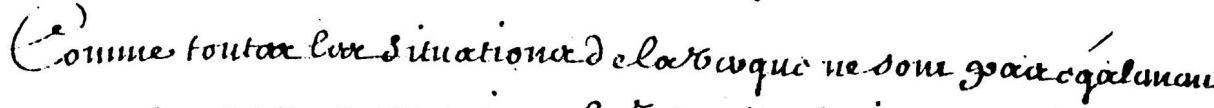

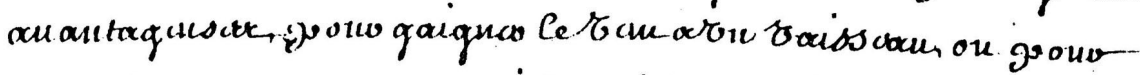

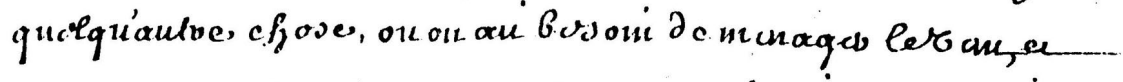

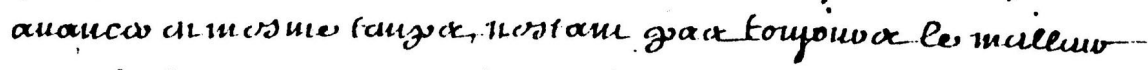

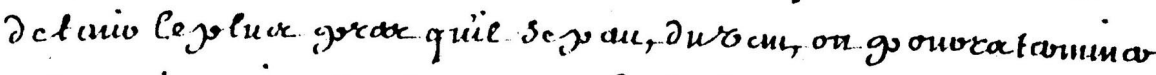

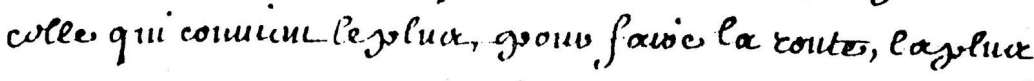

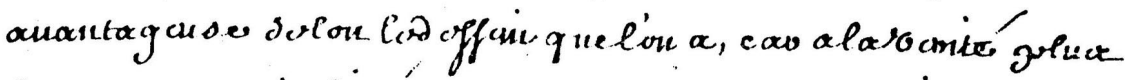

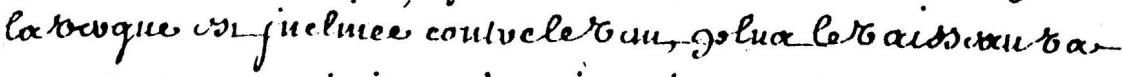

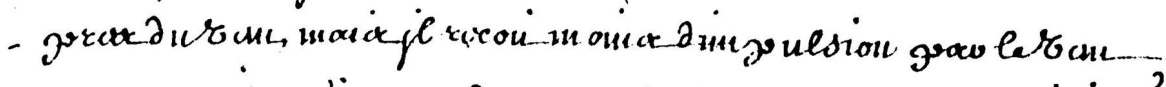

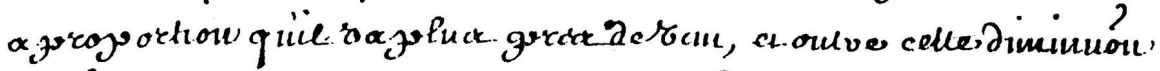

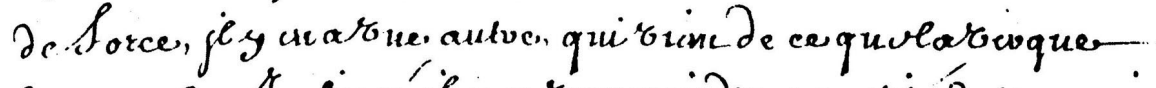

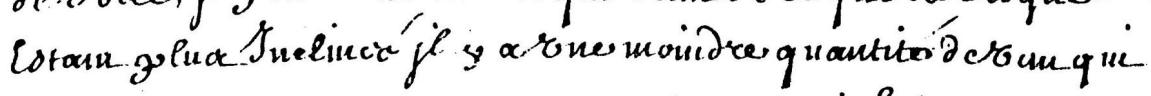

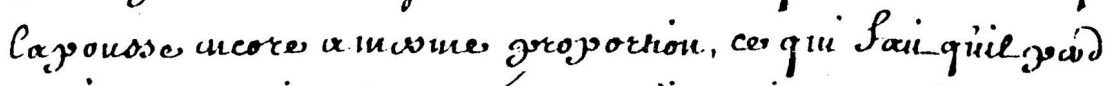

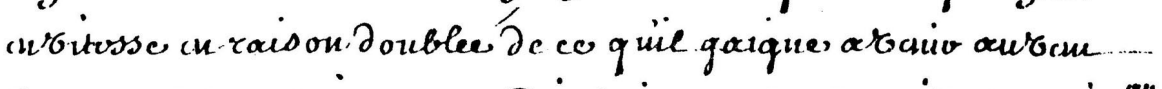

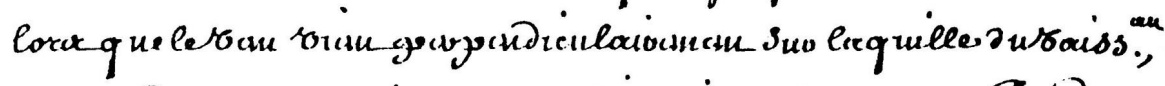

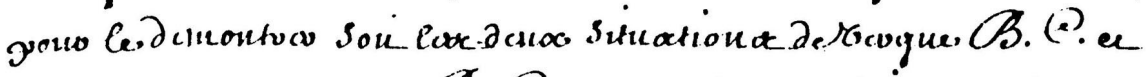

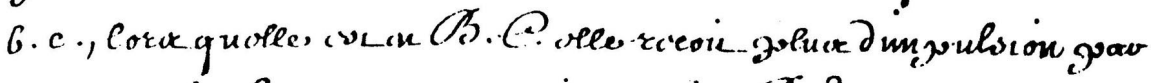

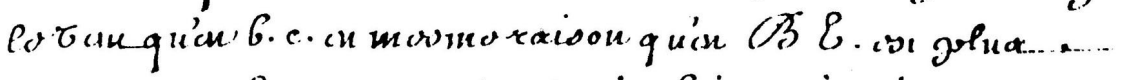

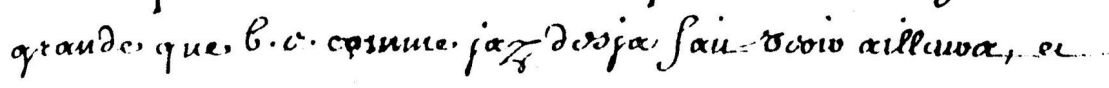




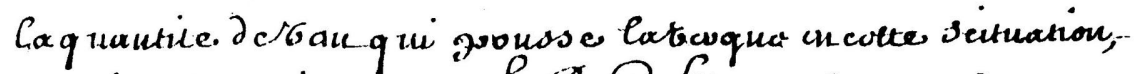

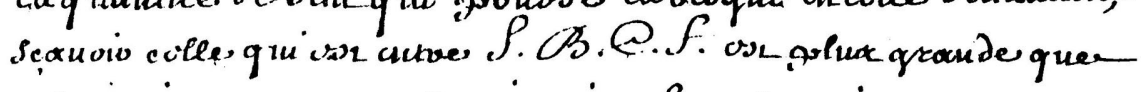

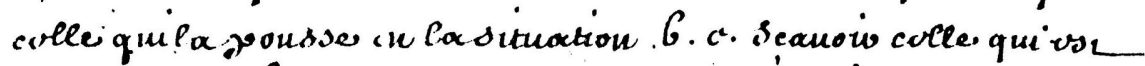

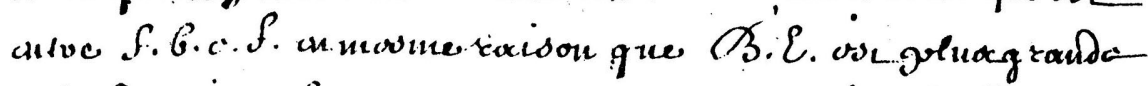

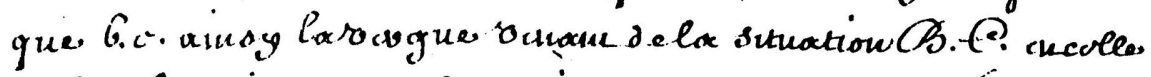

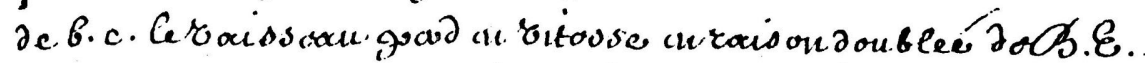

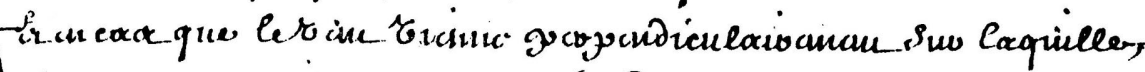

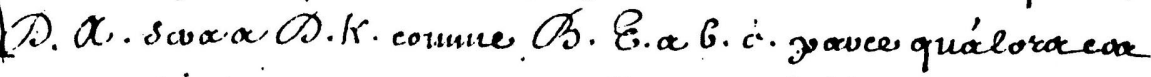

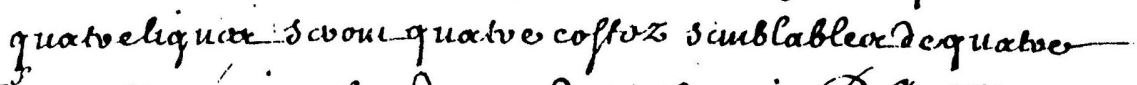

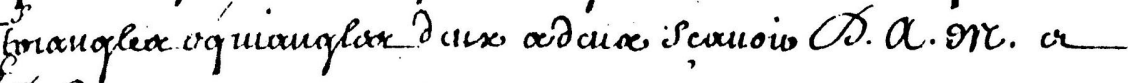

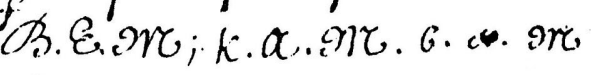

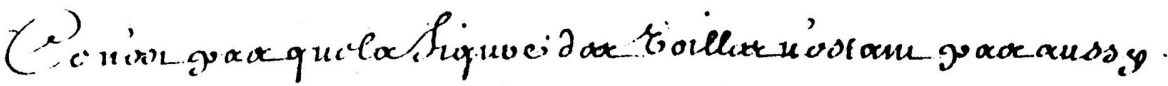

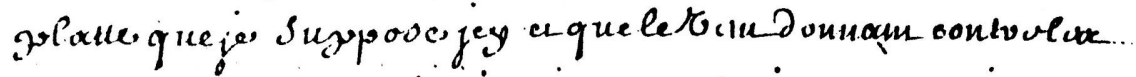

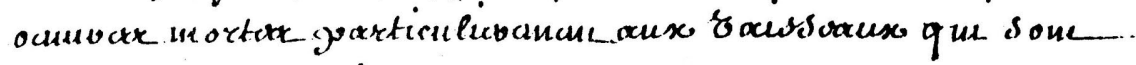

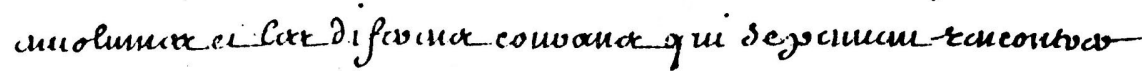

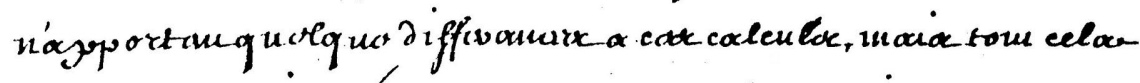

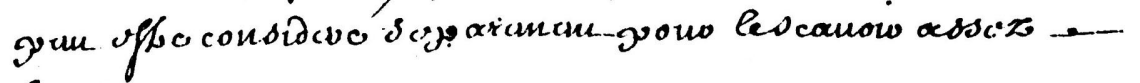
Exactarcane.

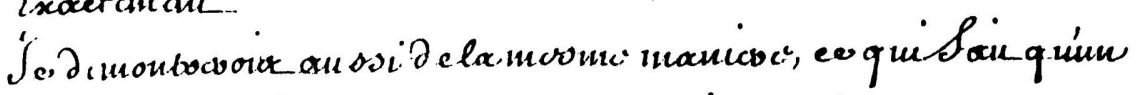

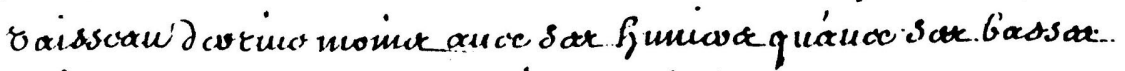

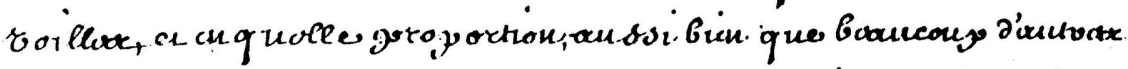

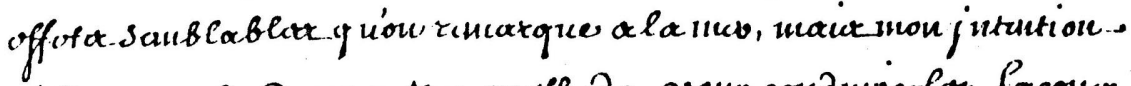

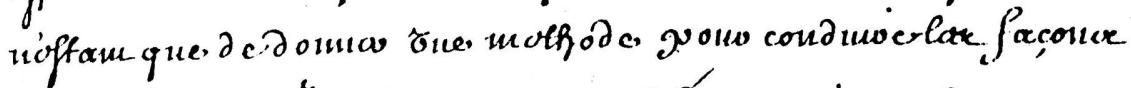

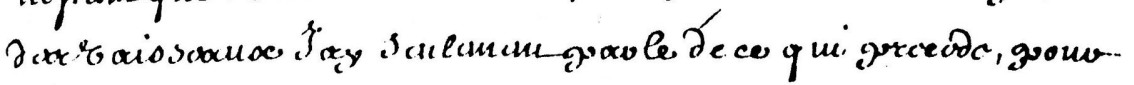

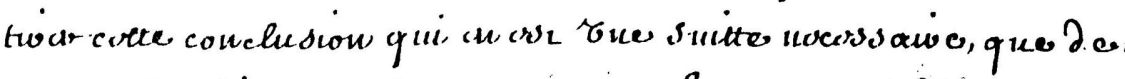

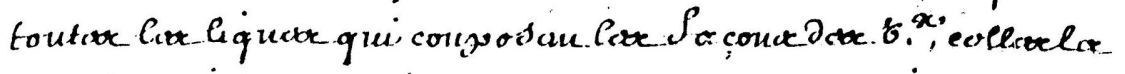

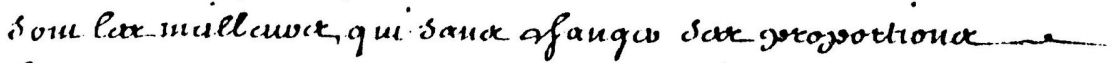

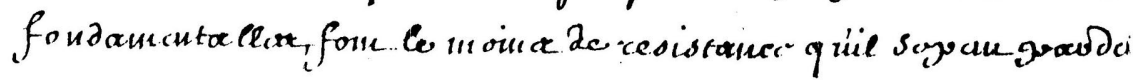




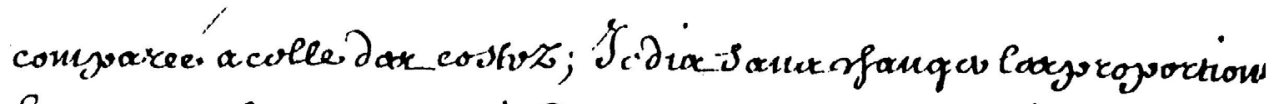

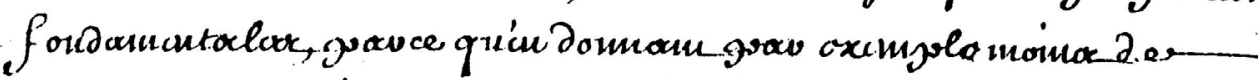

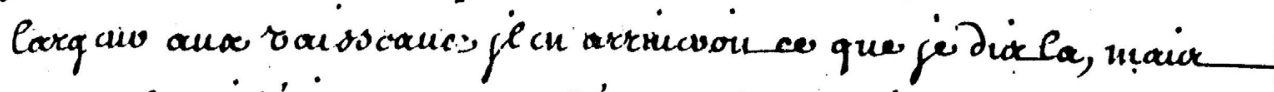

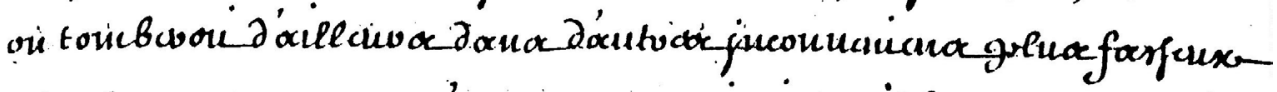

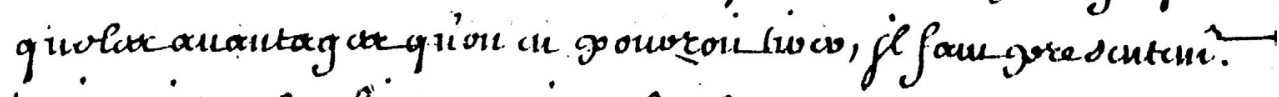

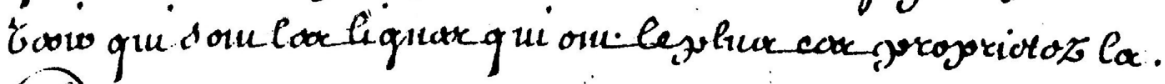

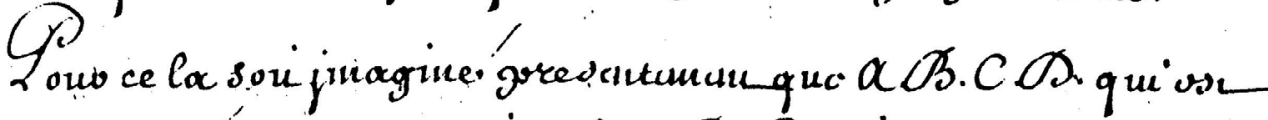

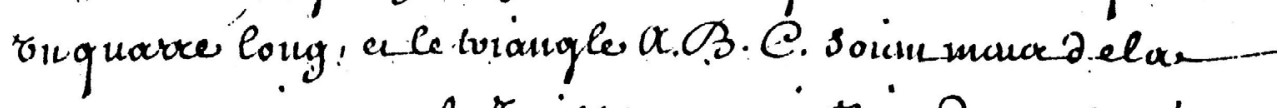

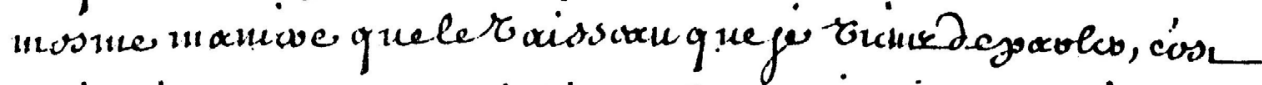

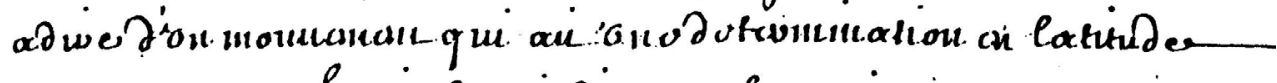

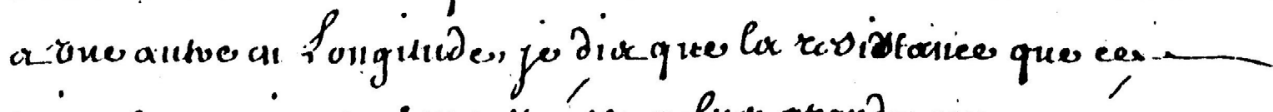

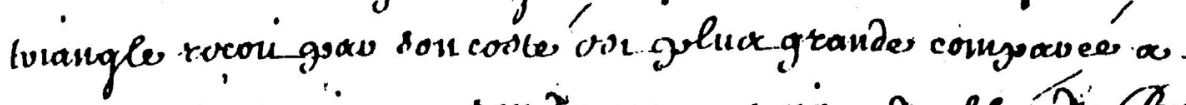
collerquolle recoir grav on tran an,

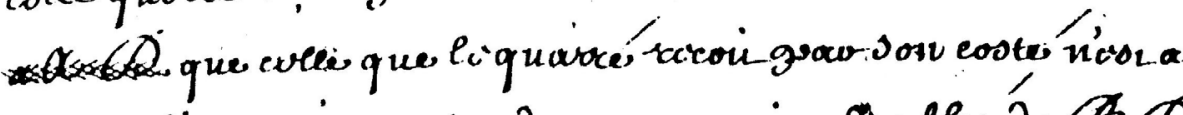

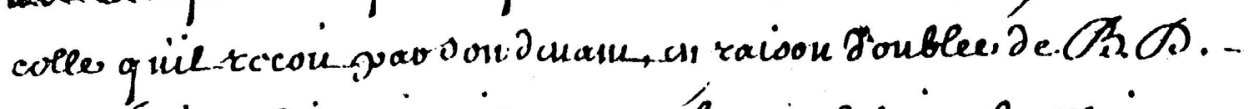

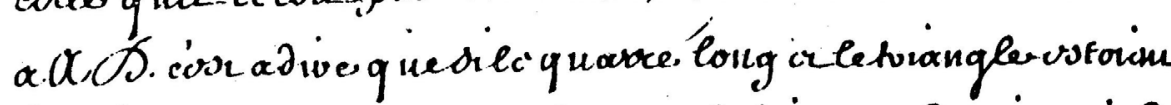

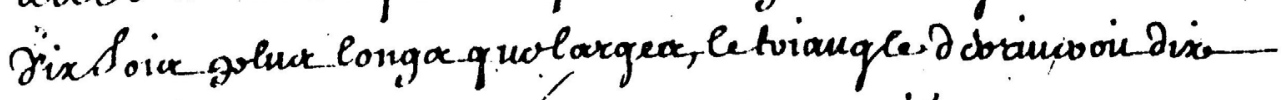

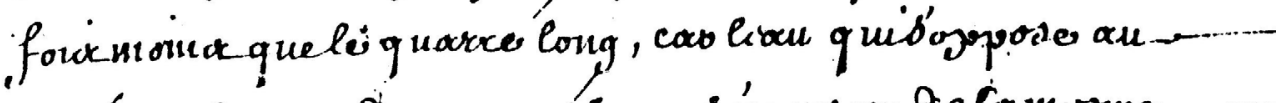

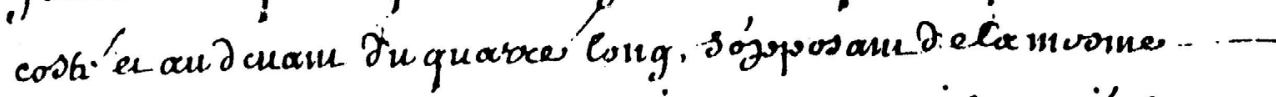

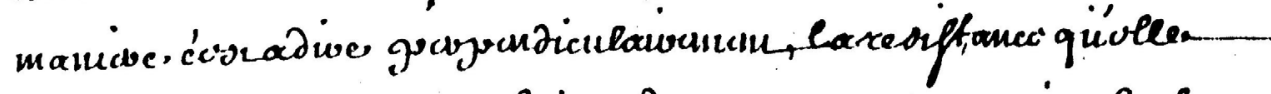

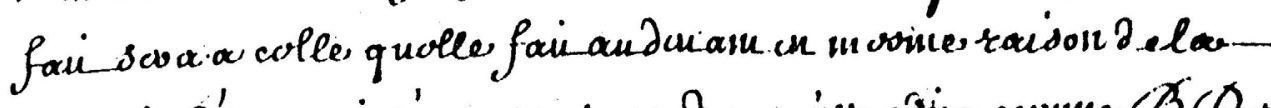

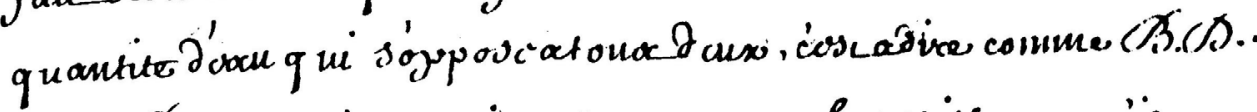

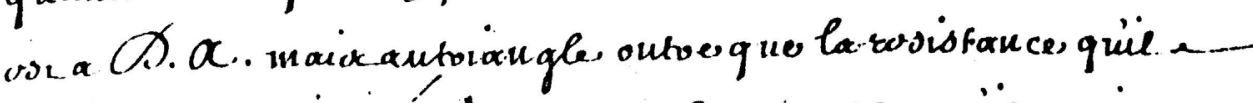

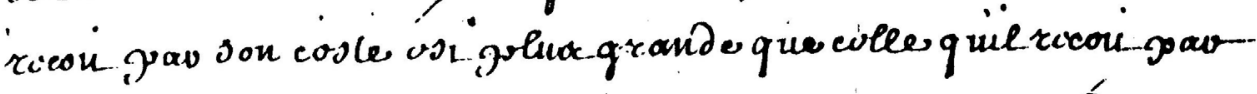

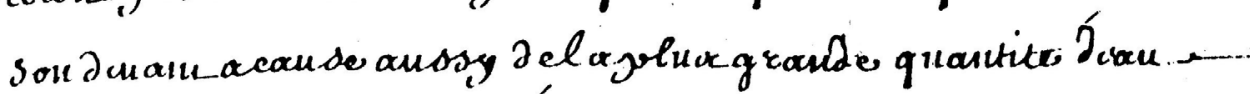

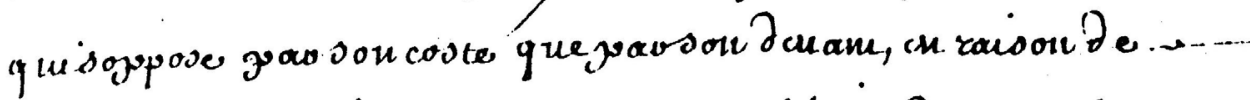

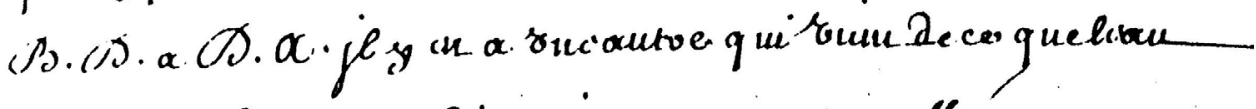

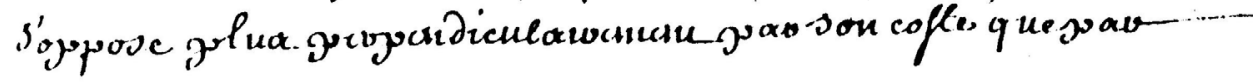




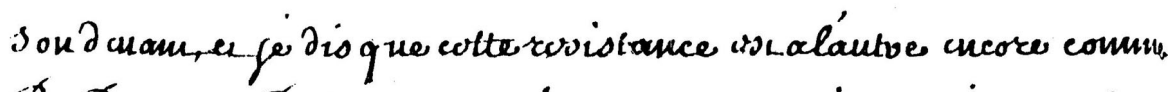

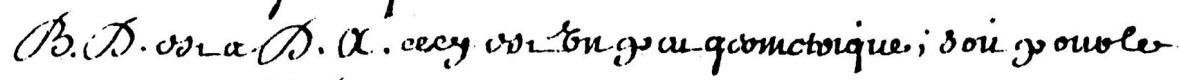
$\frac{1}{9+a}$

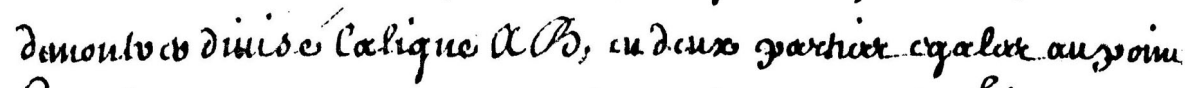

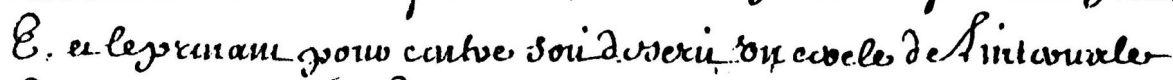

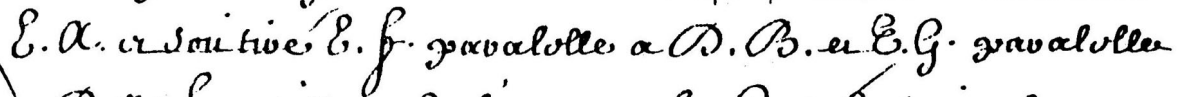

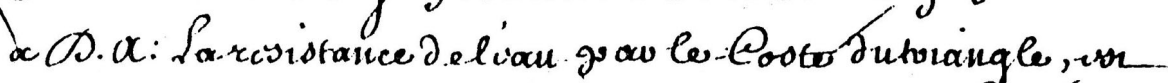

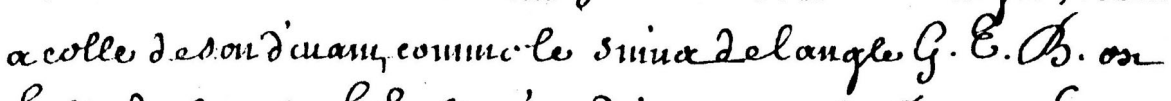

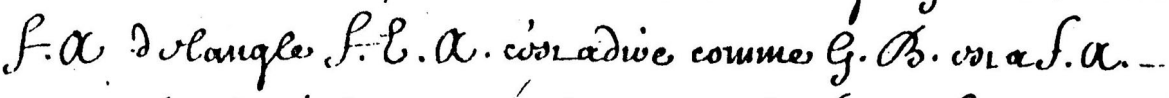

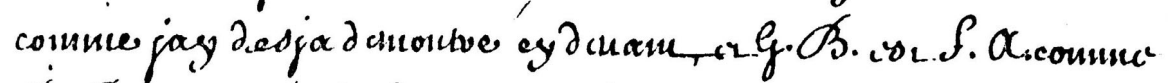

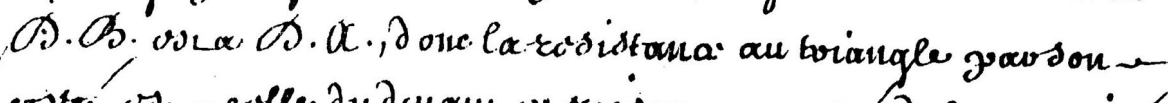

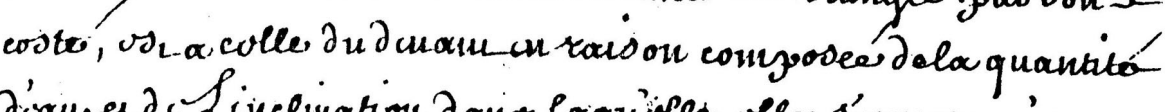

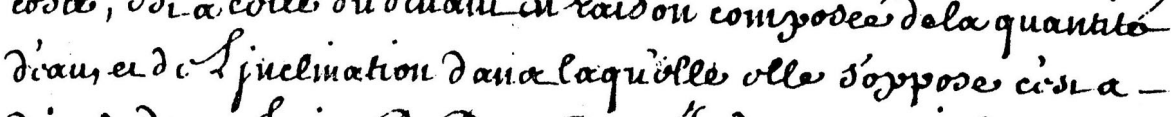

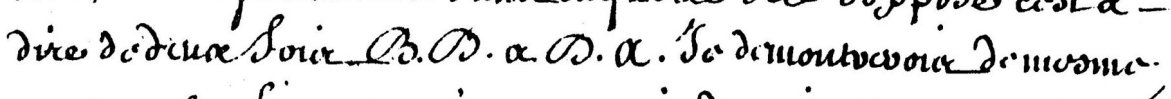

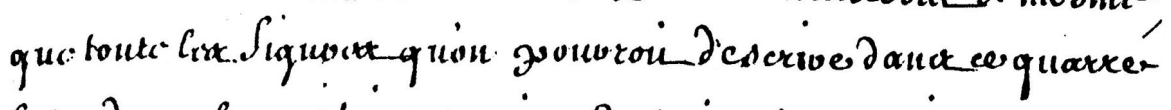

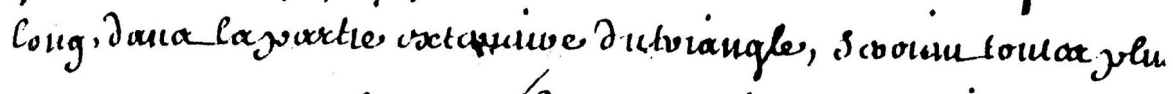

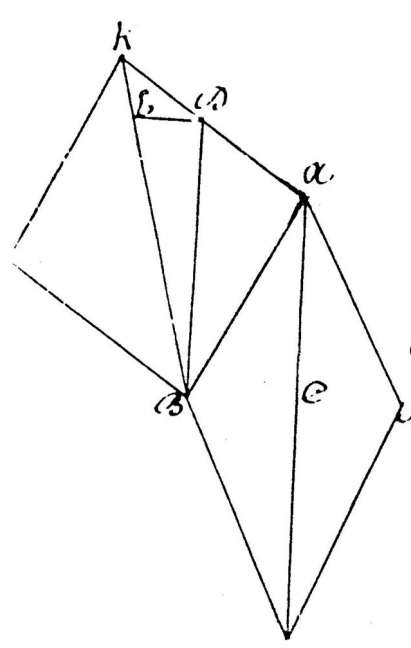

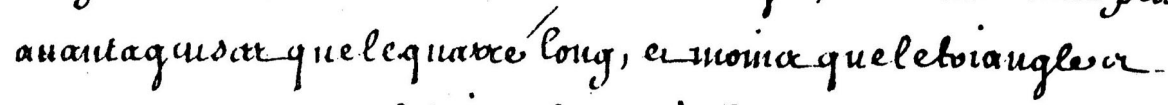

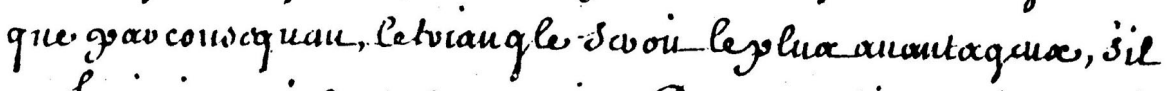

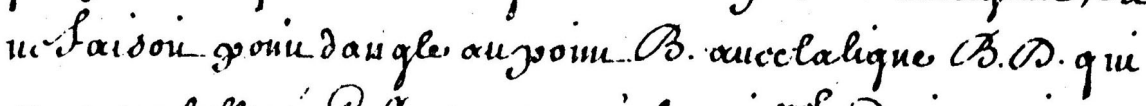

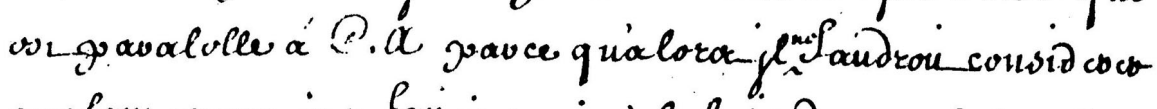

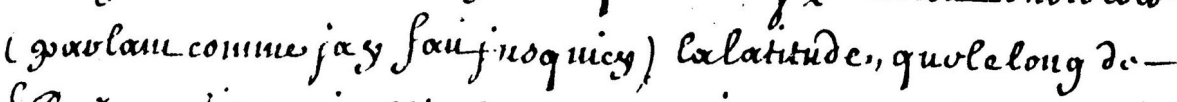

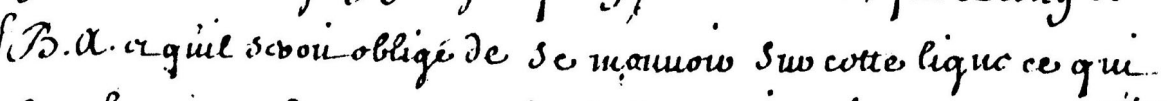

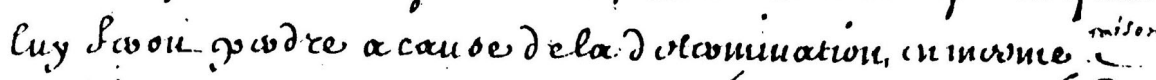

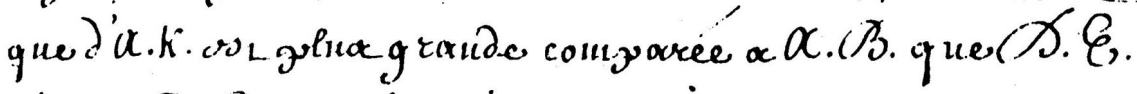

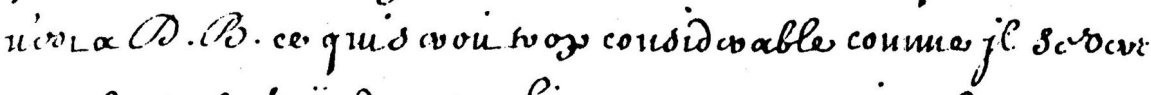

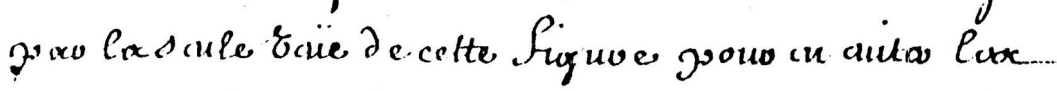

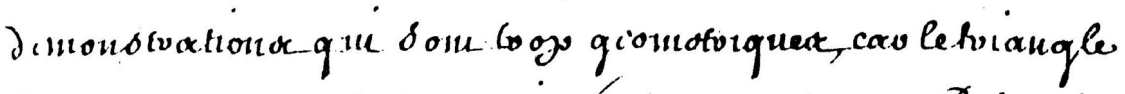

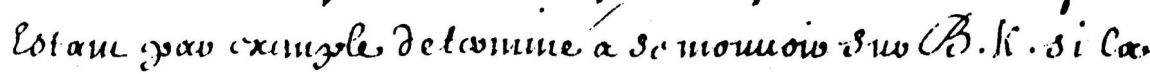

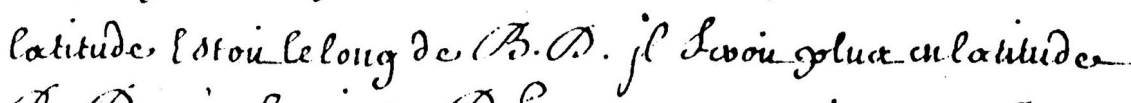

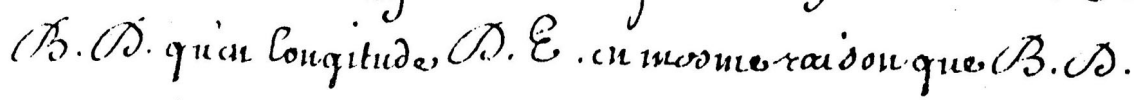




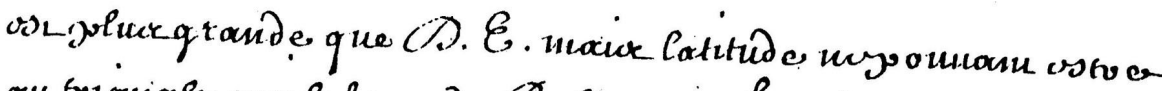

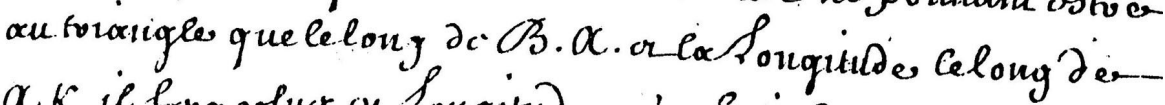

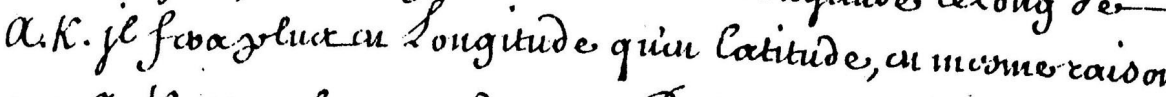

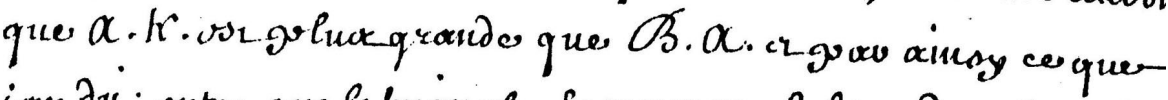

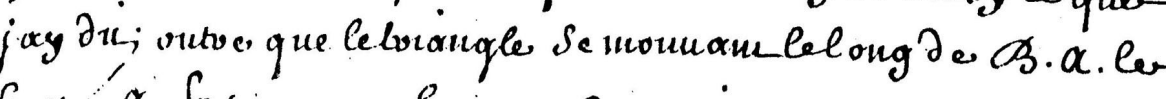

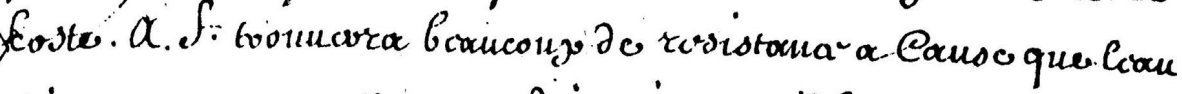

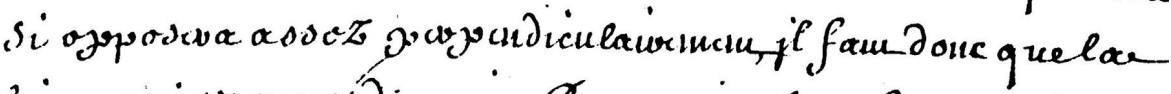

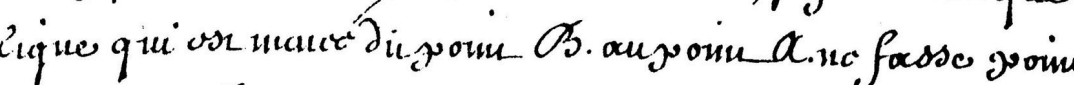

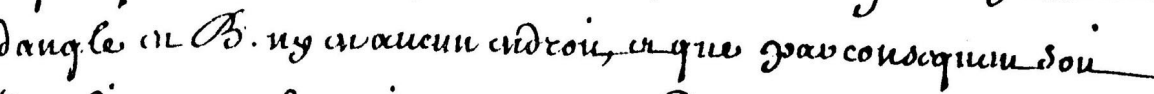

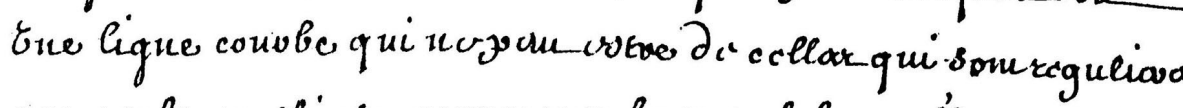

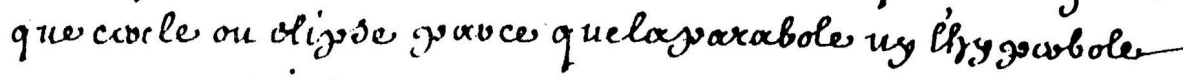

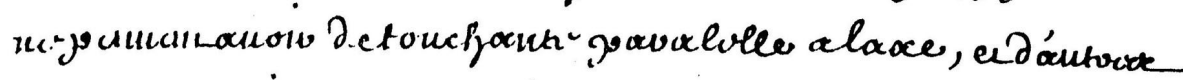

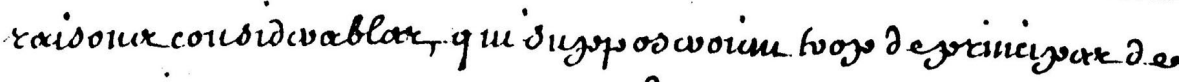

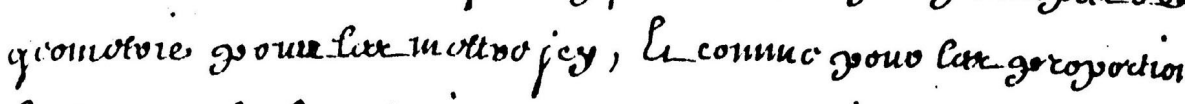

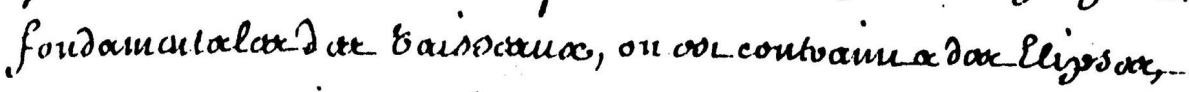

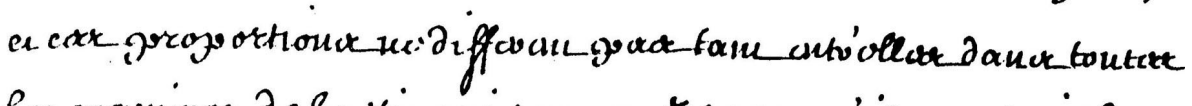

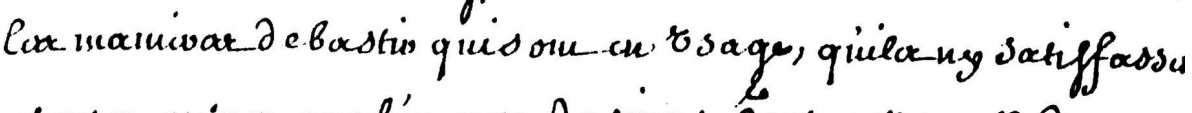

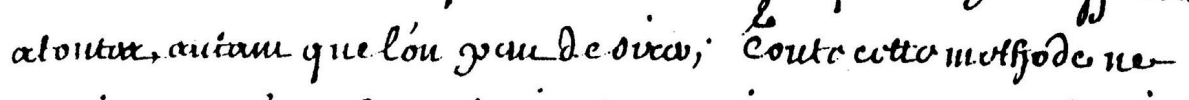

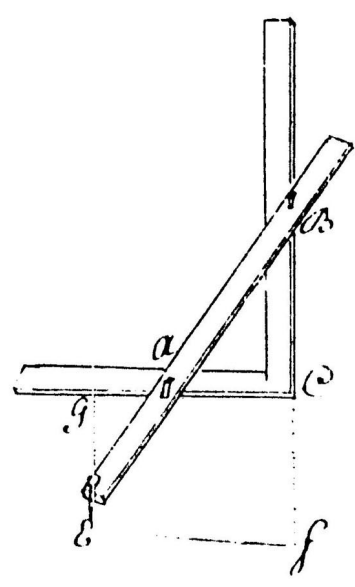

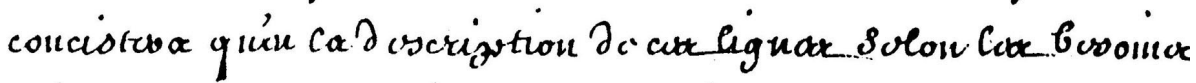

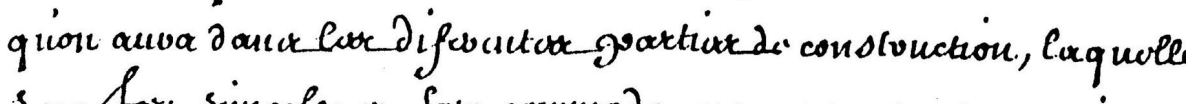

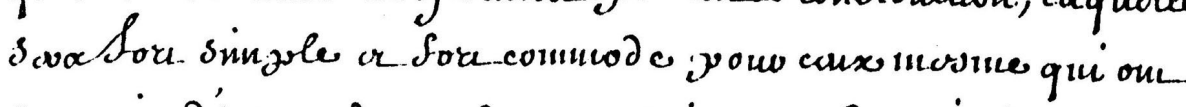

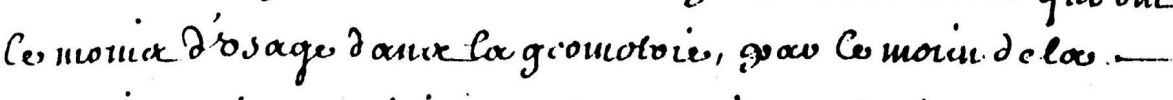

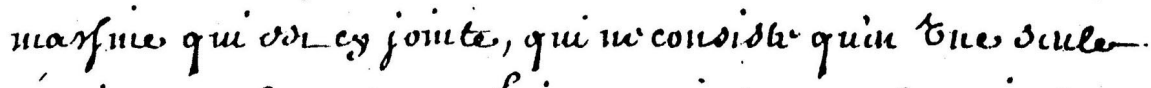

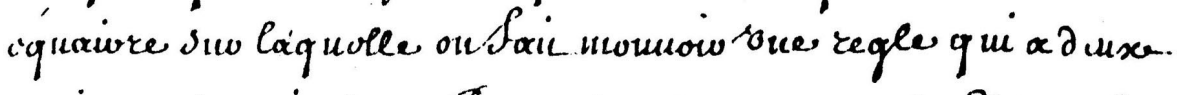

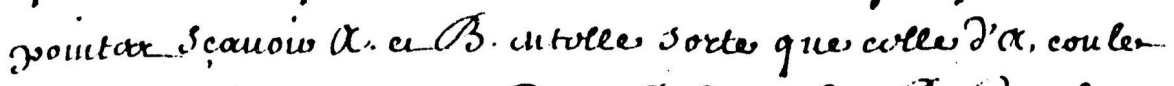

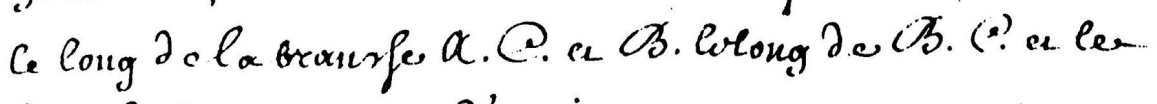

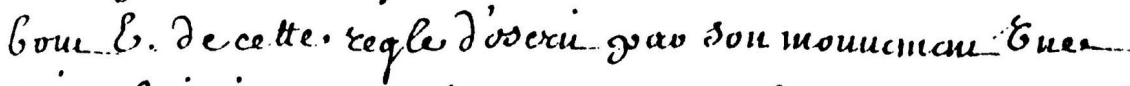

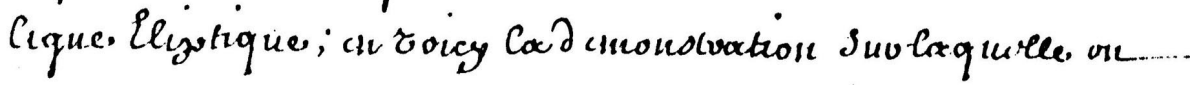


i) intoltutuation.

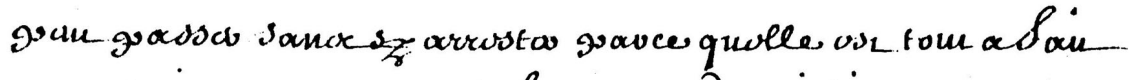

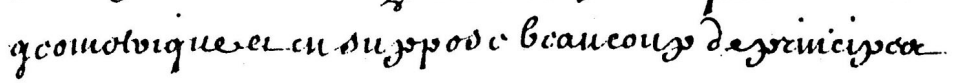

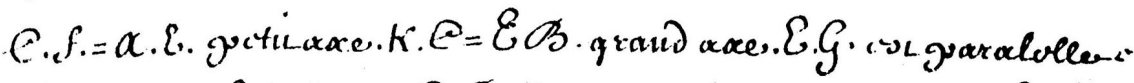

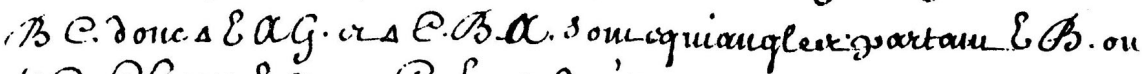

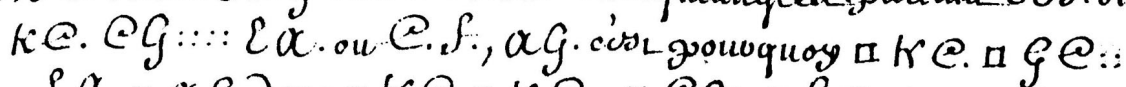

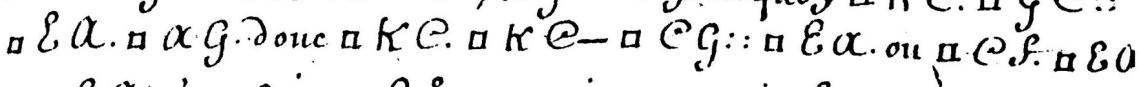

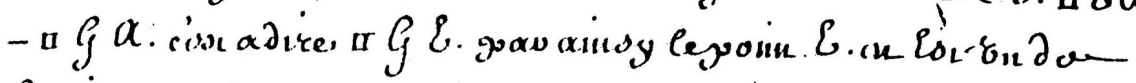

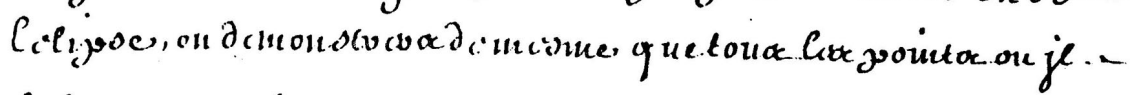
Silvounara dir sane.

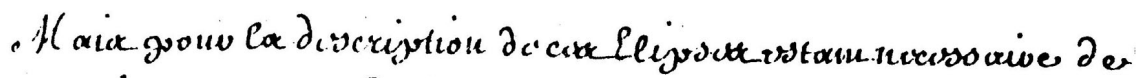

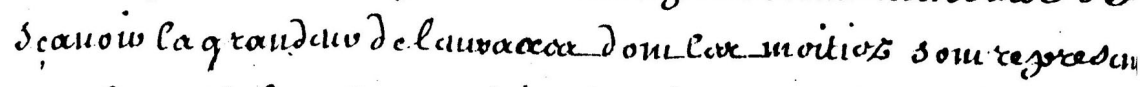

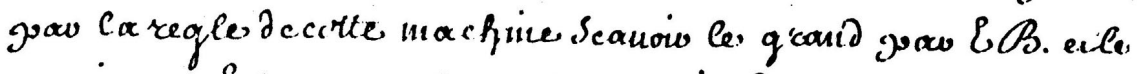

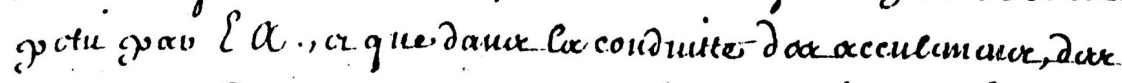

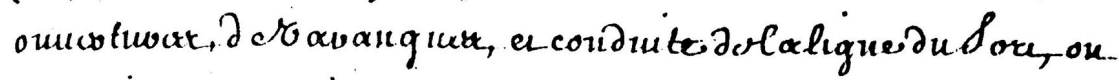

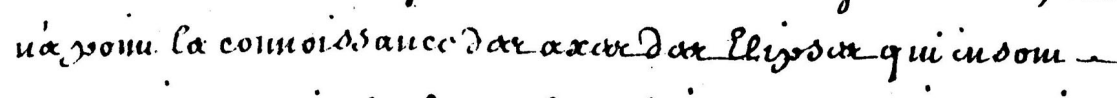

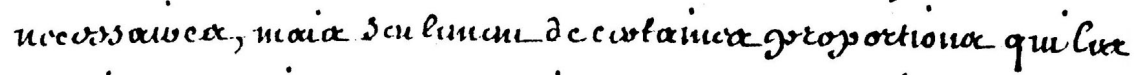

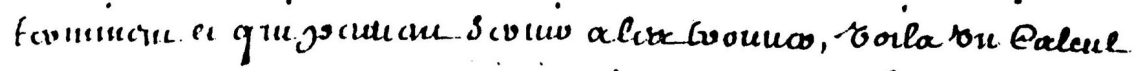

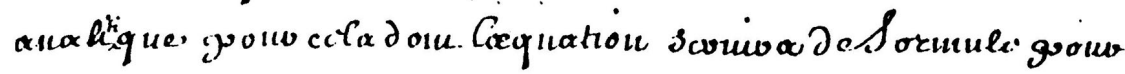

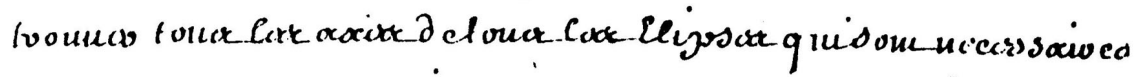

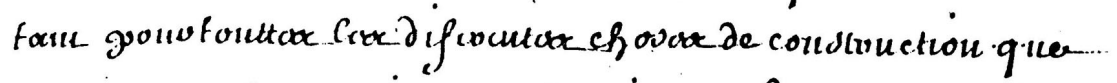

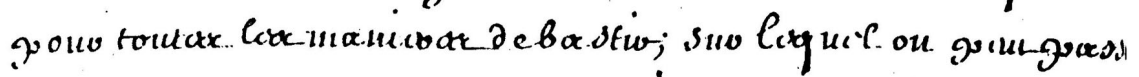

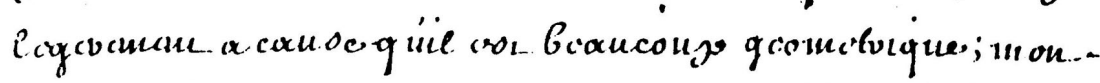

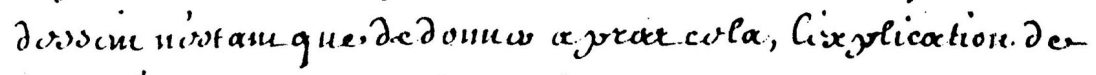

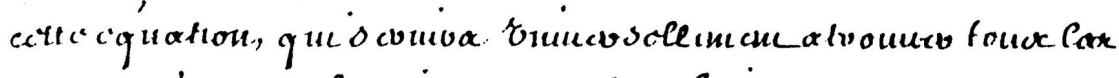

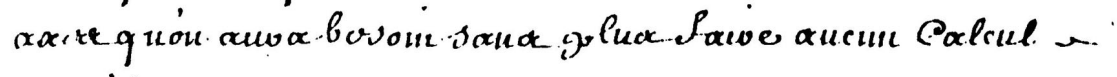
ocualitigue.

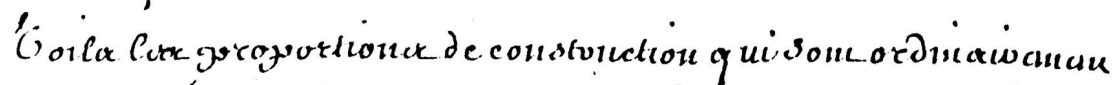

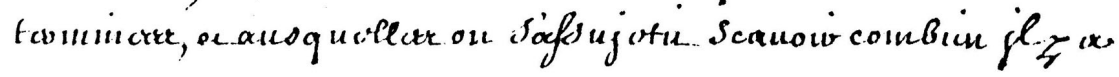




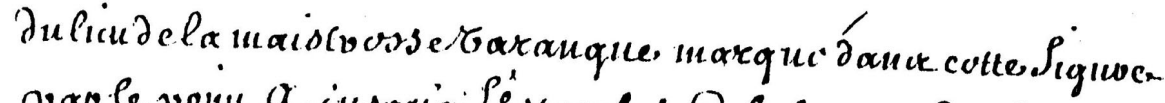

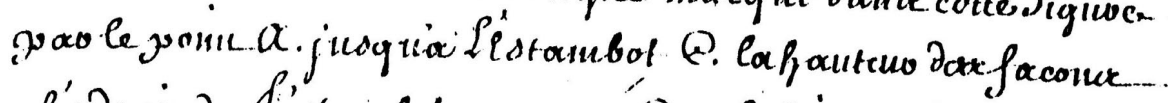

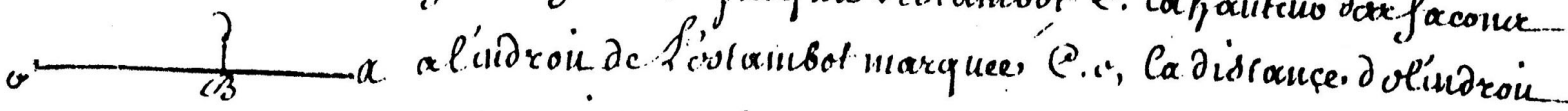

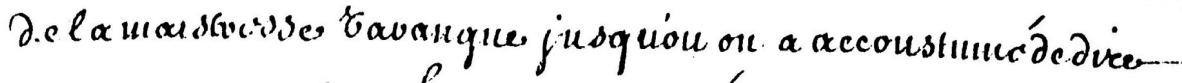

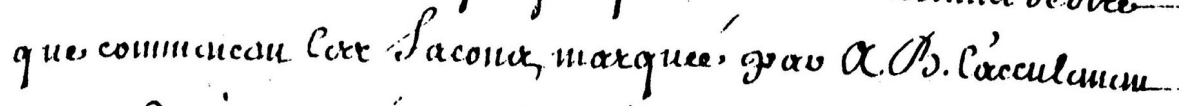

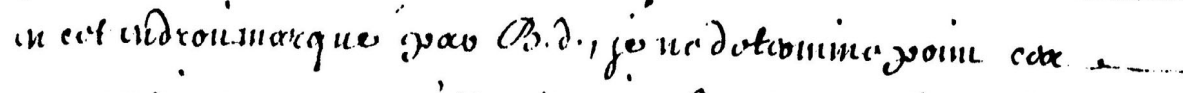

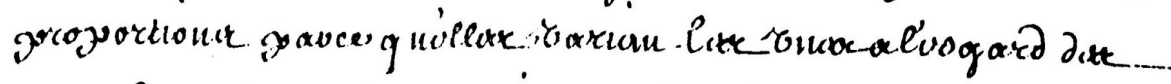

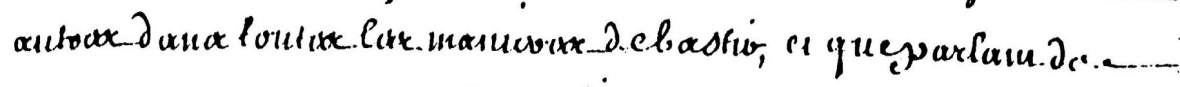

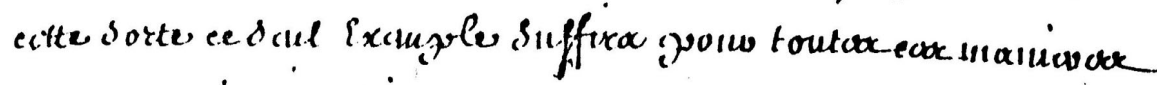

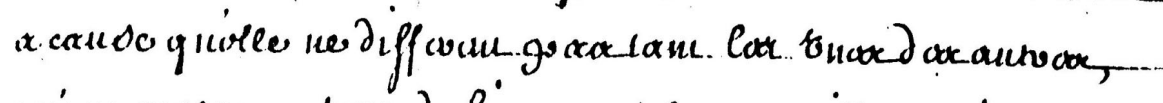

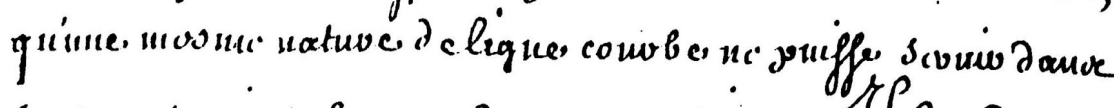

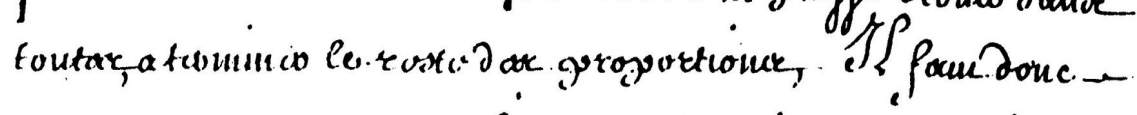

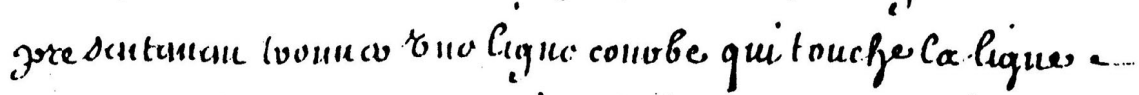

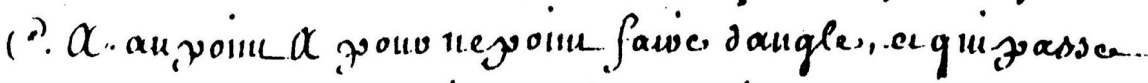

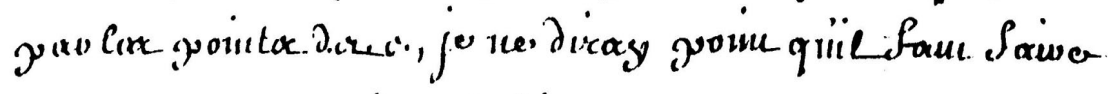

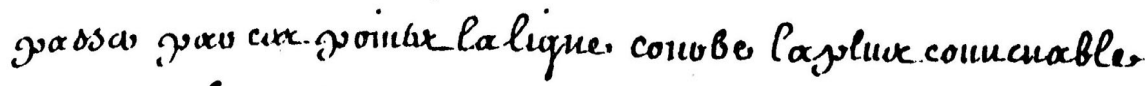

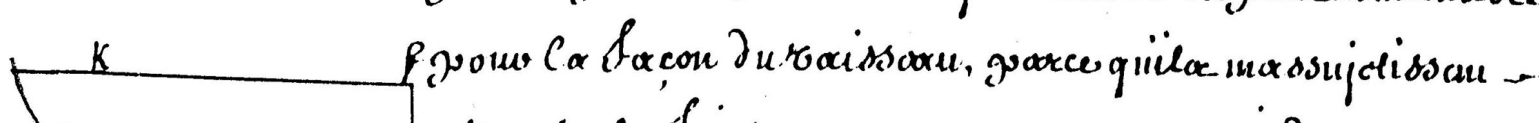

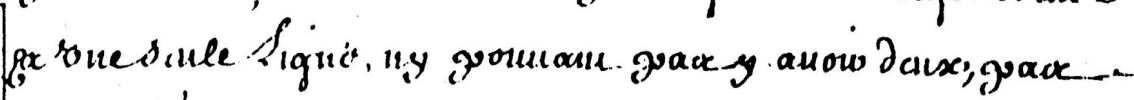

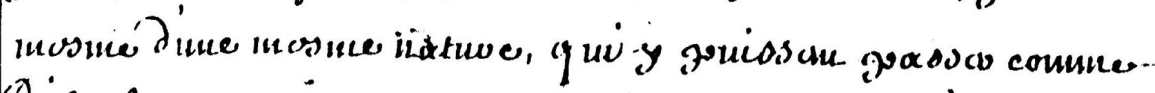

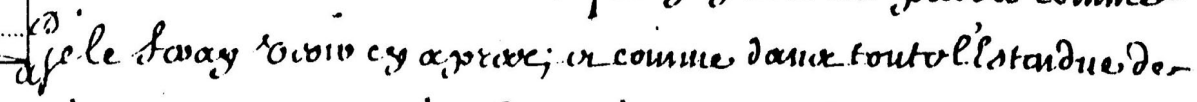

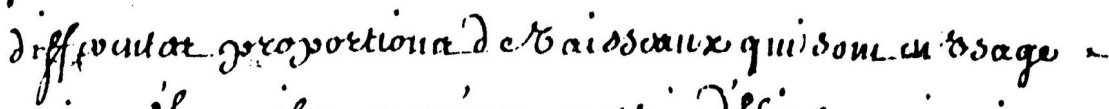

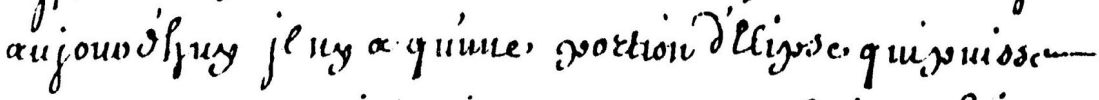

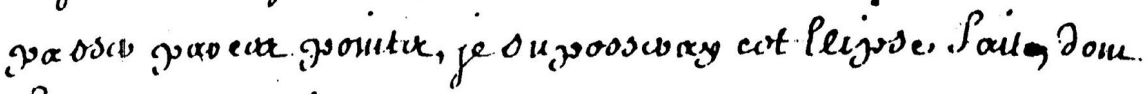

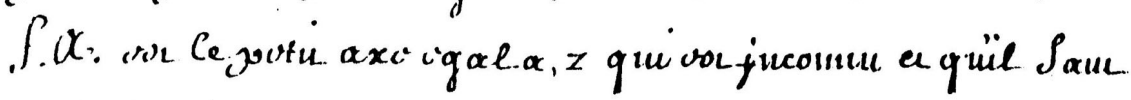
tronutis sou gorm cela. 


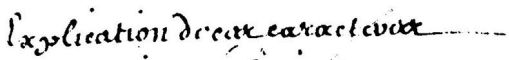

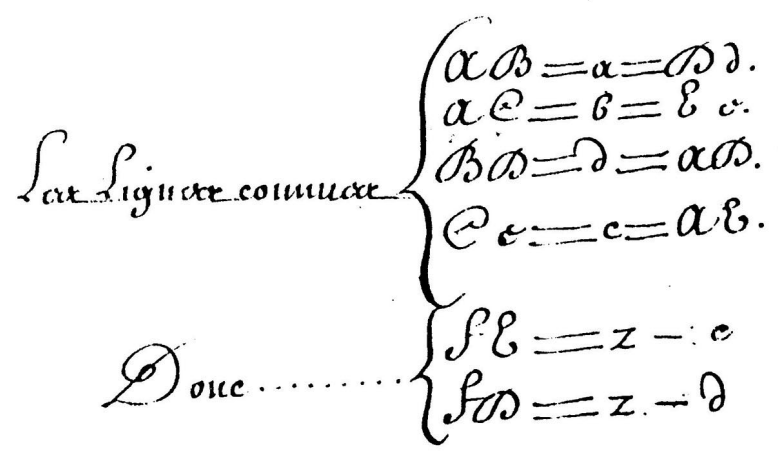

$=$ silcoire cyal aimoy-

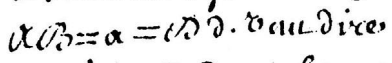

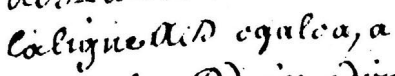
coliyalc a (D) con dize. or u'a'regoriscintria Catialuw

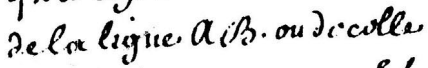
(t) a yui oos ex mosture ofofo

$\int \varepsilon \equiv z-c$

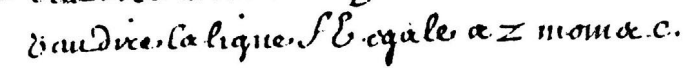

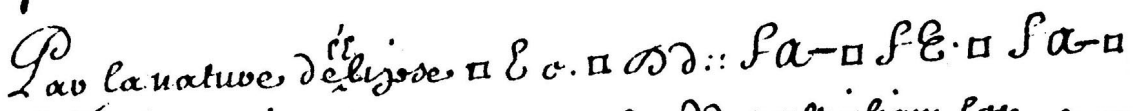

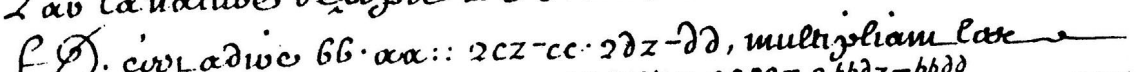

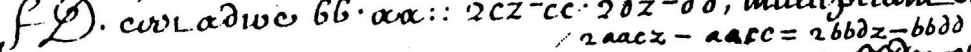

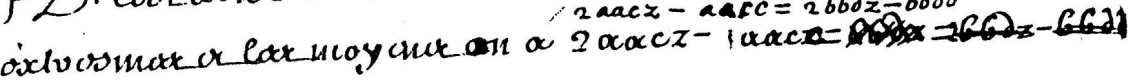
Jouc $26 G \partial z-2$ axac $z=6620-$ aace

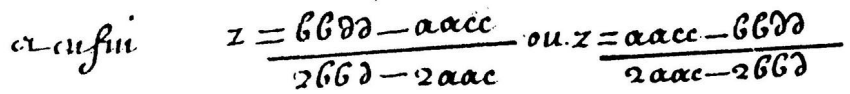

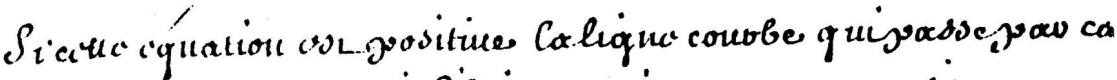

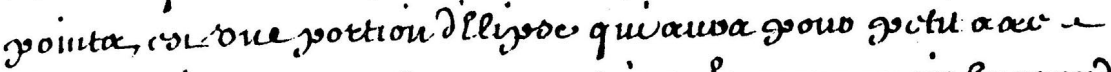

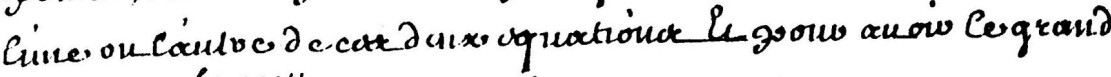
axe, fysutupelle,

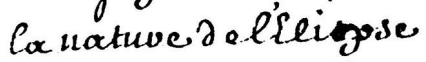

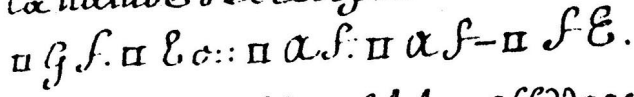

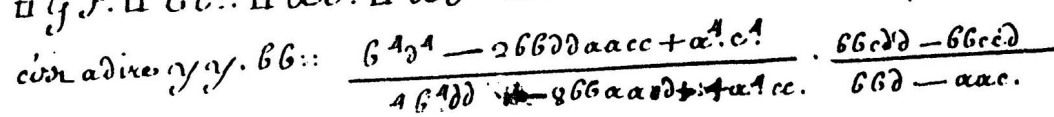

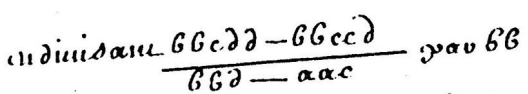

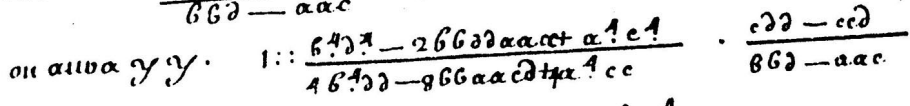

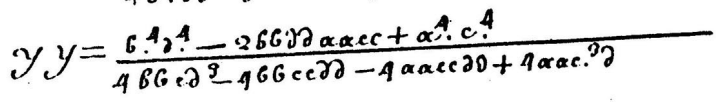

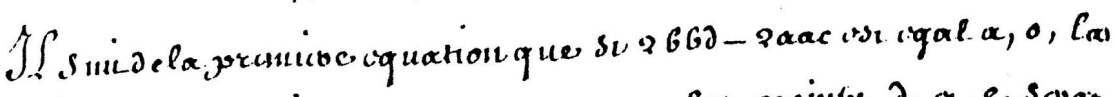

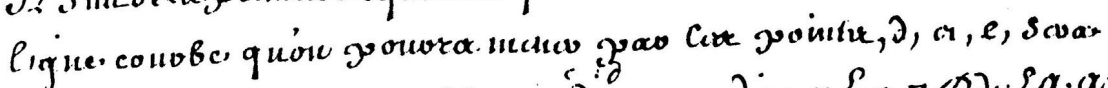

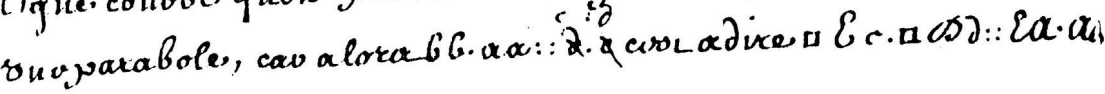


qui ost sne proystale $\partial c$ ? $x$ gourabole,

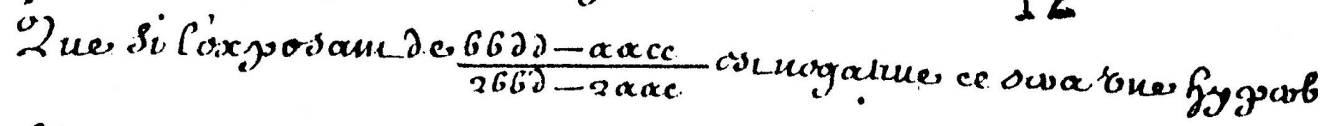

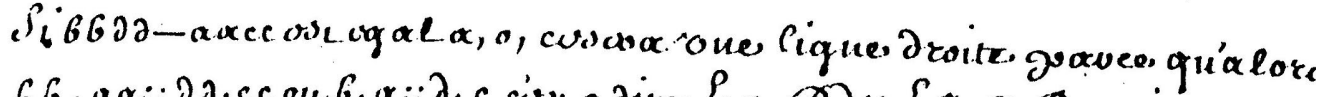

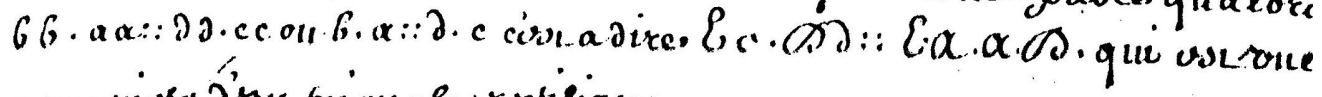

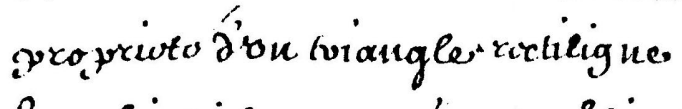

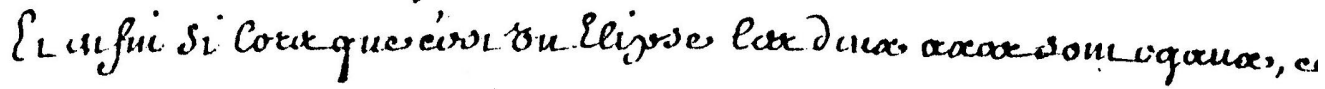
scuarou cavele.

(?)

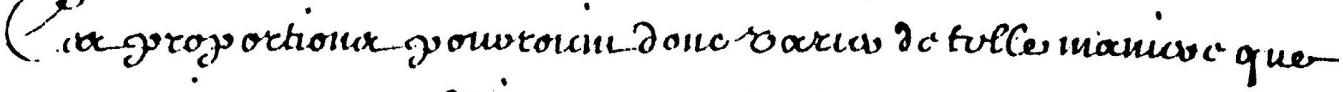

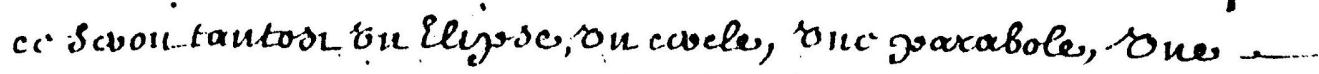

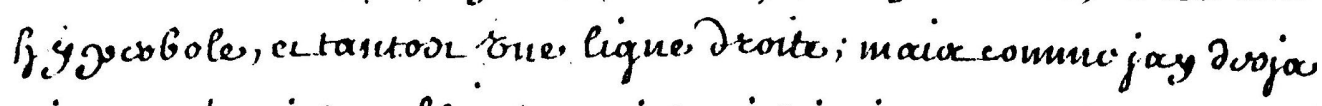

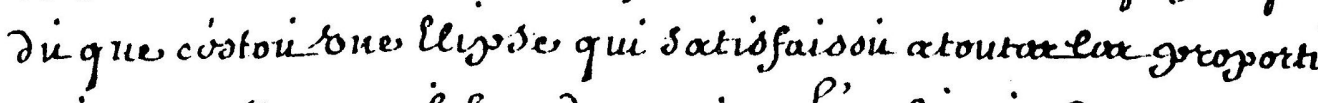

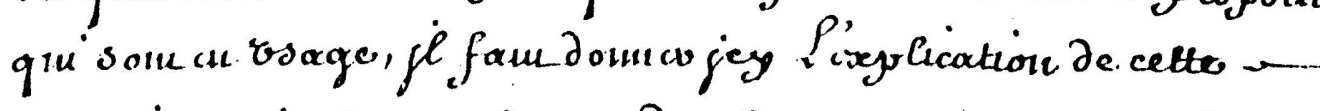

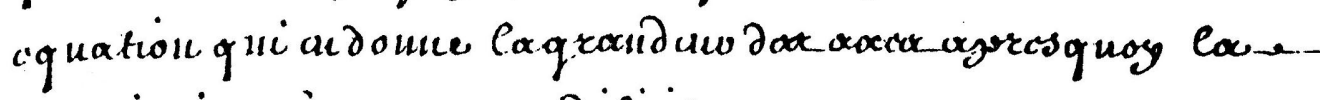

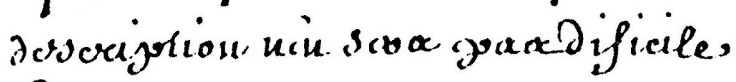

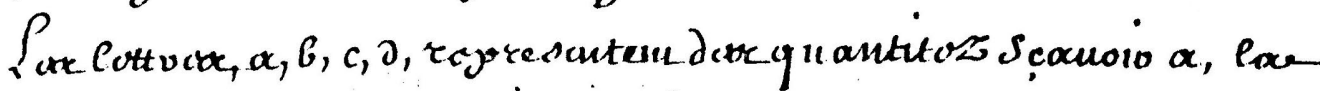

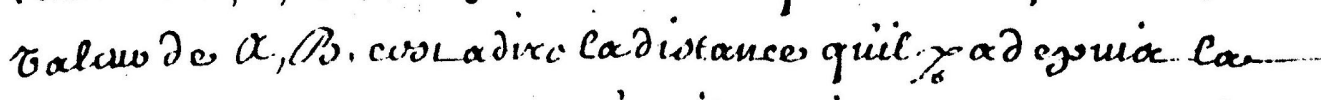

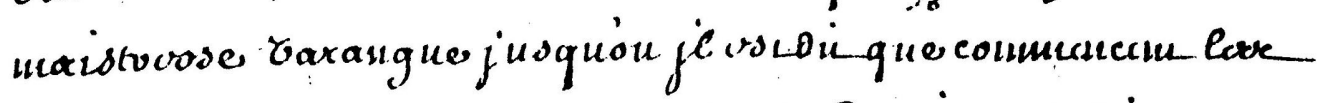

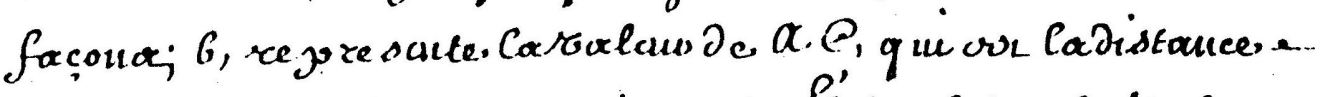

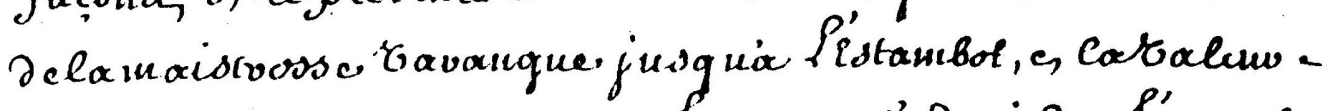

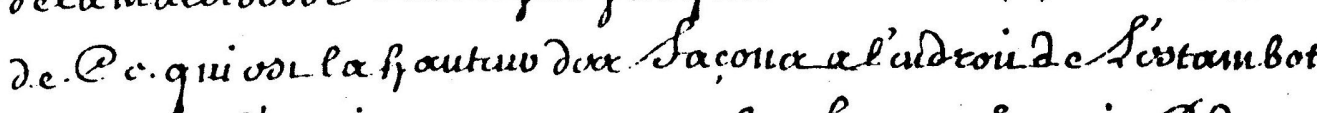

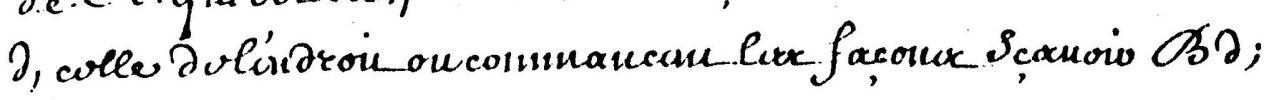

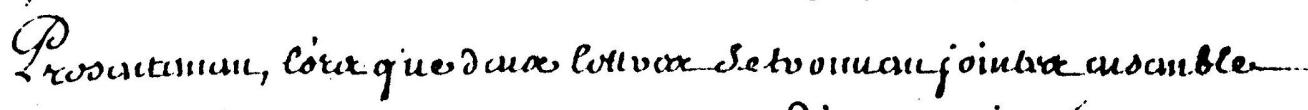

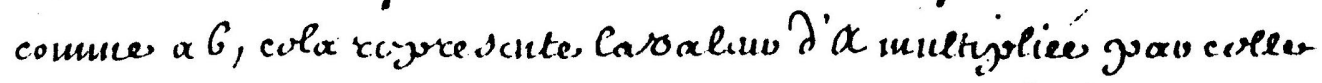

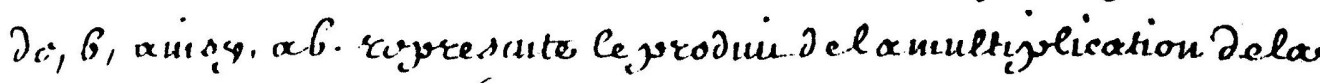

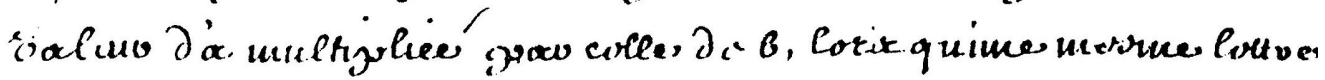

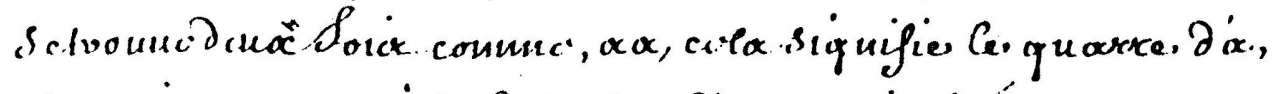

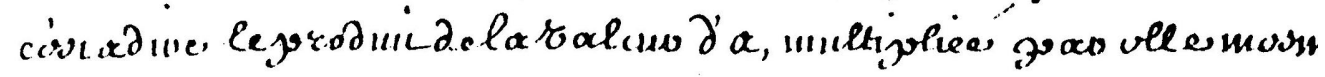

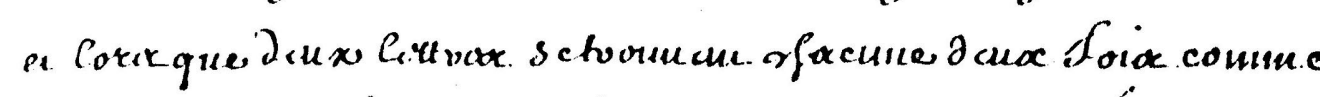

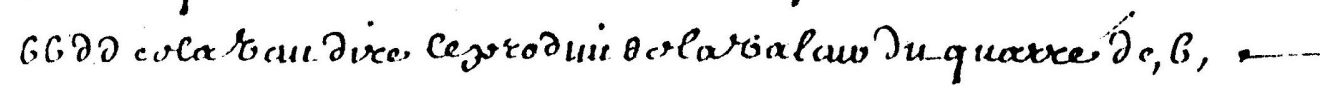




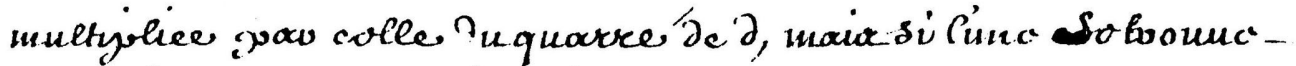

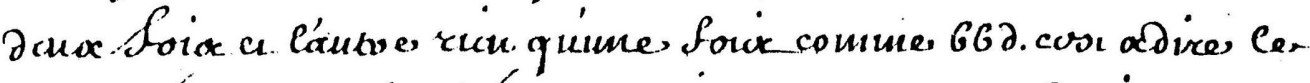

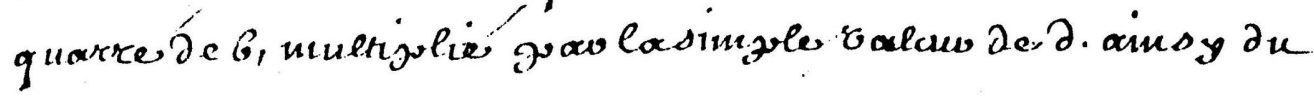
togles

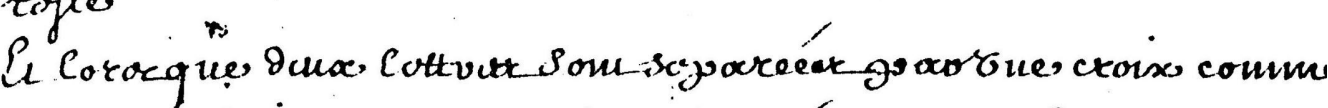

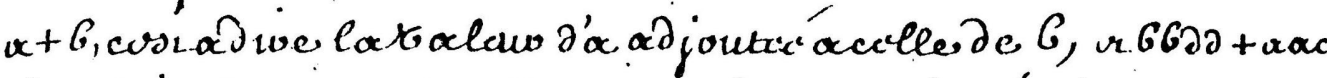

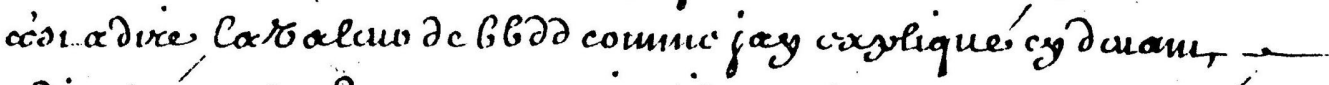

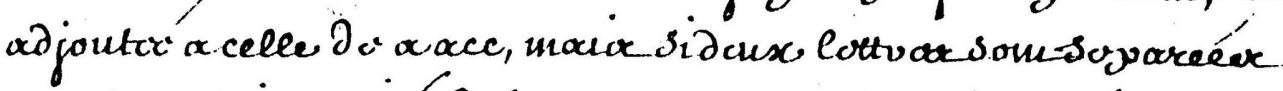

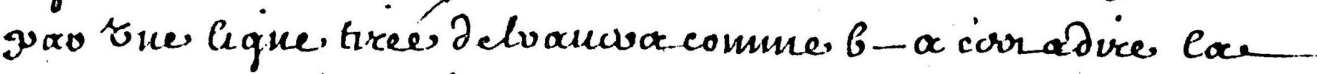

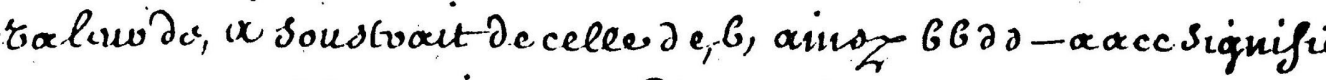

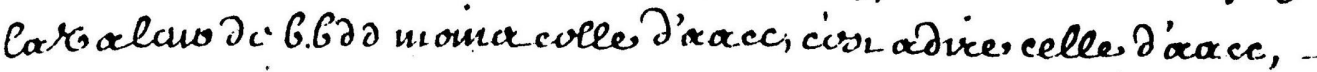
souspoitac.celle,de,GGdd,

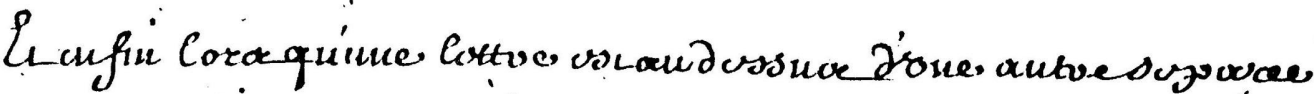

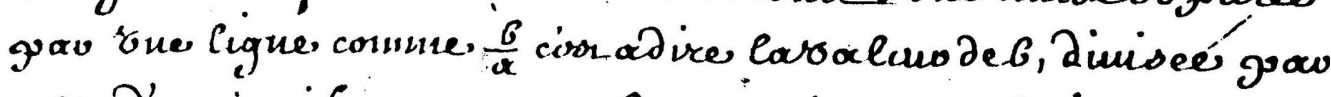

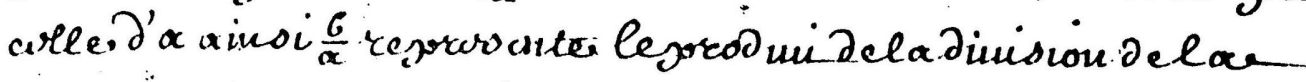

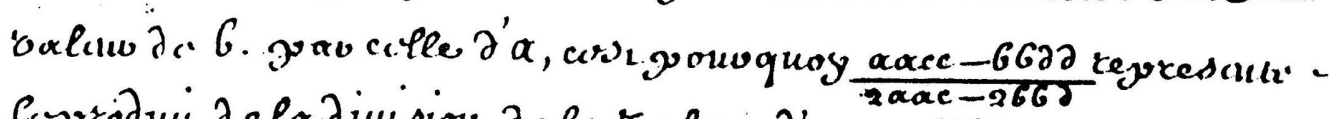

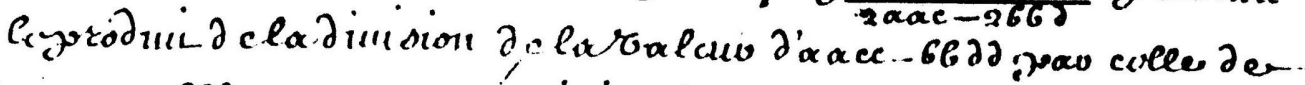

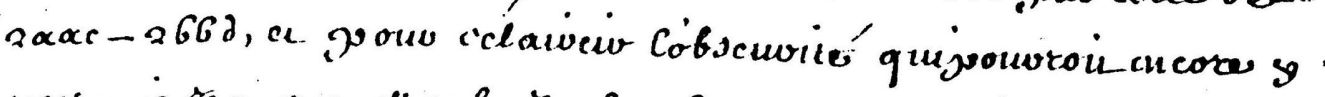

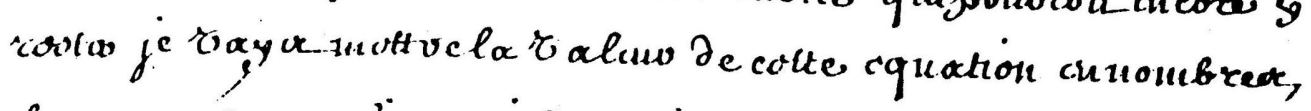

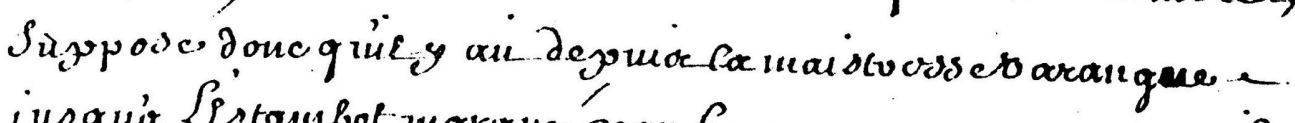

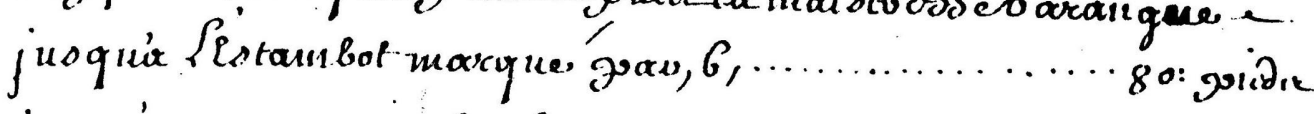

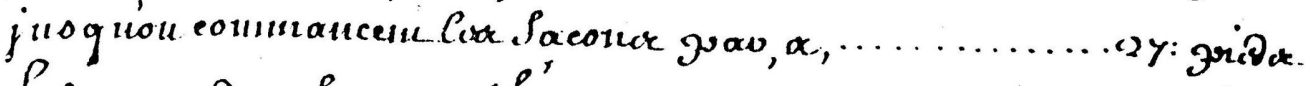

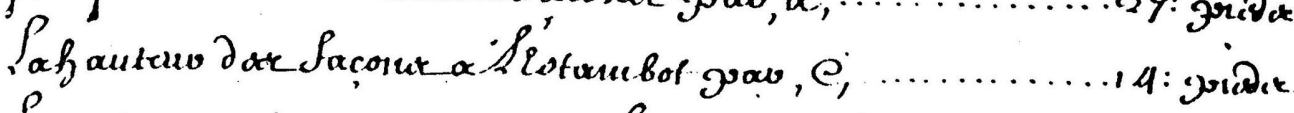

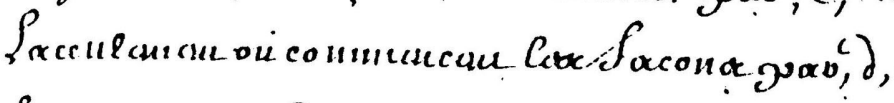

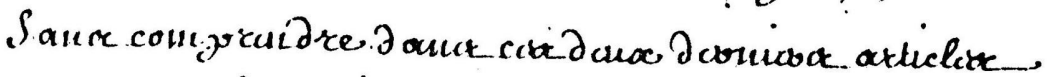

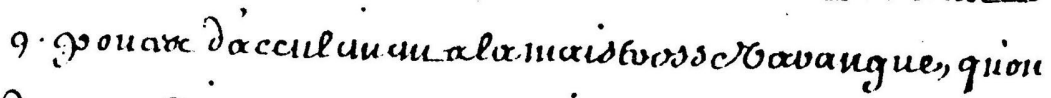

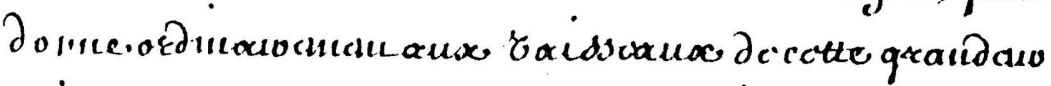

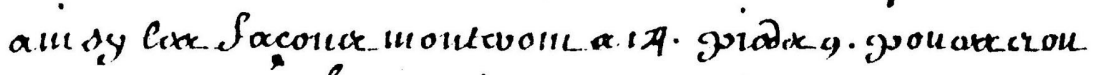

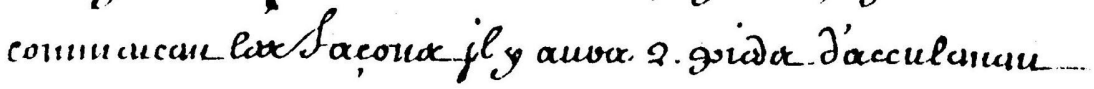




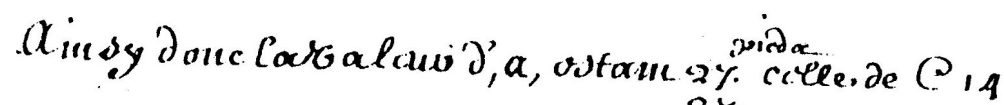

$$
\begin{aligned}
& \frac{2 \%}{189:} \\
& \text { (1) } \\
& \text { r. Cararlaw J'aca } \\
& \text { yog,cide, cc.196: } \\
& \text { Pecclle dixace..............14288.9: }
\end{aligned}
$$

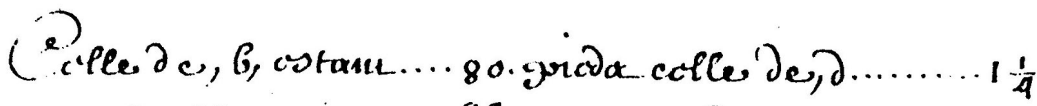

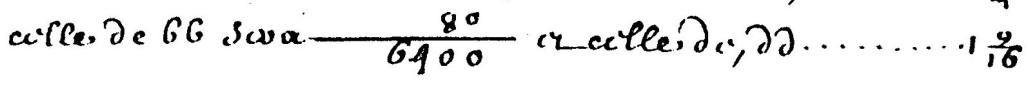

$$
\begin{aligned}
& \frac{1 \frac{9}{16}}{6400} \\
& 3900 \ldots . . . . \text { pouv } \frac{8}{16} \text { cion waire } \frac{1}{2} \\
& \text { ariediecti.de.GGJJ suar } 0000 \text { : }
\end{aligned}
$$

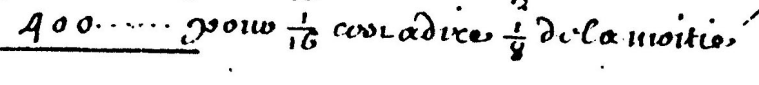

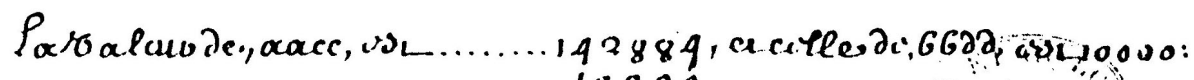

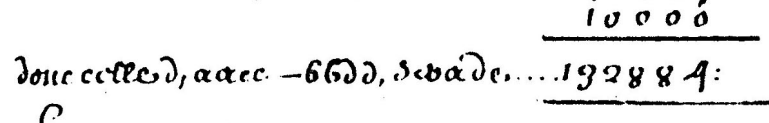

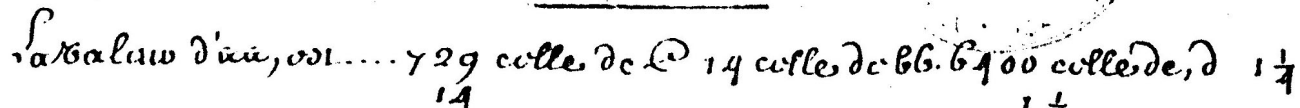

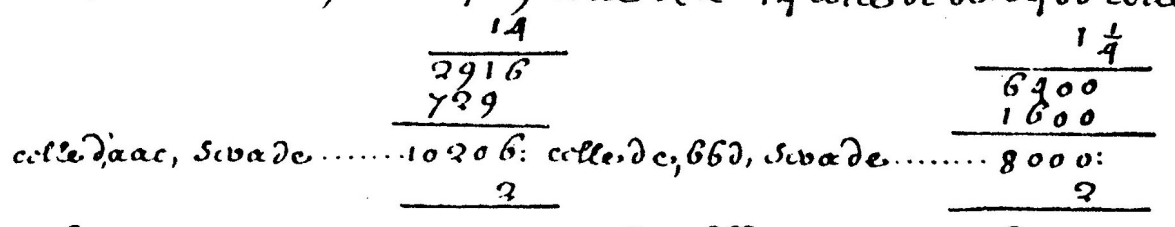

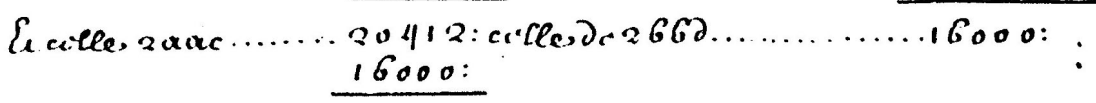

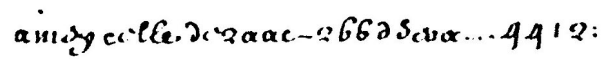




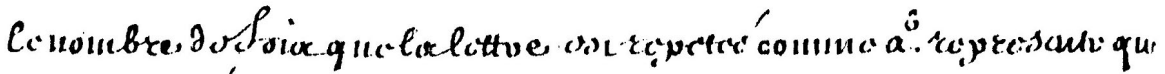

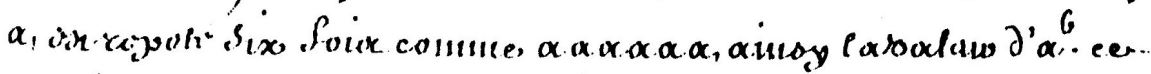

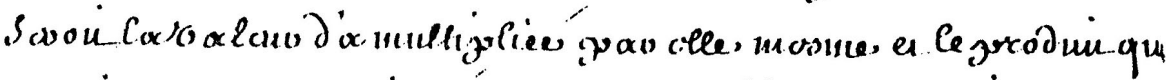

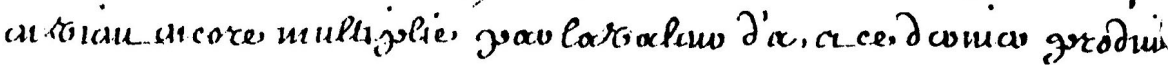

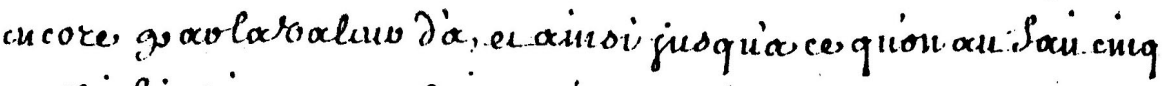

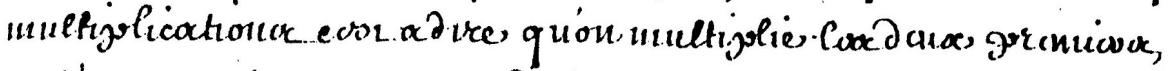

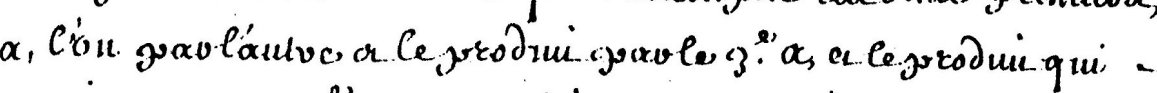

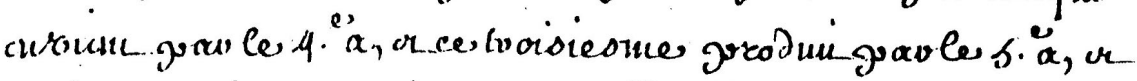

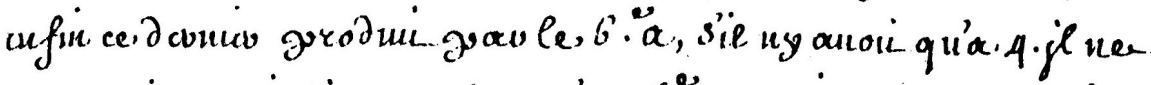

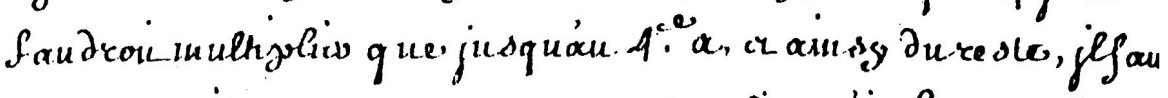

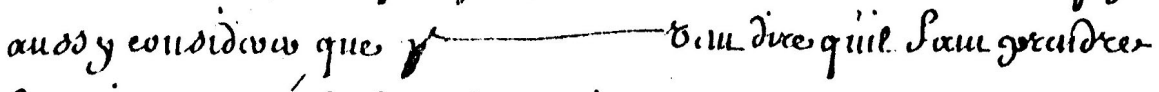

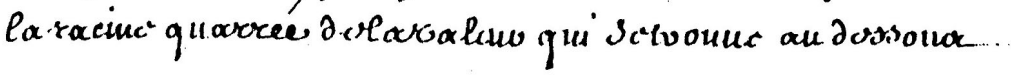

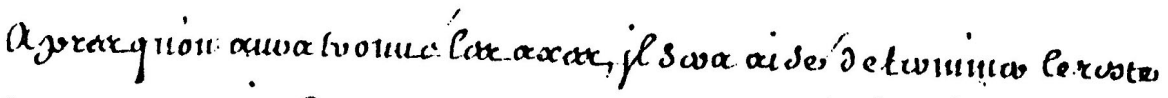

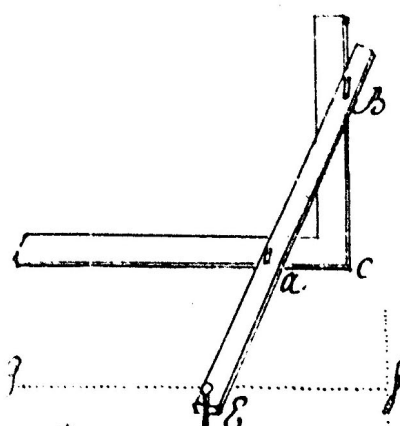

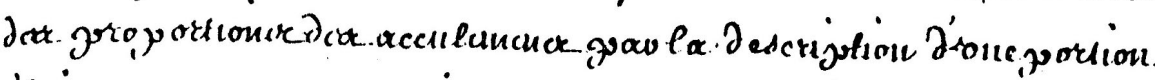

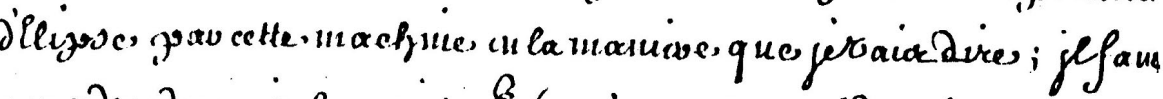

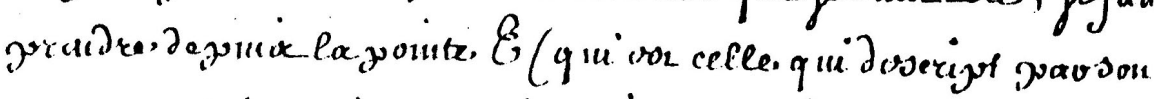

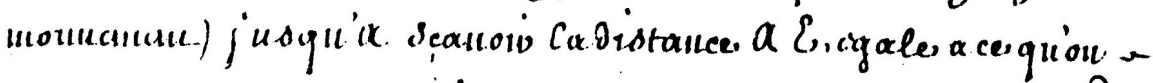

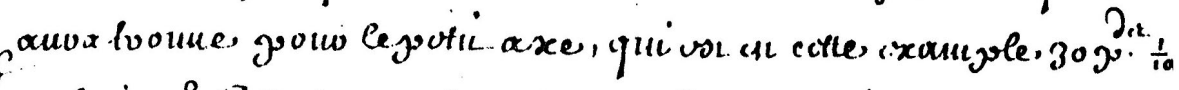

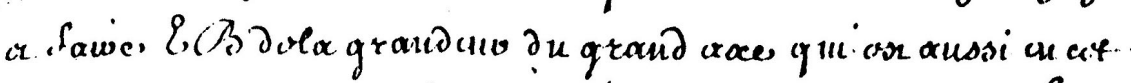

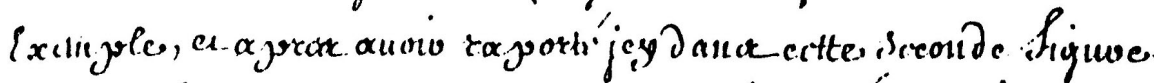

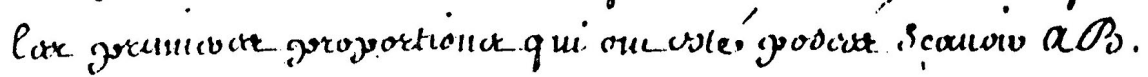

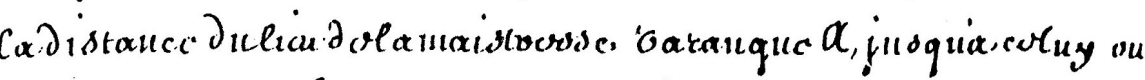

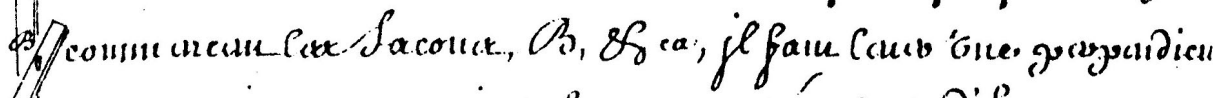

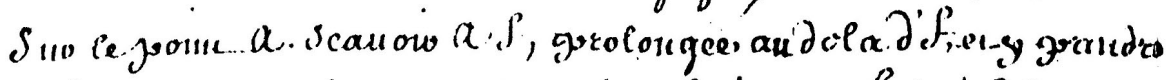

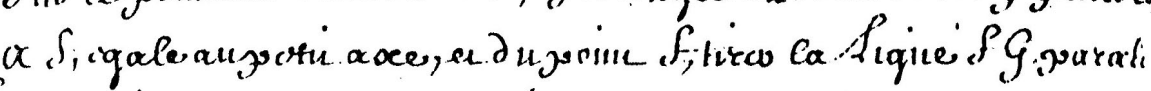

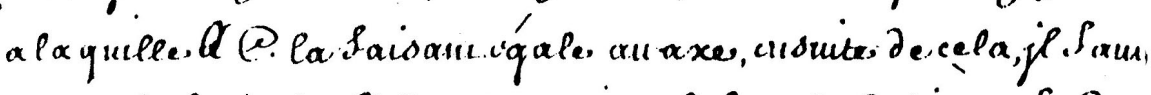

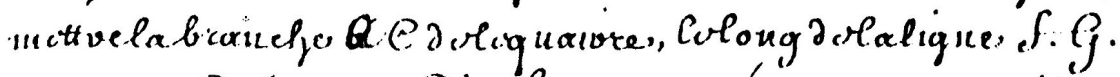

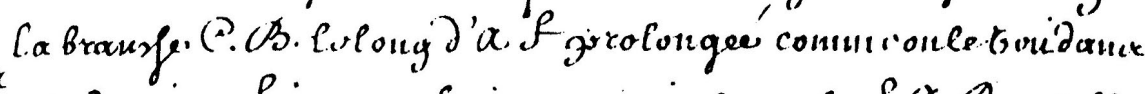

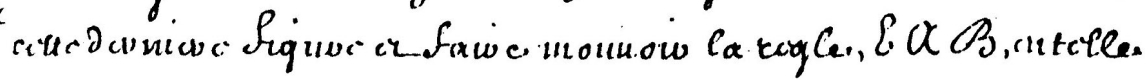




\section{4}

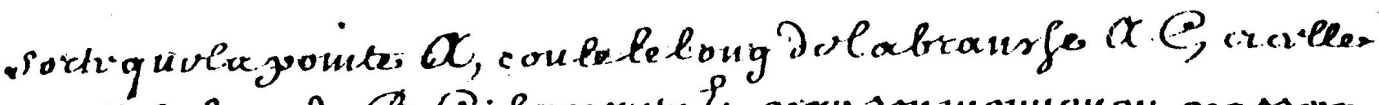

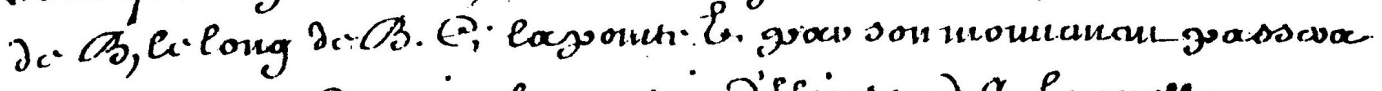

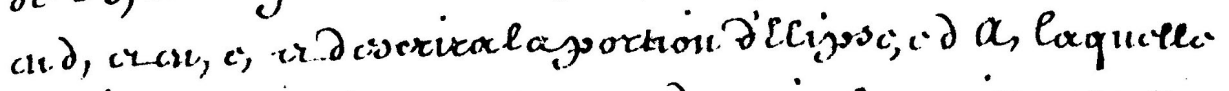

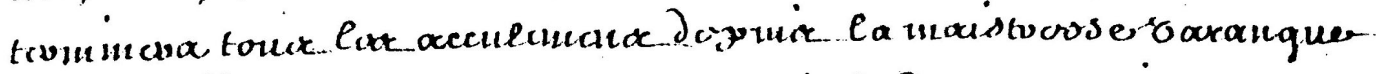

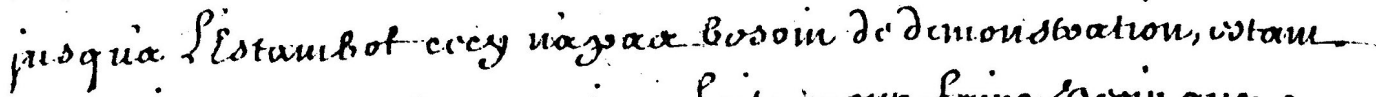

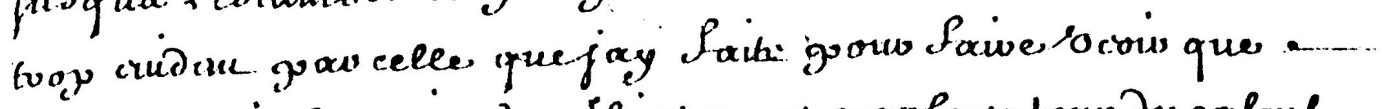

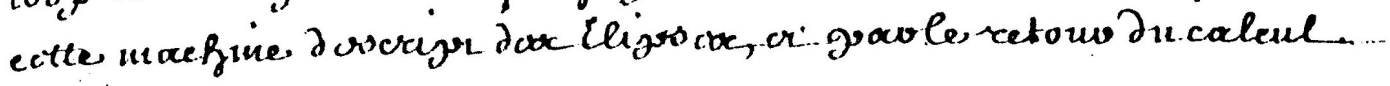
allabitiques.

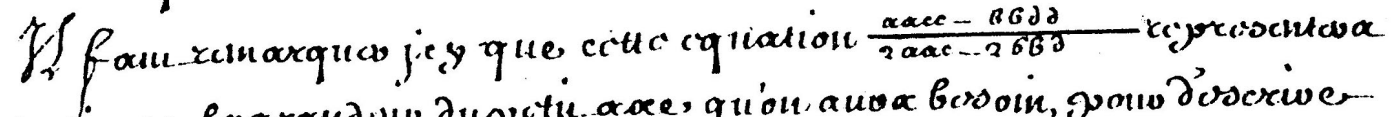

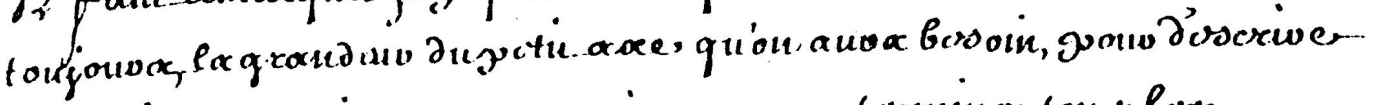

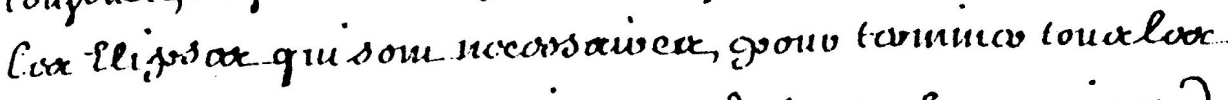

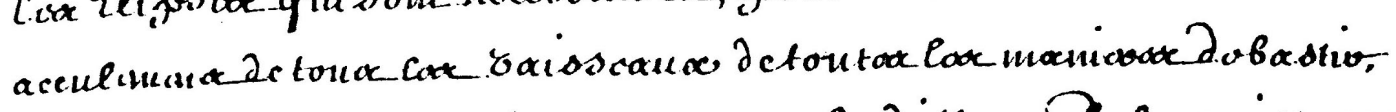

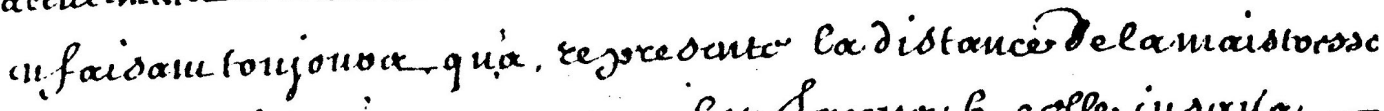

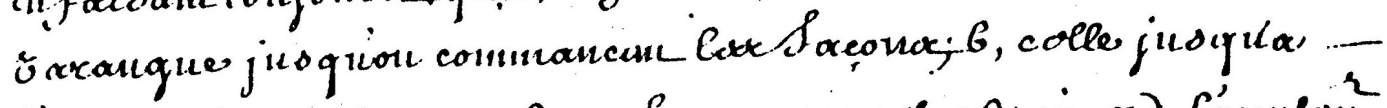

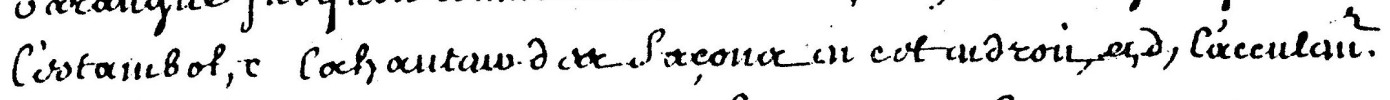

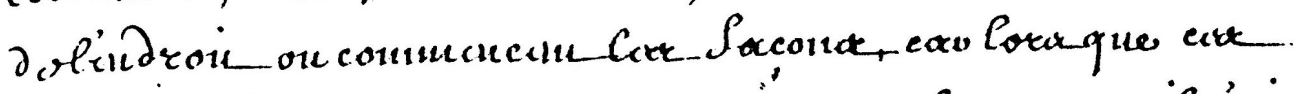

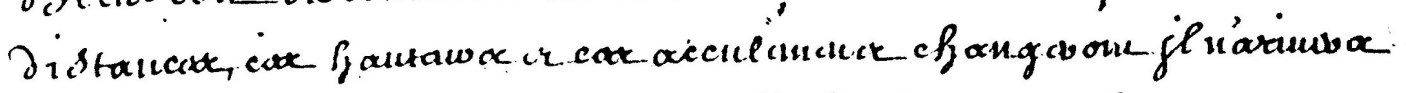

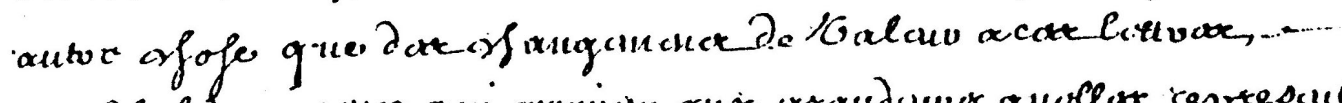

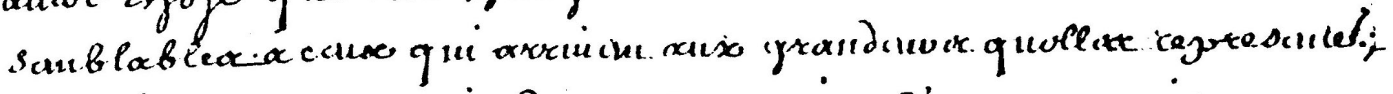

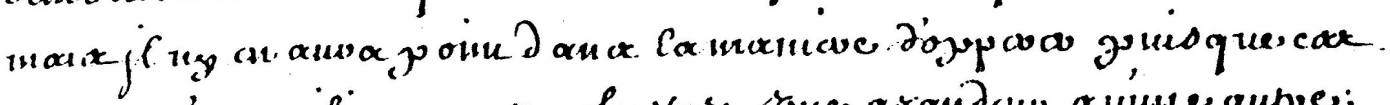

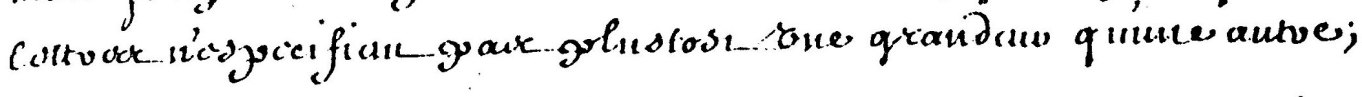

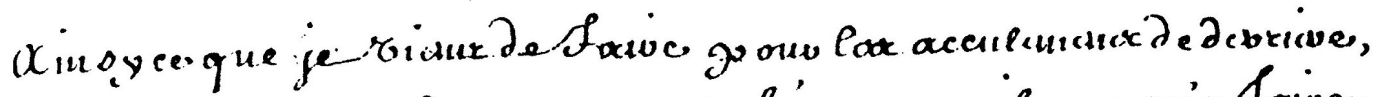

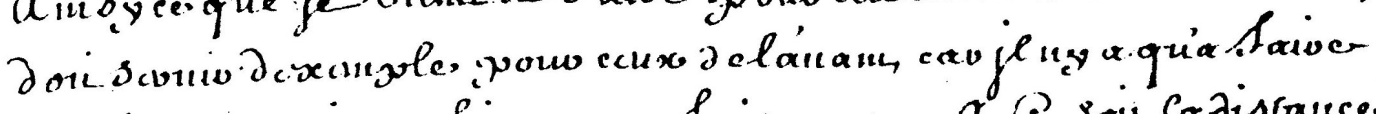

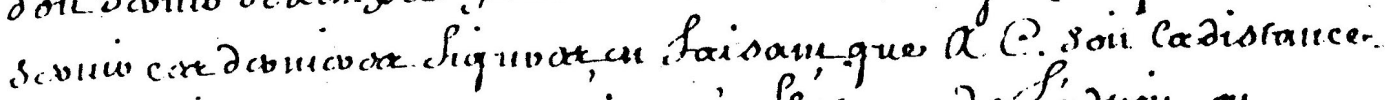

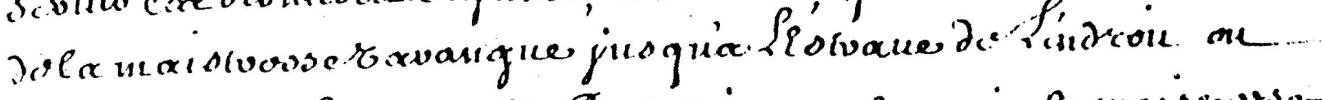

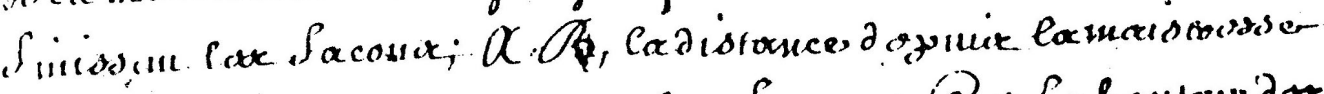

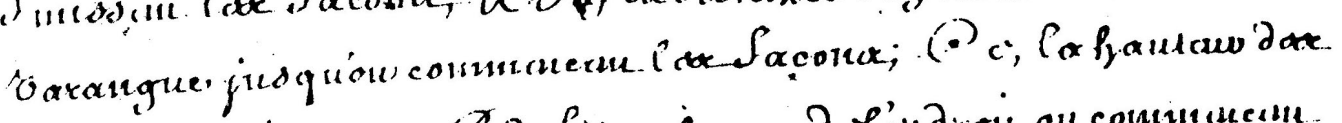

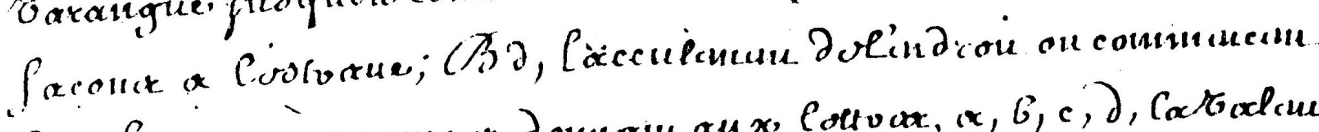

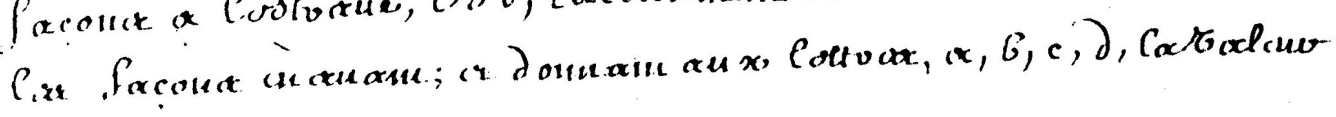




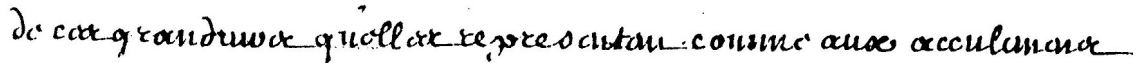

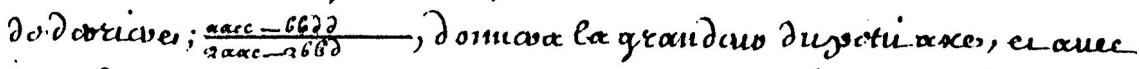

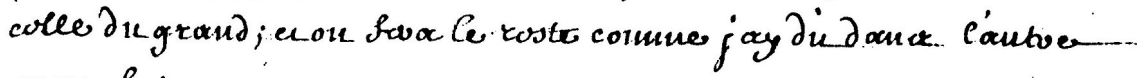
coccuyole;

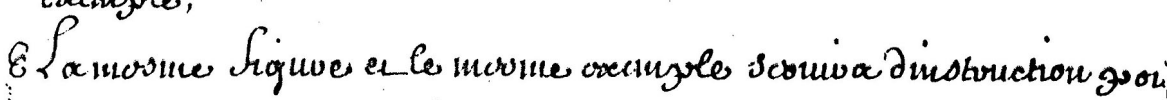

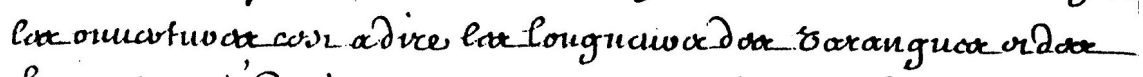

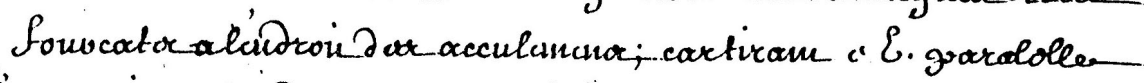

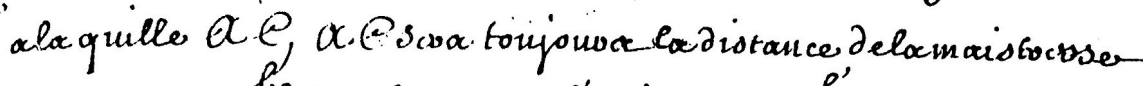

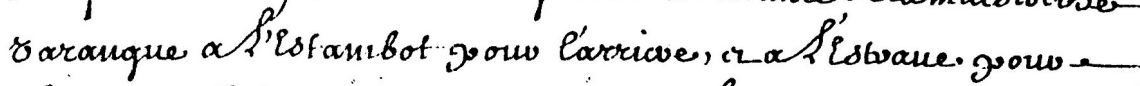

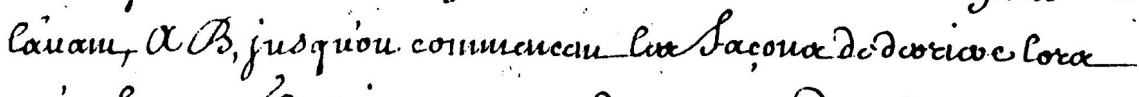

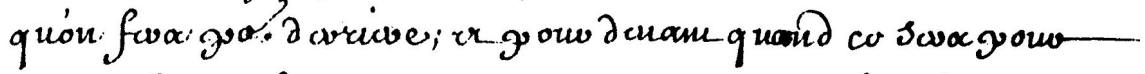

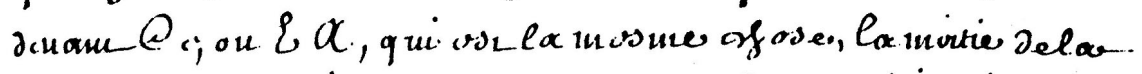

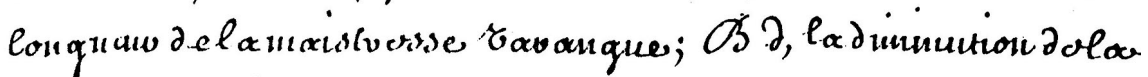

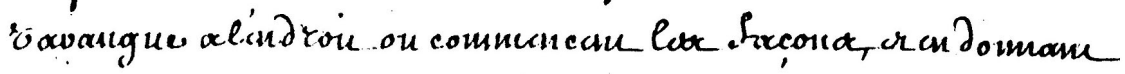

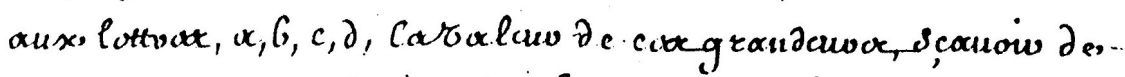

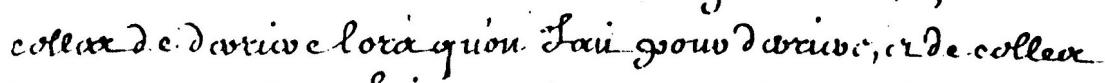

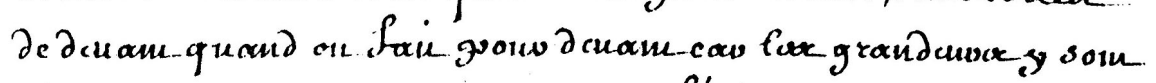

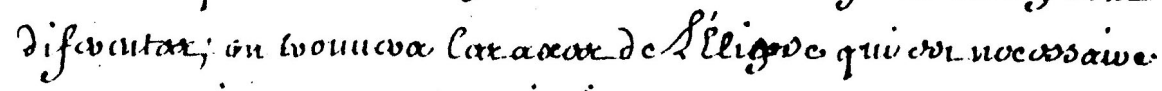

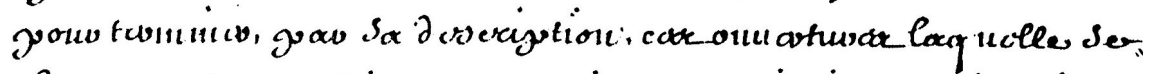

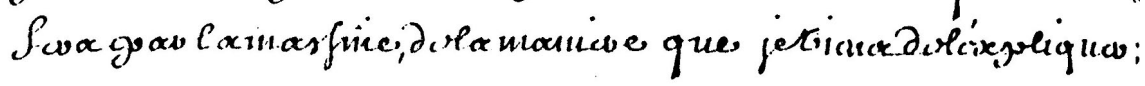

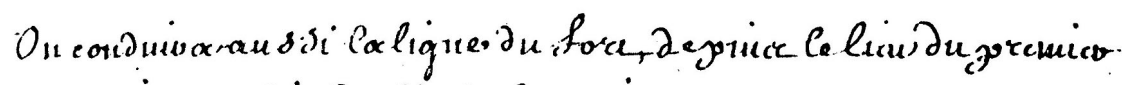

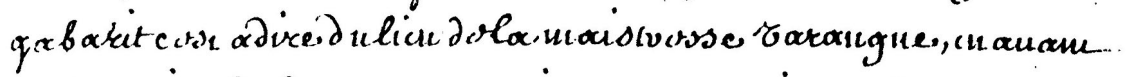

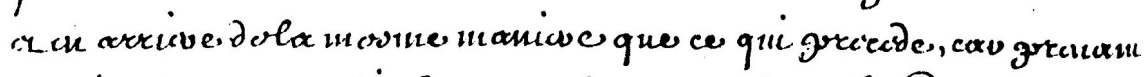

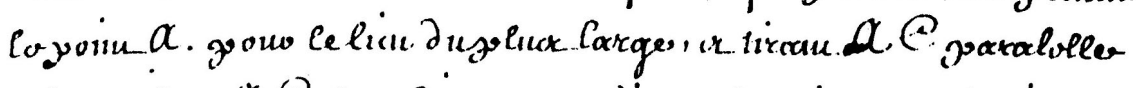

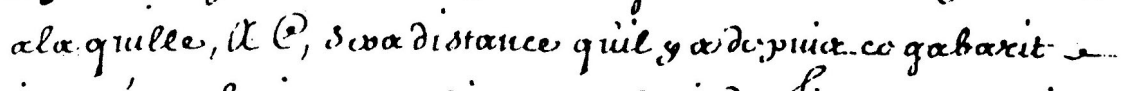

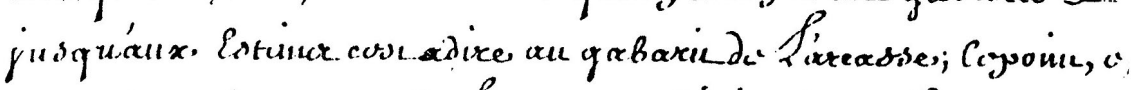

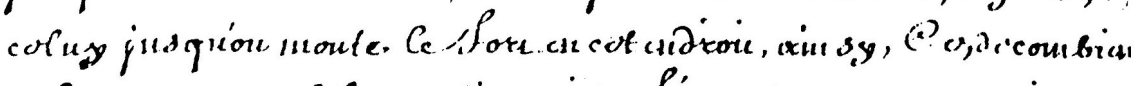

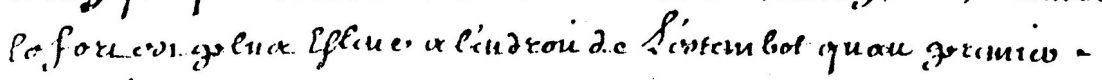

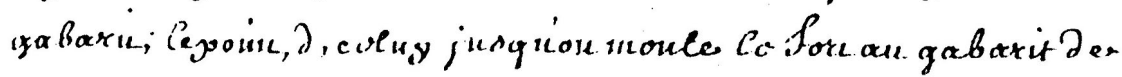




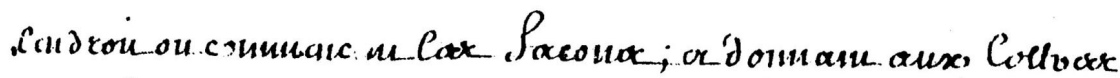

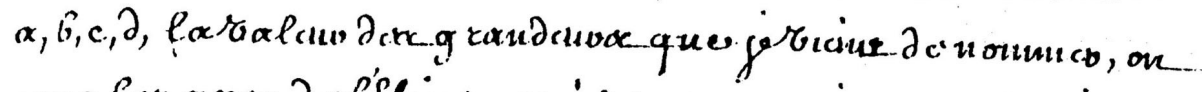

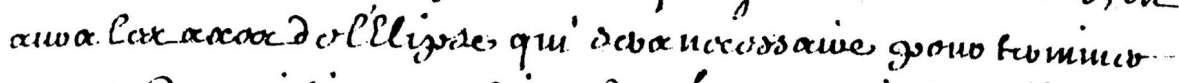

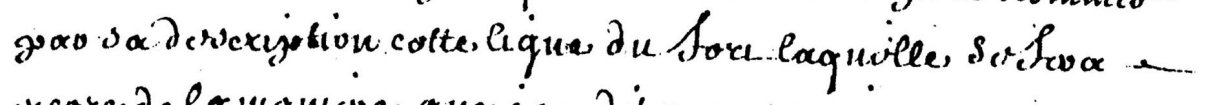

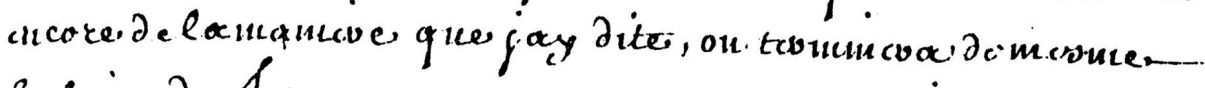

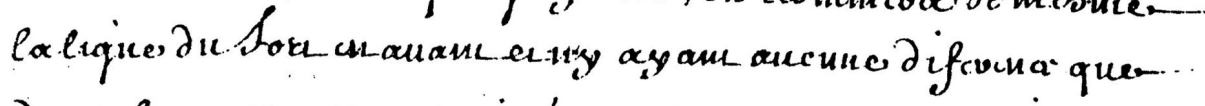

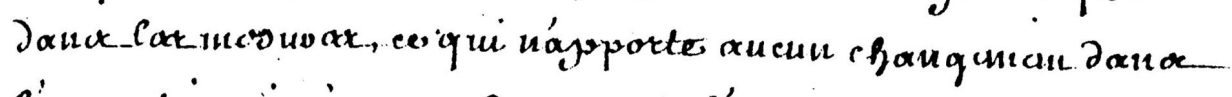

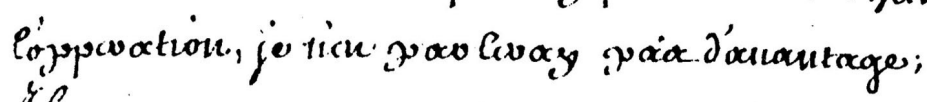

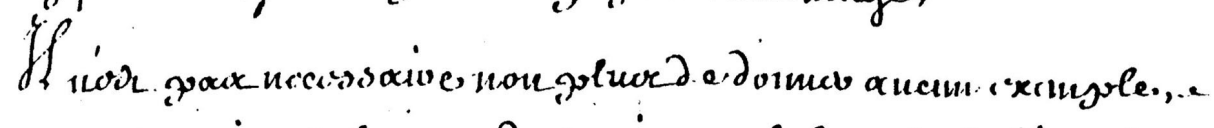

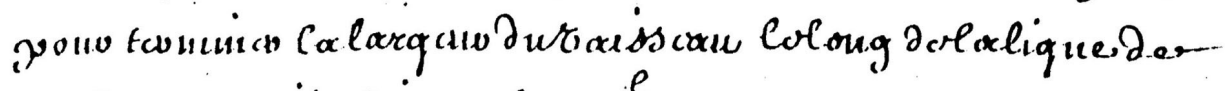

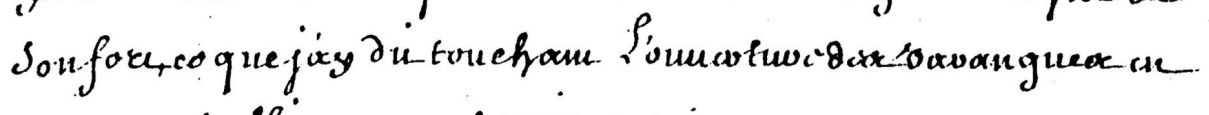
Yormant suffizastinan sormo

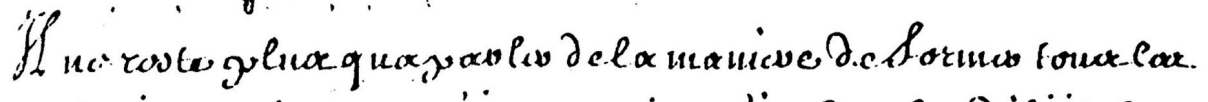

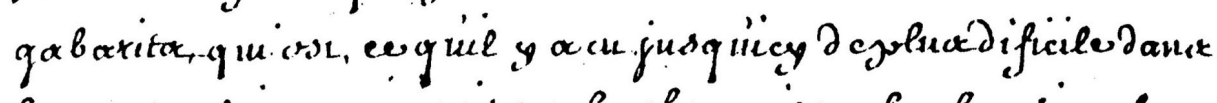

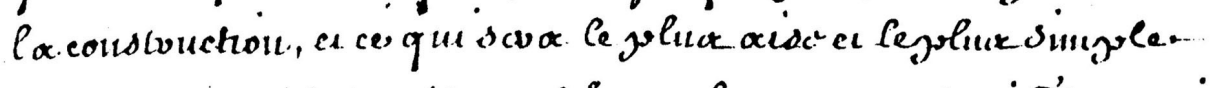

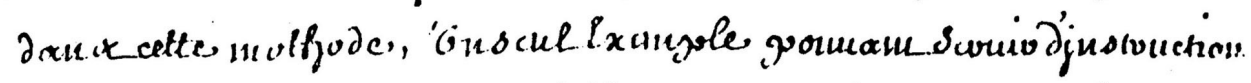

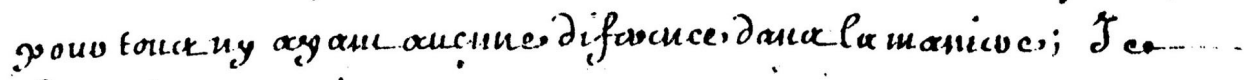
Pixy giquecoxy ainsy

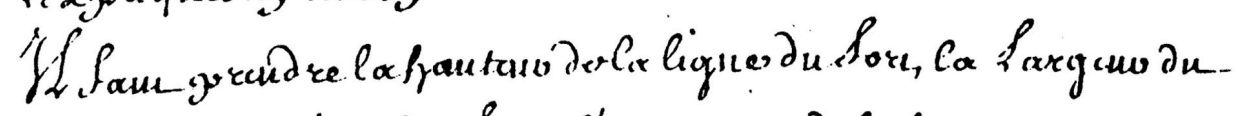

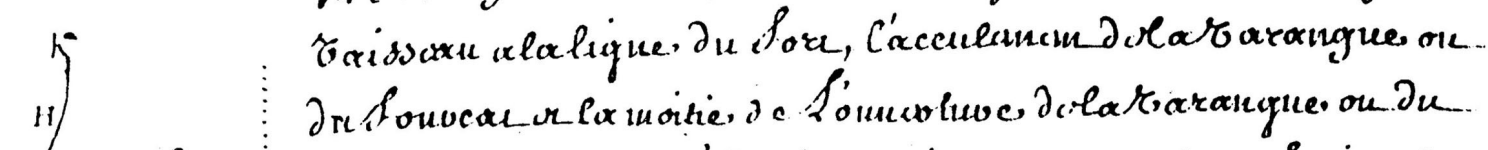

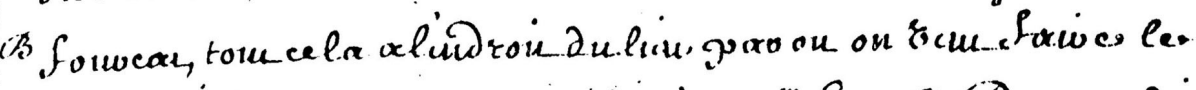

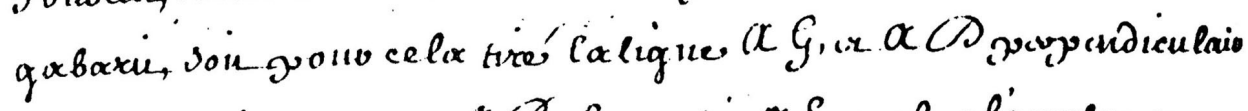

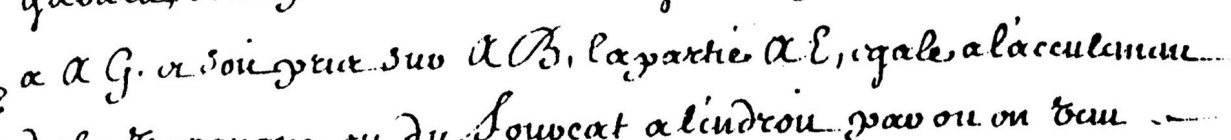

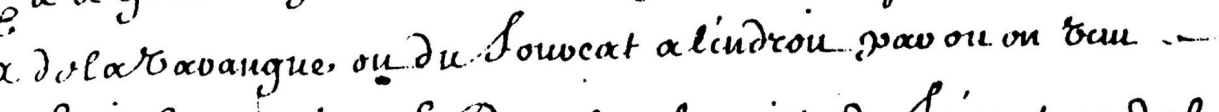

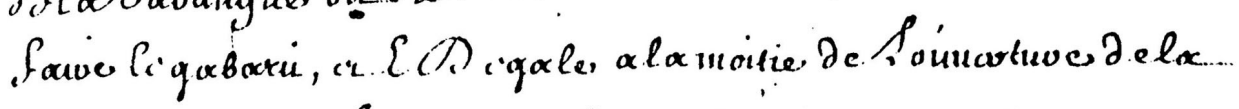

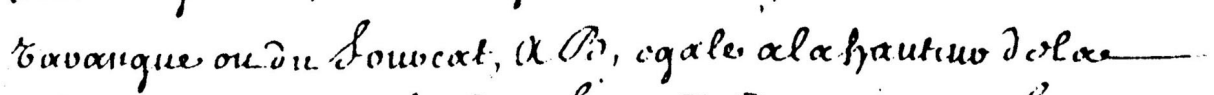

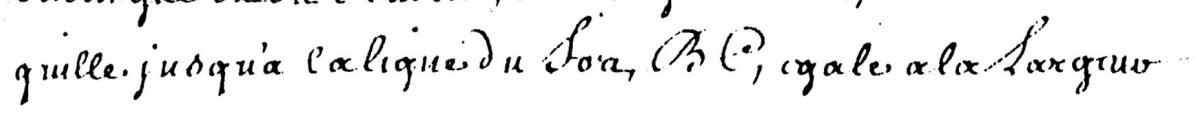




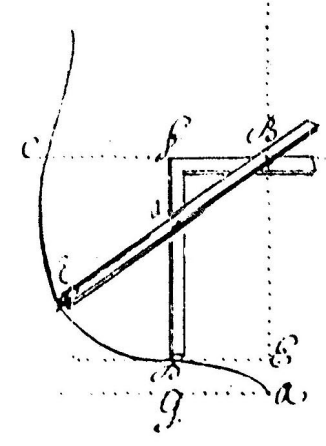

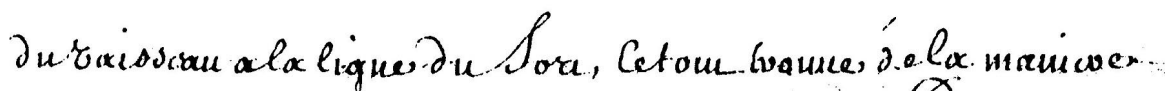

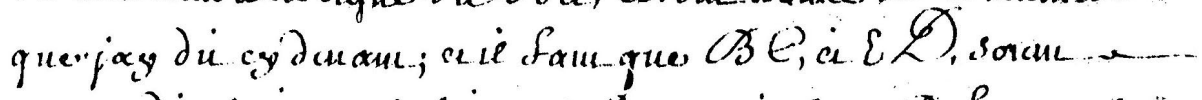

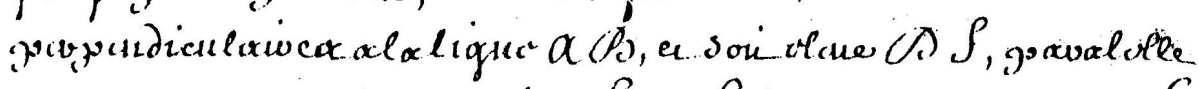

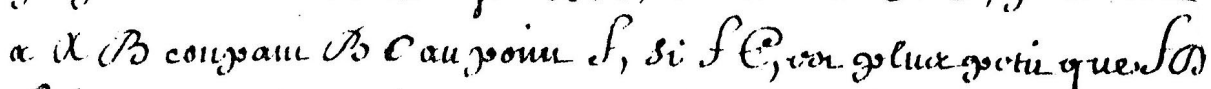

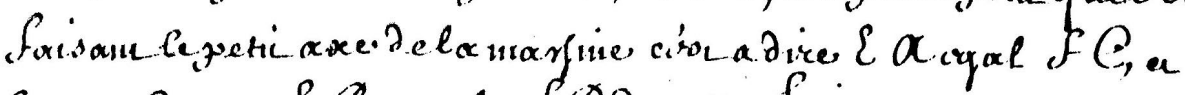

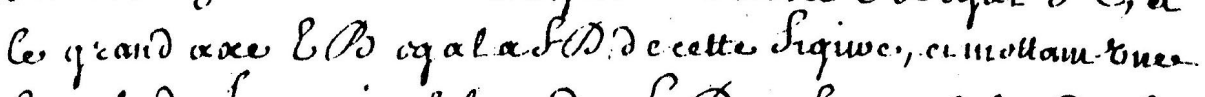

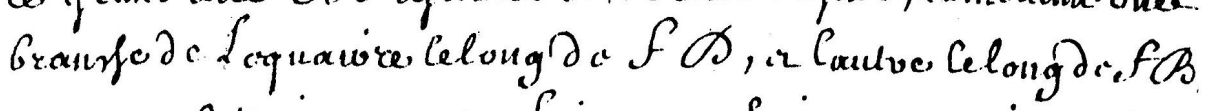

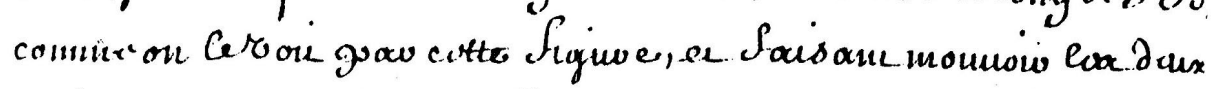

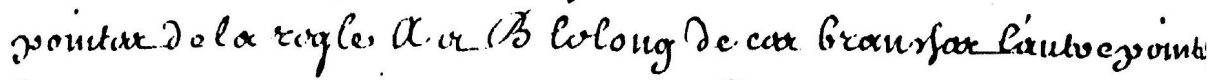

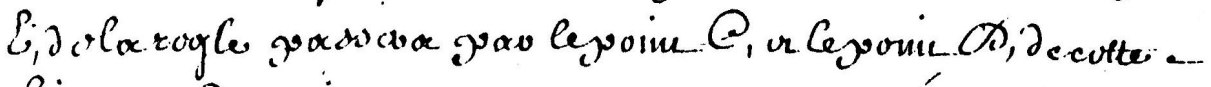

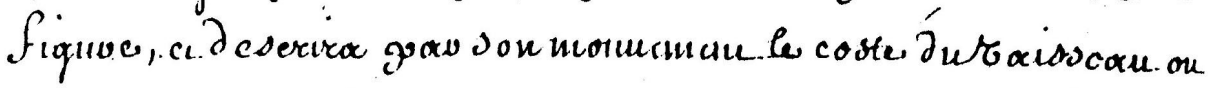

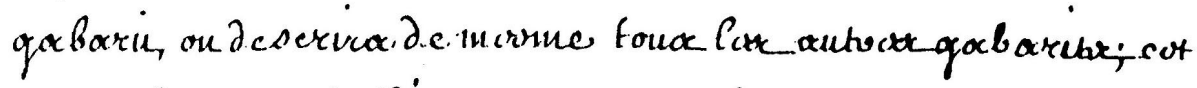

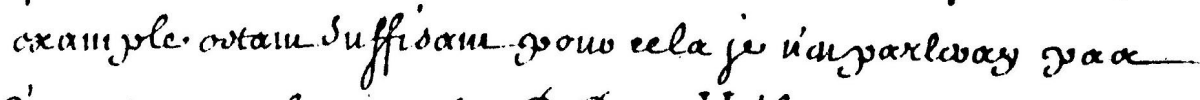

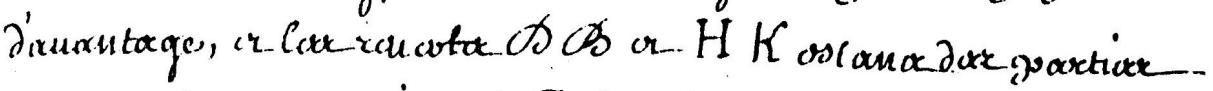

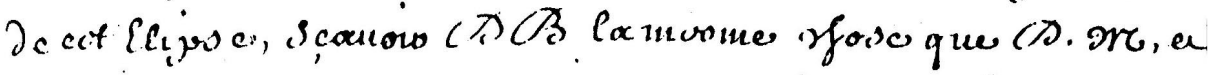

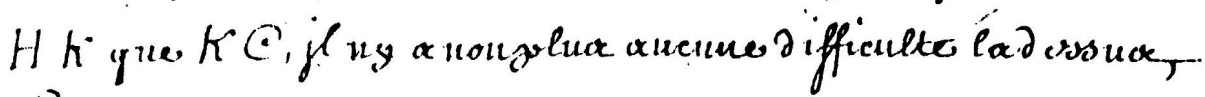

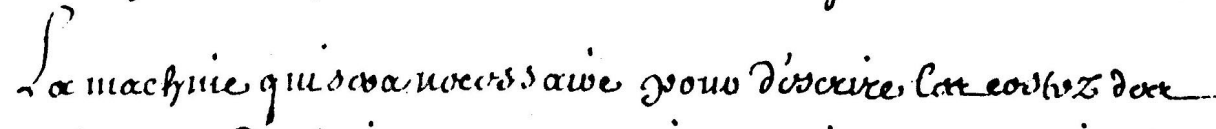

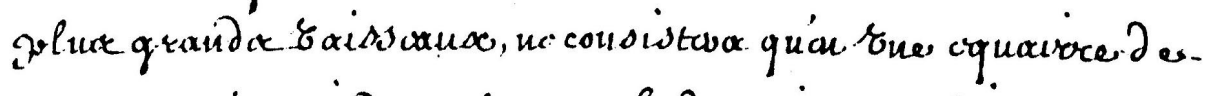

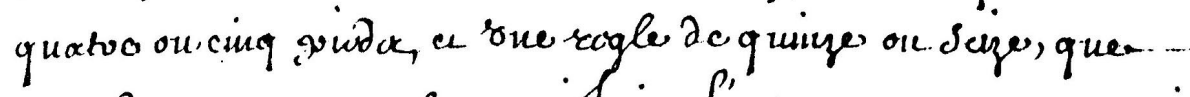

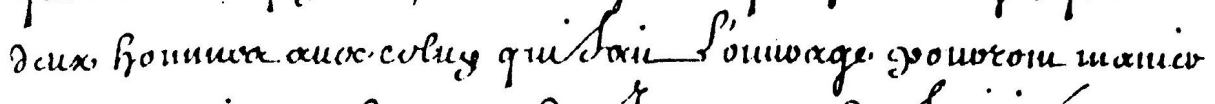

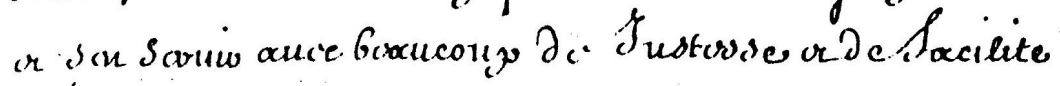

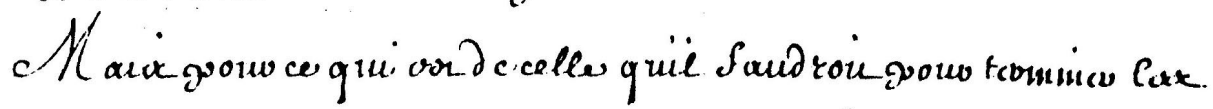

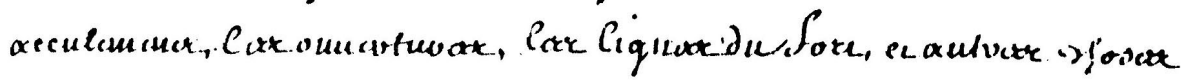

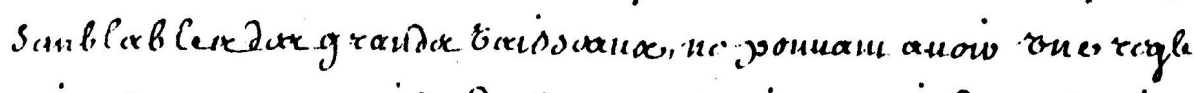

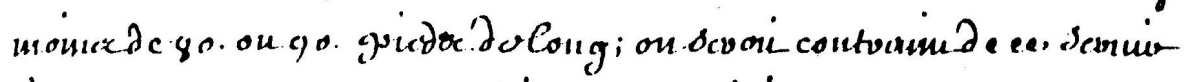

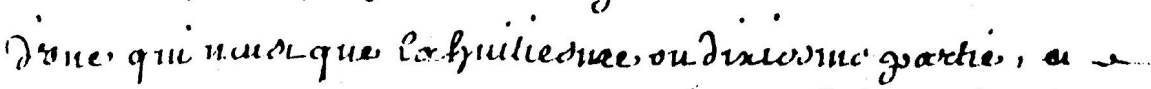

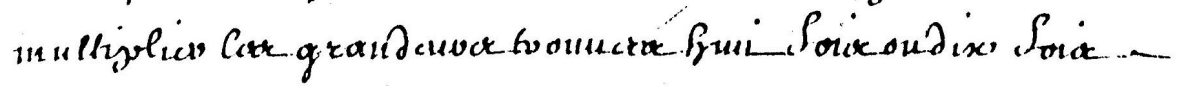

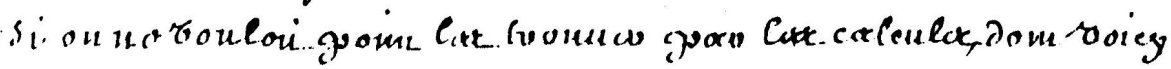




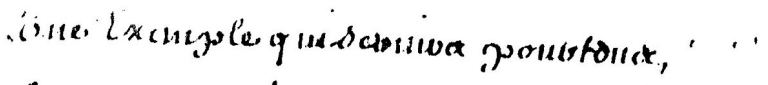

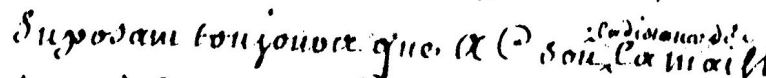

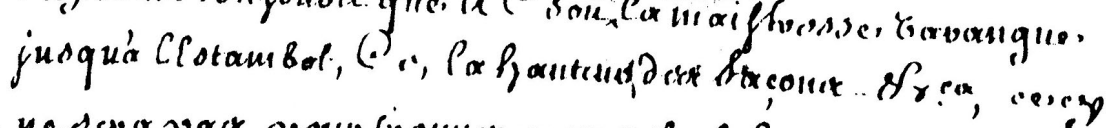

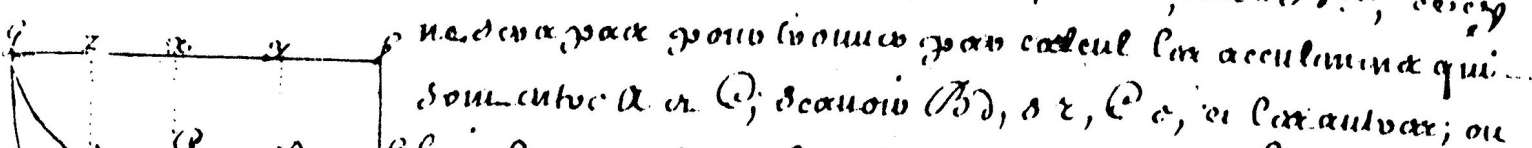

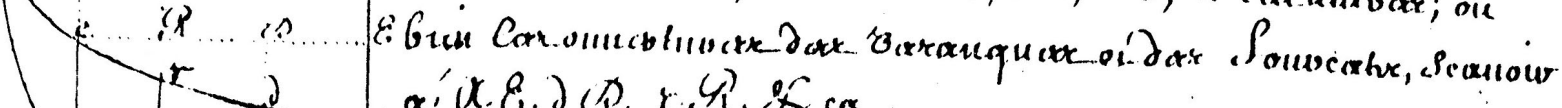

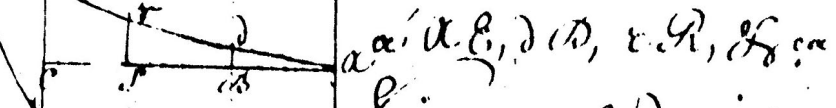

In

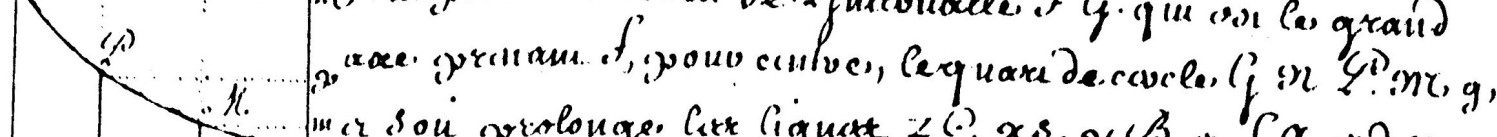

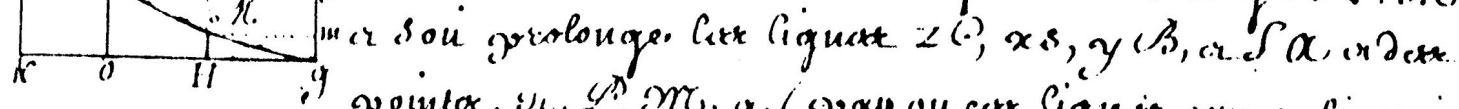

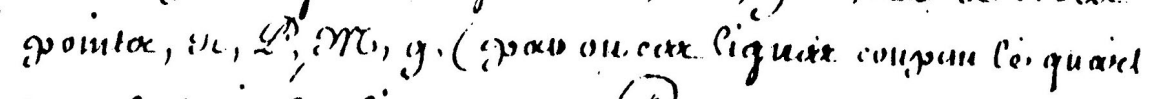

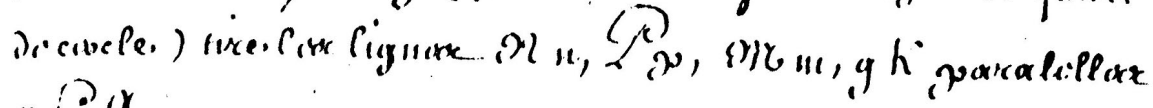
or $(x)$

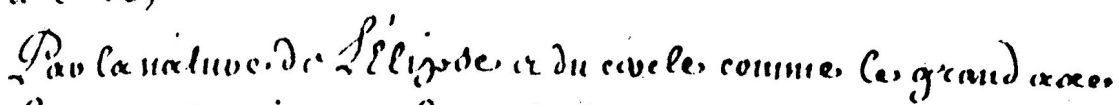

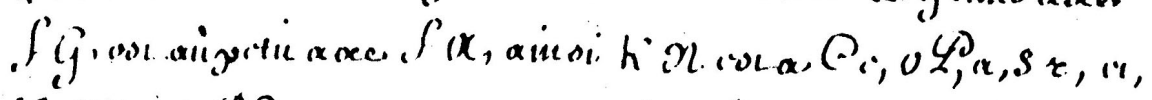

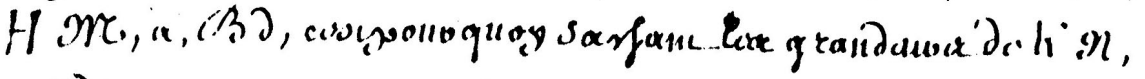

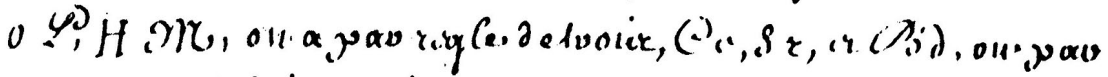

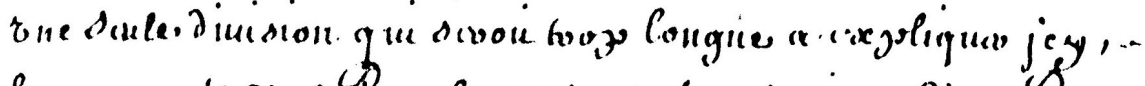

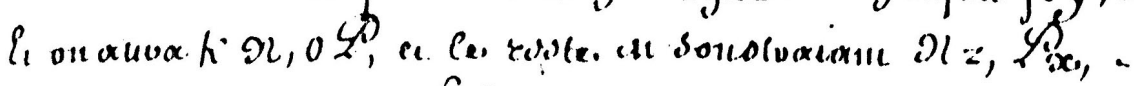

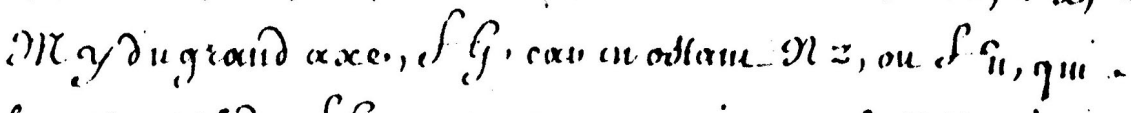

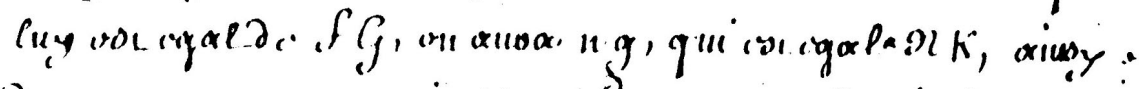

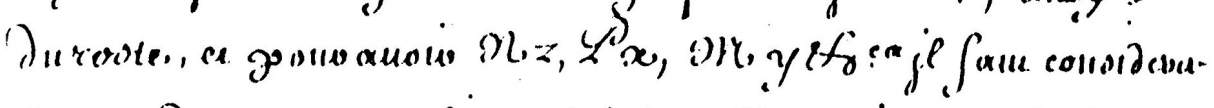

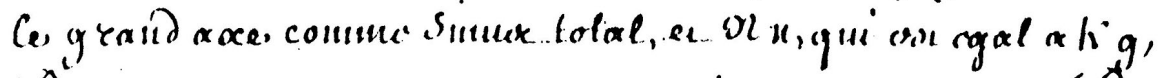

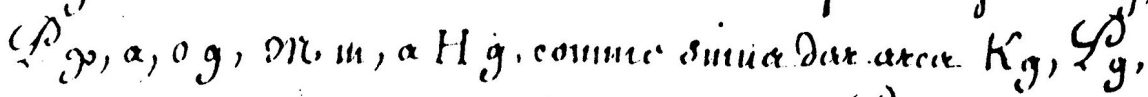

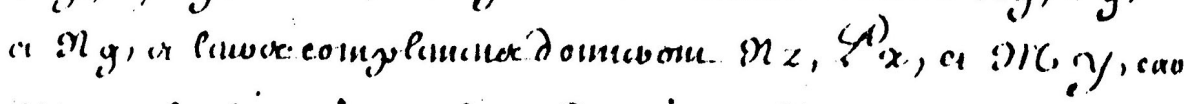

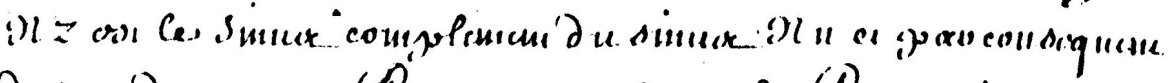

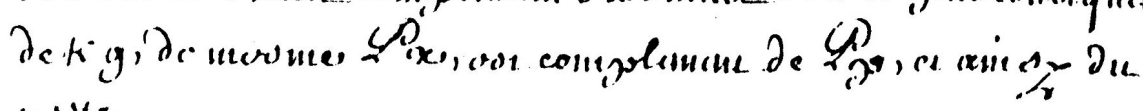
roille

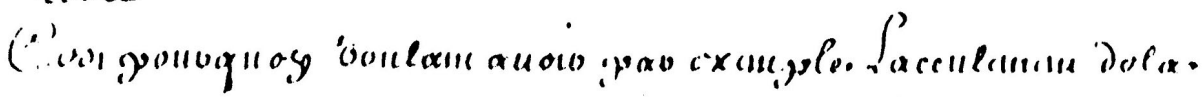




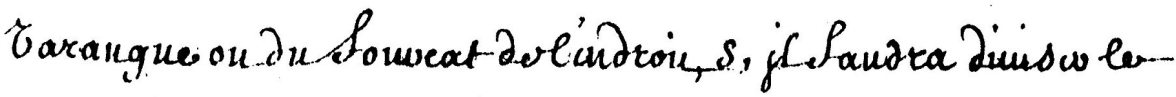

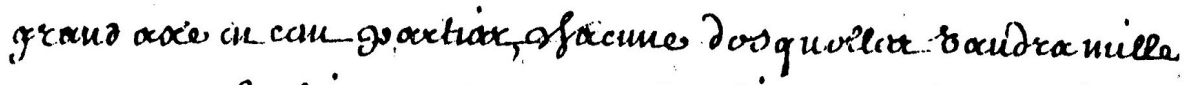

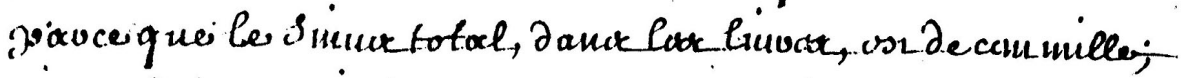

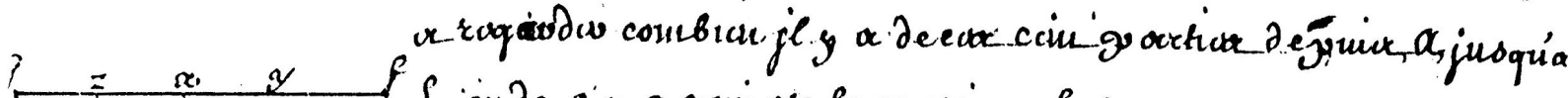

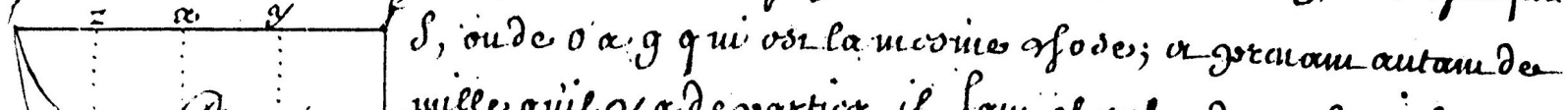

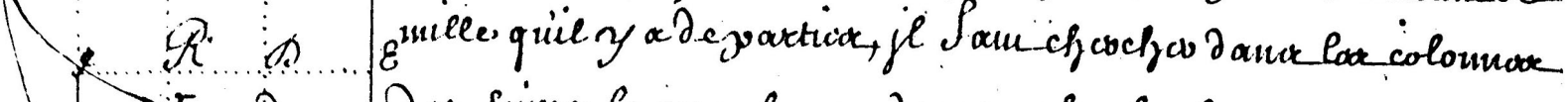
$\frac{1}{\frac{1}{3}} \frac{\partial}{b}$

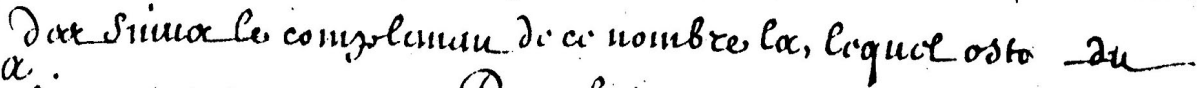

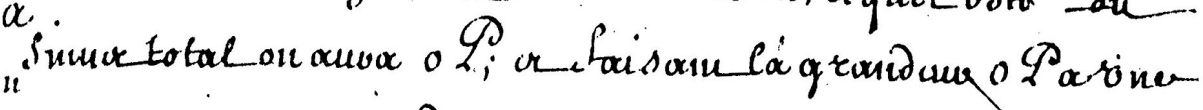

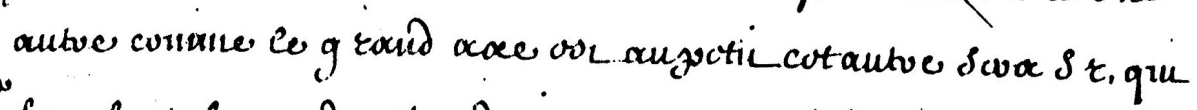

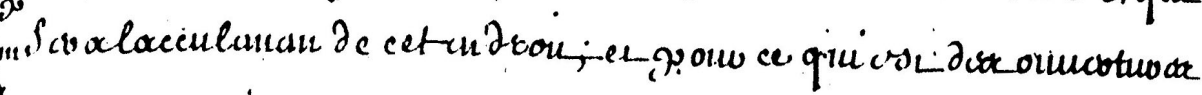

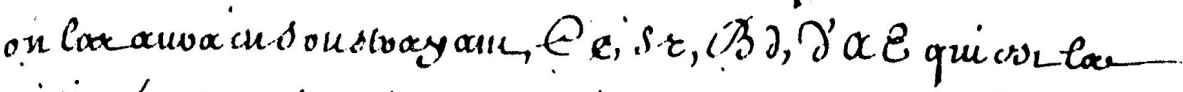

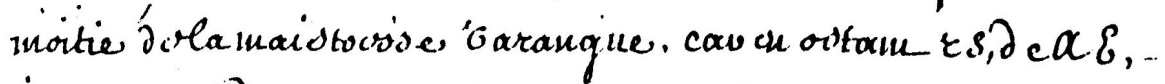

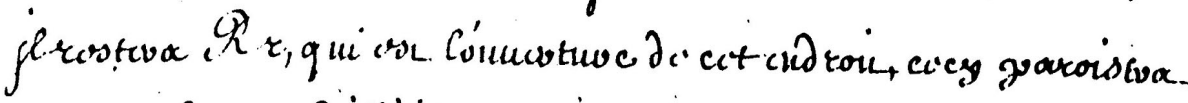

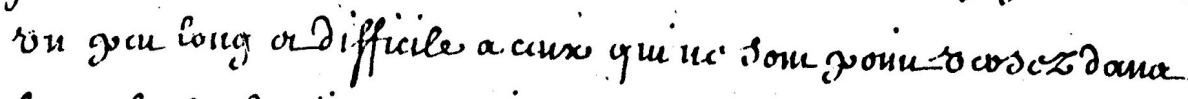

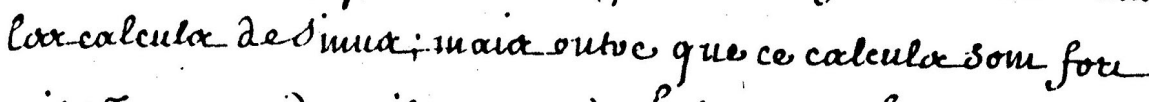

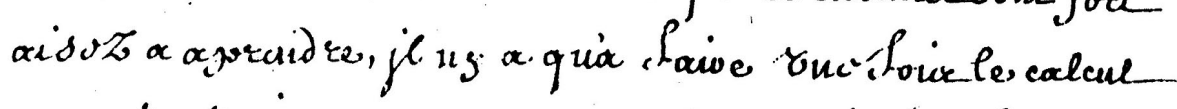

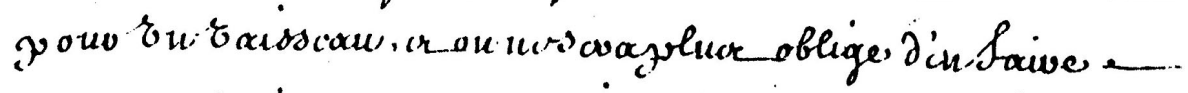

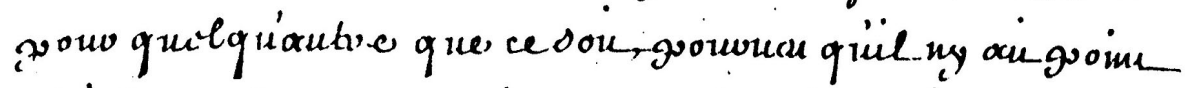

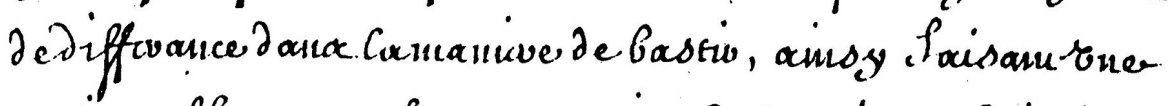

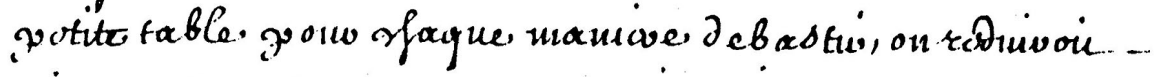

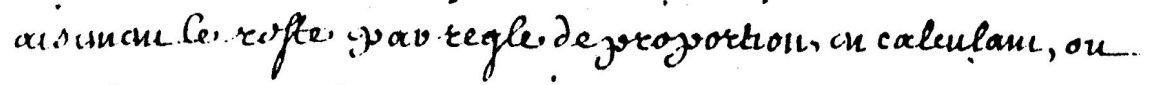

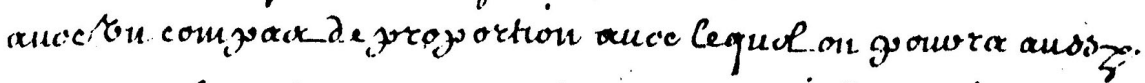

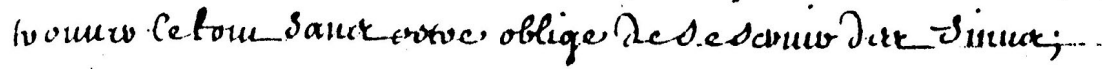

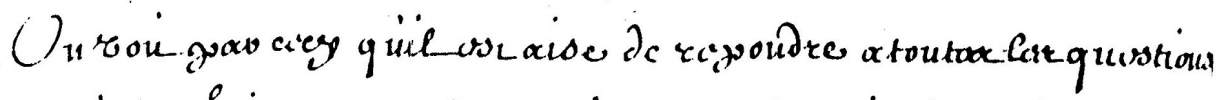

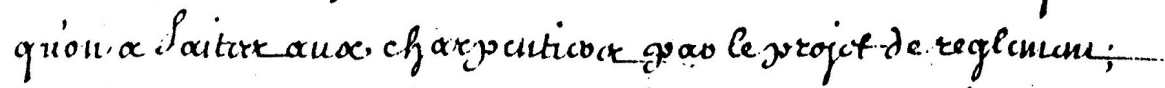

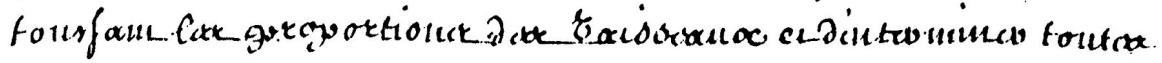

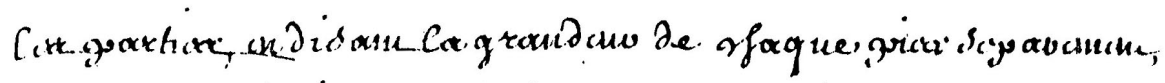

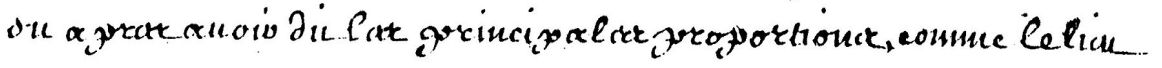




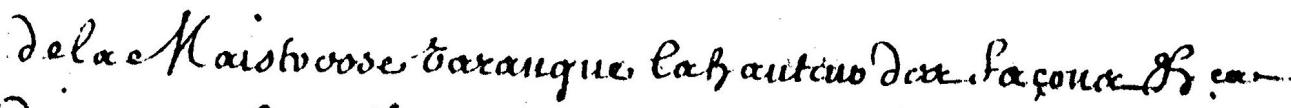

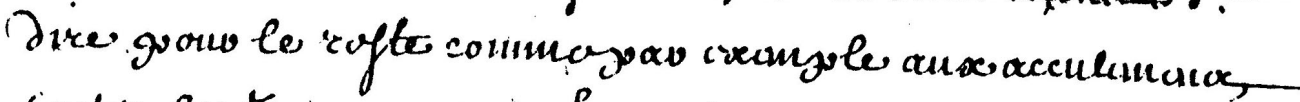

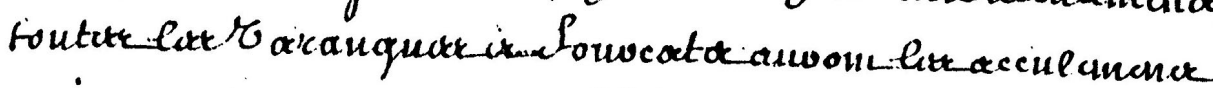

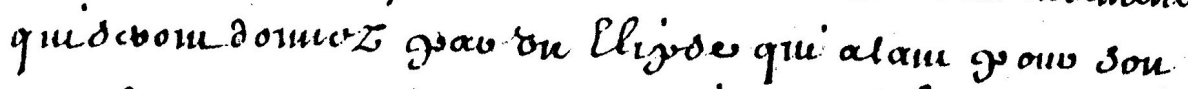

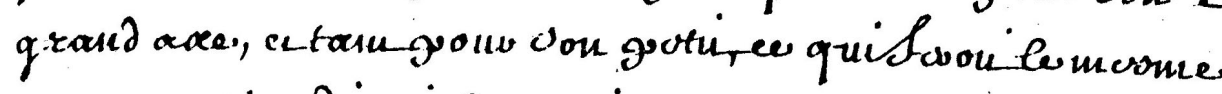
offot, que diond is ori Sepramico atomple scrond tambgea.

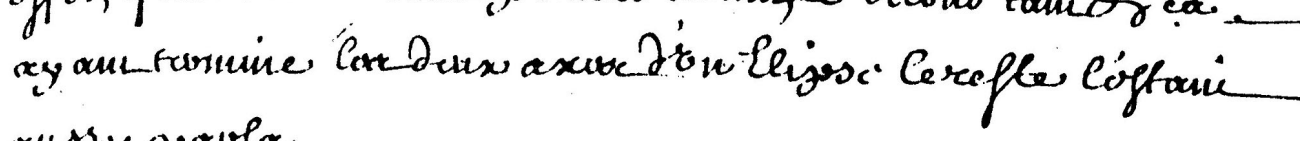
oussiy gowola,

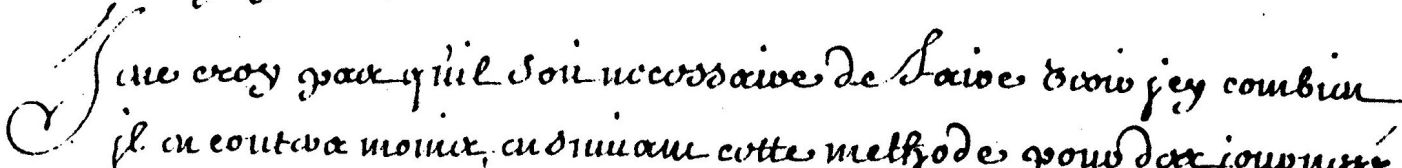

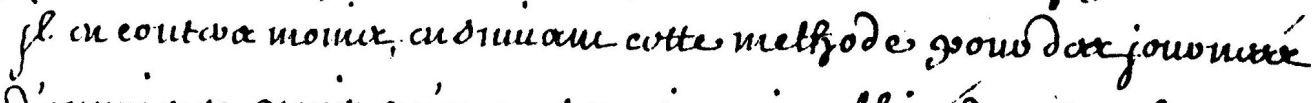

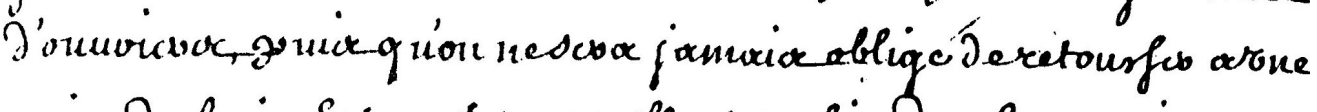

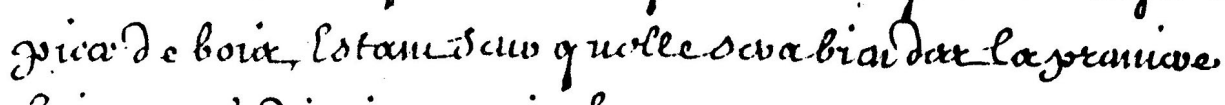

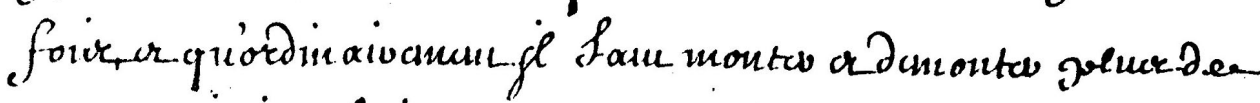

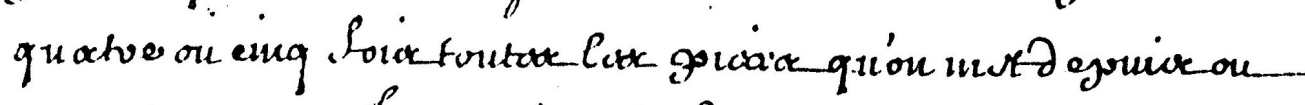

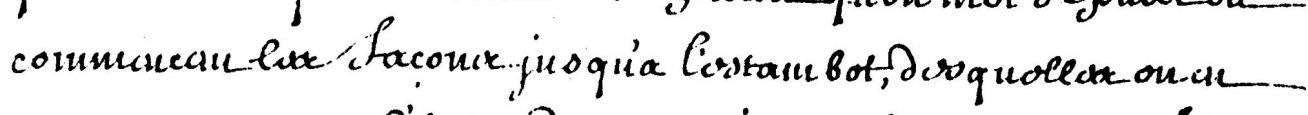

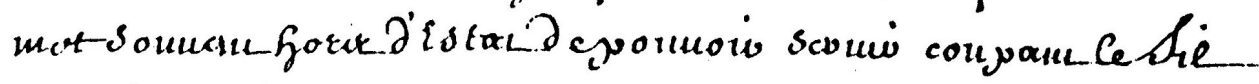

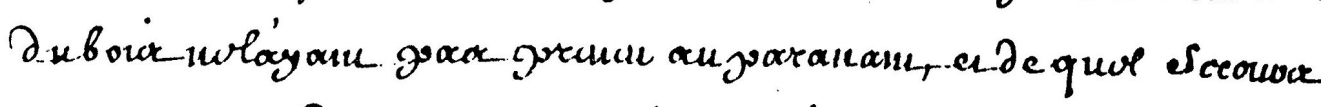

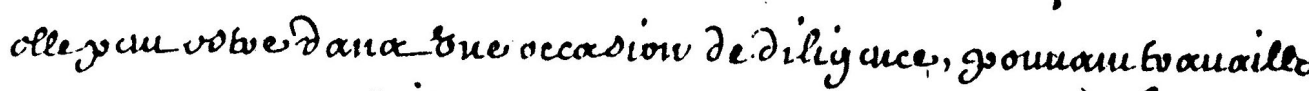

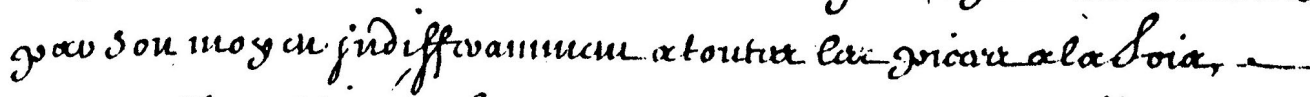

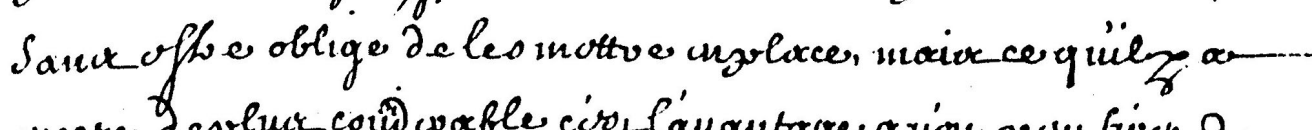

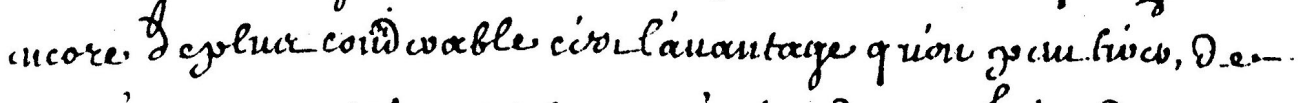

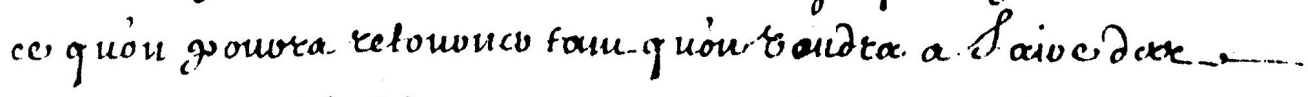

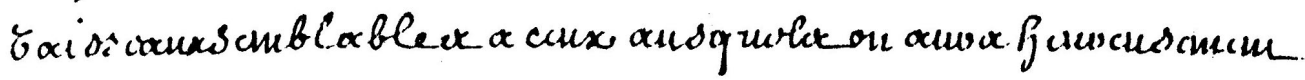

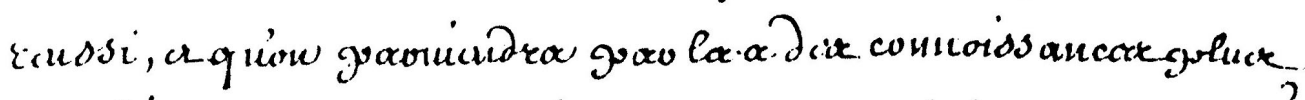

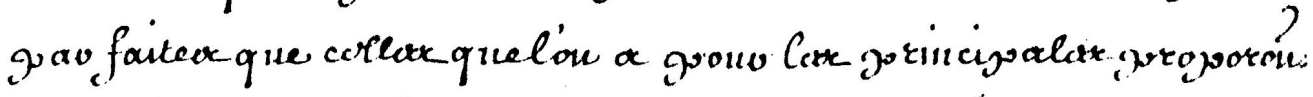

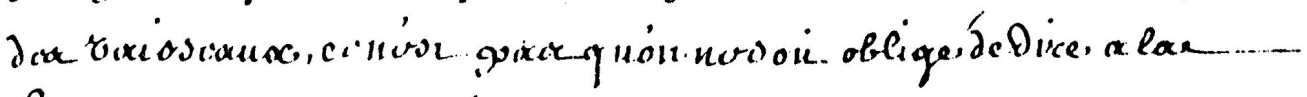

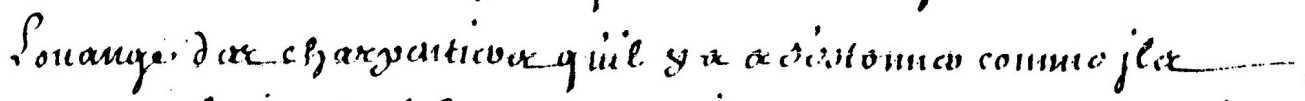

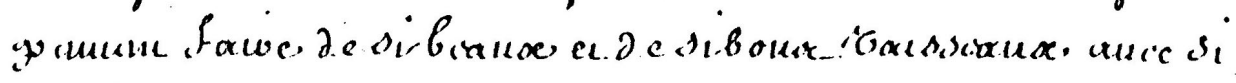




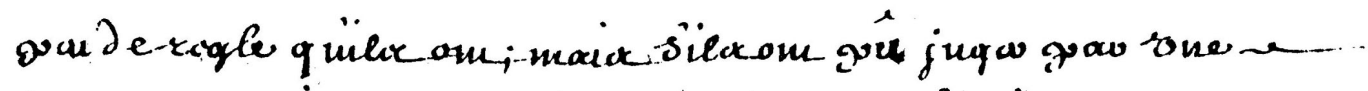

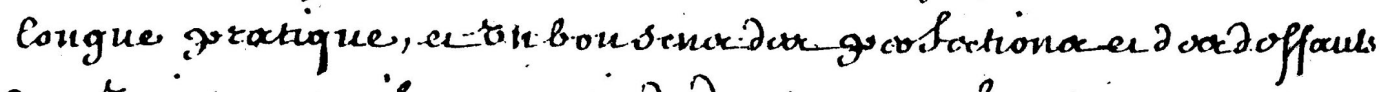

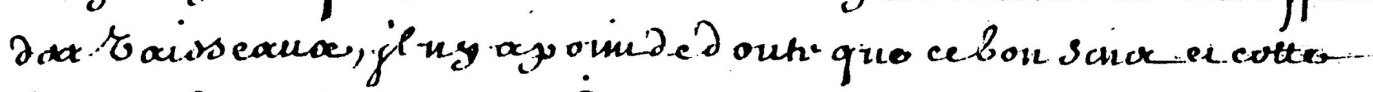

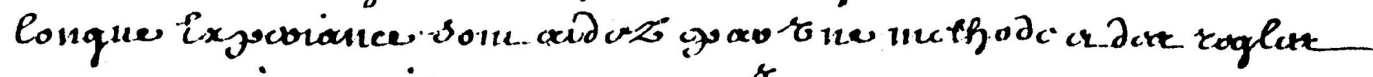

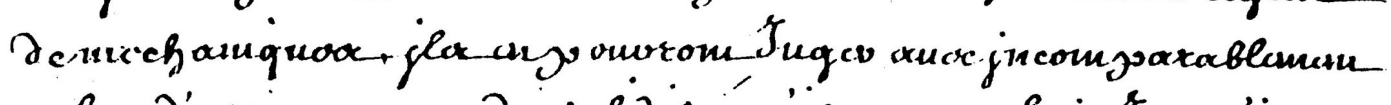

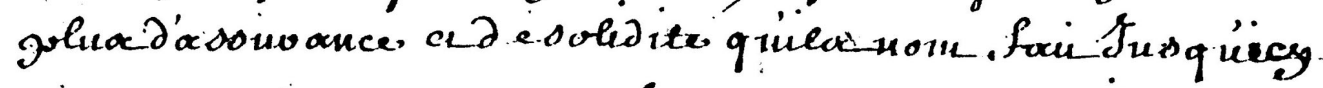

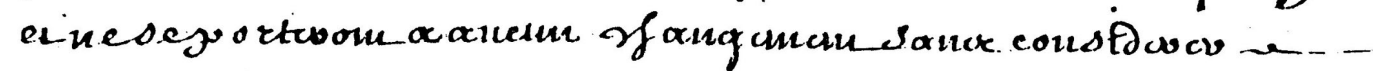

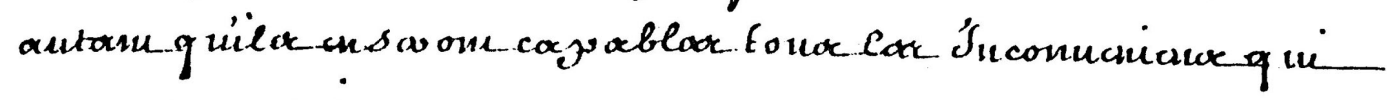
crevourcoul arrunb-... 